UNIVERSIDADE DE SÃO PAULO

ESCOLA POLITÉCNICA

JOSÉ CARLOS MIERZWA

\title{
DESAFIOS PARA O TRATAMENTO DE ÁGUA DE ABASTECIMENTO E O POTENCIAL DE APLICAÇÃO DO PROCESSO DE ULTRAFILTRAÇÃO
}




\section{UNIVERSIDADE DE SÃO PAULO ESCOLA POLITÉCNICA JOSÉ CARLOS MIERZWA}

\section{DESAFIOS PARA O TRATAMENTO DE ÁGUA DE ABASTECIMENTO E O POTENCIAL DE APLICAÇÃO DO PROCESSO DE ULTRAFILTRAÇÃOO}

Tese apresentada à Escola Politécnica da Universidade de São Paulo para a obtenção do Título de Livre-Docente pelo Departamento de Engenharia Hidráulica e Sanitária, em Saneamento Ambiental. 


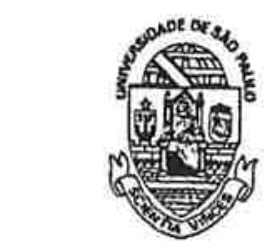

\section{REITORIA}

Proc. USP $n^{\circ}$ 03.1.1379.3.2

Portaria

946

1204

A REITORA DA UNIVERSIDADE DE SÃO PAULO, usando de suas atribuições legais, EX P ED E a presente Portaria para declarar que tendo JOSE CARLOS MIERZWA, Professor Doutor, ref. MS-3, do QDUSP-PG, em Regime de Dedicação Integral à Docência e à Pesquisa, lotado na Escola Politécnica (Departamento de Engenharia Hidráulica e Sanitária), obtido o título de Livre-Docente, conforme elementos constantes do Processo USP n⿳0 03:1.1379.3.2, fica, a contar de 20/07/2009, designado para exercer a função de Professor Associado, ref. MS-5, do mesmo Quadro, Parte, Regime e Lotação, nos termos do artigo 84 do Estatuto da Universidade de São Paulo.

Reitoria da Universidade de São Paulo,. 23 UUL 2009.
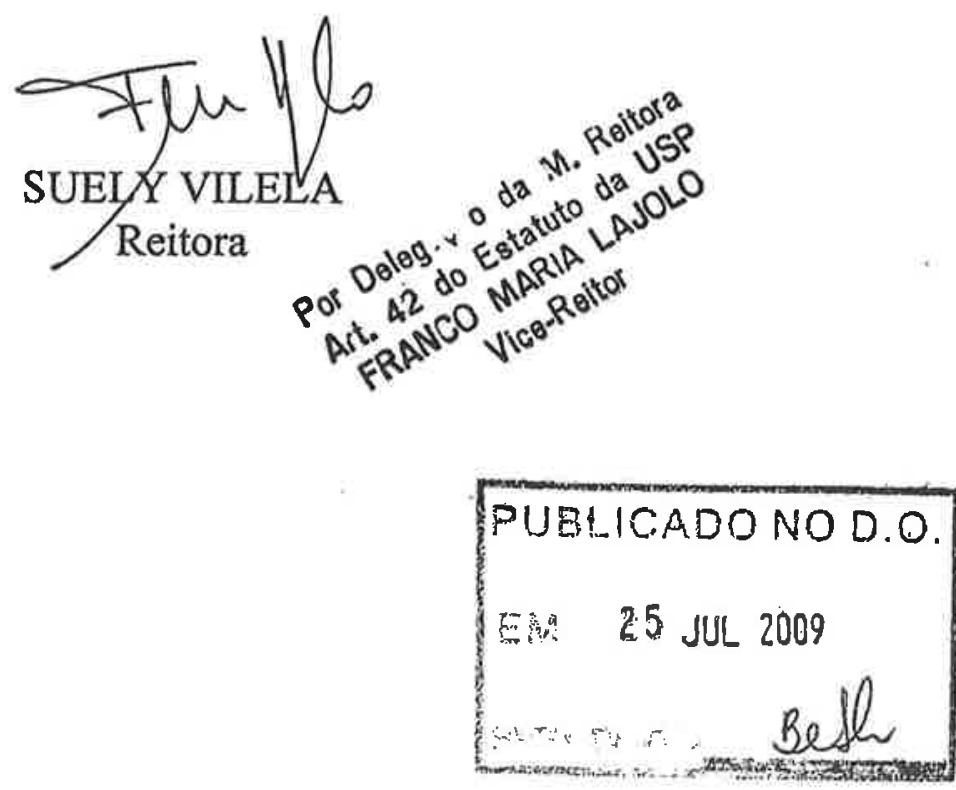


\section{AGRADECIMENTOS}

Aos agentes financiadores do Programa de Pesquisa em Saneamento Básico, FINEP, Caixa Econômica Federal e CNPq, pelos recursos financeiros para o desenvolvimento da pesquisa.

Ao Prof. Dr. Ivanildo Hespanhol, pela significativa contribuição para o desenvolvimento de minha carreira acadêmica e ao estímulo para o desenvolvimento deste trabalho.

A todos os pesquisadores, alunos e amigos que colaboraram direta ou indiretamente para a realização da pesquisa. 


\section{RESUMO}

Nesta pesquisa foi feita avaliação da viabilidade técnica e econômica do processo de ultrafiltração, com membranas enroladas em espiral, para o tratamento de água de abastecimento. O desenvolvimento deste tema levou em consideração os atuais problemas de qualidade das águas de mananciais utilizados para abastecimento e o fato do sistema convencional de tratamento de água apresentar limitações para enfrentar os novos desafios impostos. A avaliação foi feita com base nos resultados obtidos na operação de uma unidade piloto utilizando membranas de ultrafiltração com diferentes capacidades de separação. Procurou-se avaliar o desempenho operacional do sistema e também a capacidade de separação de contaminantes tradicionalmente utilizados para controle de desempenho de estações de tratamento de água, além de alguns contaminantes específicos, como nonilfenol, estrogênios naturais e etinilestradiol. A operação contínua da unidade piloto, totalizando 7.866 horas na primeira etapa e 10.600 horas na segunda, utilizando membranas com peso molecular de corte de 3.500 e $10.000 \mathrm{~g} \mathrm{~mol}^{-1}$, respectivamente, resultou em taxas médias de fluxo de $21,47 \mathrm{~L} \cdot \mathrm{h}^{-1} \cdot \mathrm{m}^{-2}$, com pressão de $418,3 \mathrm{kPa}$, e 18,39 $L . h^{-1} \cdot \mathrm{m}^{-2}$, com pressão de $160,9 \mathrm{kPa}$. As remoções de cor e turbidez foram superiores a $90 \%$ e de Escherichia coli e coliformes totais foram de 100\%. A partir dos custos de investimento e operação, determinou-se que o custo de produção de água por ultrafiltração é de US\$ 0,20 (vinte centavos de dólar), por metro cúbico e que as membranas são o item mais relevante na sua composição. Em relação aos novos riscos associados à qualidade da água, foi verificado que o etinilestradiol é o contaminante que exige maior atenção e que o processo de ultrafiltração apresentou potencial para a sua remoção. Como conclusão, pode-se afirmar que o processo de ultrafiltração apresenta elevado potencial de aplicação para tratamento de água no pais.

Palavras-chave: Tratamento de água. Ultrafiltração. Avaliação de custos. PROSAB. 


\begin{abstract}
This work evaluates the technical and economical feasibility of ultrafiltration process for drinking water treatment, using spiral wound membranes. For the development of this research it was taken into account emerging issues related to drinking water quality and limitations of conventional water treatment systems to address these issues. The evaluation was done based on the results obtained from a pilot plant unit, using spiral wound ultrafiltration membranes with different molecular weight cut-off (MWCO), considering membrane operational performance as well as contaminant removal capacity, particularly the ones normally used for conventional drinking water treatment plants monitoring, besides nonylphenol, natural estrogens, and ethynilestradiol. Continuous operation during 7.866, and 10.600 hours using 3.500 and $10.000 \mathrm{~g} \cdot \mathrm{mol}^{-1} \mathrm{MWCO}$ membranes, respectively, resulted in a permeate flow rates of $21,47 \mathrm{~L} \cdot \mathrm{h}^{-1} \cdot \mathrm{m}^{-2}$ at $418,3 \mathrm{kPa}$, and $18,39 \mathrm{~L} \cdot \mathrm{h}^{-1} \cdot \mathrm{m}^{-2}$ at $160,9 \mathrm{kPa}$. Color and turbidity removal were higher than $90 \%$, and Escherichia coli and total coliform achieved $100 \%$ removal. A preliminary cost analysis for an ultrafiltration system resulted in a treated water cost of US\$ 0.20 per cubic meter, and showed that membrane cost is the most relevant parameter. With regard the emerging risks related to drinking water quality it was determined that ethynilestradiol is the most relevant contaminant, and that its removal using ultrafiltration process could be possible. Based on these results it is concluded that ultrafiltration technology for drinking water treatment has a high potential for application in Brazil.
\end{abstract}

Keywords: Water treatment. Ultrafiltration. Costs evaluation. PROSAB. 


\section{SUMÁRIO}

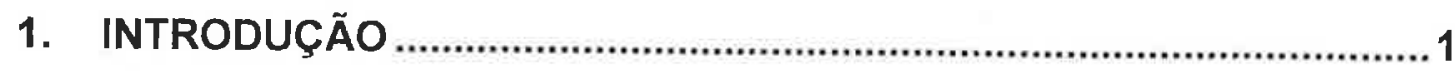

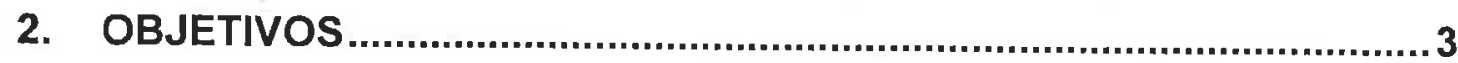

3. REVISÃO DA LITERATURA ............................................................

3.1. Sistema convencional de tratamento de água para abastecimento 4

3.2. Tecnologia de separação por membranas …................................

3.2.1. Projeto de sistemas de separação por membranas, que utilizam pressão hidráulica como força motriz.

3.3. Processos de separação por membranas para tratamento de água de abastecimento 12

3.4. Contaminantes orgânicos presentes em microquantidades em mananciais de água para abastecimento público 19

3.4.1. Panorama sobre substâncias químicas disponíveis e sua presença em mananciais de água

3.4.2. Riscos associados aos contaminantes orgânicos potencialmente presentes em mananciais de água para abastecimento

3.5. Presença de contaminantes orgânicos em mananciais de água para abastecimento.

3.6. Remoção no tratamento

3.7. Comprometimento da qualidade da água dos mananciais da Região Metropolitana de São Paulo

3.8. Tendências para o futuro

4. METODOLOGIA

4.1. Equipe, materiais e métodos - PROSAB-04 46 
4.1.1. Avaliação preliminar do potencial de utilização de sistemas de UF.............46

4.1.1. Avaliação na unidade piloto instalada no Reșervatório Guarapiranga.........48

4.1.1.1. Condições operacionais da unidade piloto ............................................50

4.2. Equipe, materiais e métodos PROSAB-05 ............................. 56

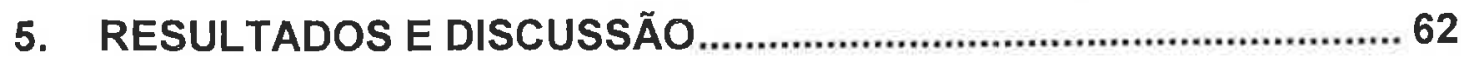

5.1. Ensaios para a avaliação preliminar do processo de UF no

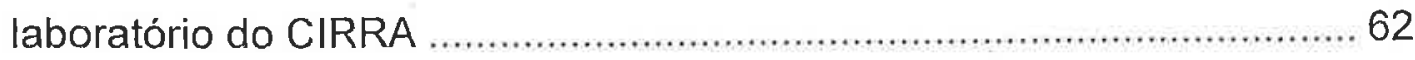

5.2. Resultados do desempenho da unidade piloto - PROSAB-04 ......66 66

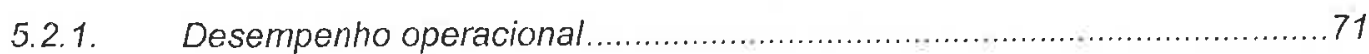

5.2.2. Eficiência na remoção de contaminantes...............................................77

5.3. Resultados do desempenho da unidade piloto - PROSAB-05...... 81

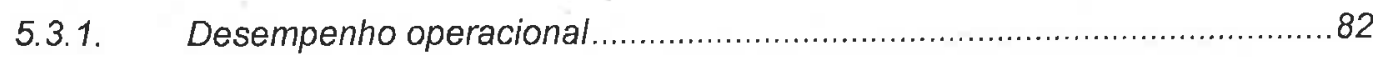

5.3.2. Desempenho na remoção de contaminantes.............................................90.

5.3.3. Avaliação da presença de perturbadores endócrinos em mananciais da



5.4. Avaliação preliminar de custos do processo de ultrafiltração para tratamento de água de abastecimento ...................................... 105

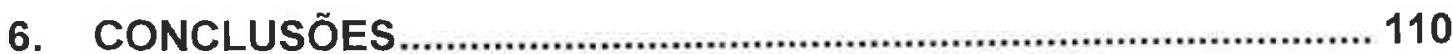






\section{LISTA DE FIGURAS}

Figura 3.1 - Capacidade dos principais processos de separação por membranas que utilizam pressão hidráulica como força motriz

Figura 3.2 - Representação esquemática do funcionamento dos processos de separação por membranas na prática.

Figura 3.3 - Representação do ganho em inovação em função do investimento em pesquisa e desenvolvimento 14 Figura 3.4 - Distribuição das unidades de separação por membranas nos EUA 19

Figura 3.5 - Participação no valor de produção de algumas classes de atividades 22

Figura 3.6 - Representação do funcionamento do sistema endócrino com base no princípio da "gangorra" (WHO, 2002) 27

Figura 3.7 - Principais contaminantes identificados em cursos d'água nos Estados Unidos da América. 33

Figura 3.8 - Variação da condutividade elétrica da água do Reservatório Guarapiranga 41

Figura 4.1 - Indicação do local de instalação das unidades piloto utilizadas para o desenvolvimento da pesquisa. 45

Figura 4.2 - Esquema do arranjo utilizado nos ensaios por ultrafiltração .... 49 Figura 4.3 - Foto unidade ultrafiltração utilizada nos ensaios de laboratório 50

Figura 4.4 - Fluxograma de processo da unidade piloto de ultrafiltração do PROSAB-04

Figura 4.5 - Vista frontal da unidade piloto de ultrafiltração do PROSAB-04 52

Figura 4.6 - Vista lateral da unidade piloto de ultrafiltração do PROSAB-04

Figura 4.7 - Variação da viscosidade da água com a temperatura, para normalização da vazão de permeado 
Figura 4.8 - Fluxograma da unidade piloto utilizada no PROSAB-05 ......... 58

Figura 4.9 - Vista geral da unidade piloto do PROSAB-05 ....................... 59

Figura 4.10 - Vista lateral da unidade piloto do PROSAB-05 ….................. 59

Figura 5.1 - Resultados do ensaio para a determinação da taxa de fluxo para a membrana de ultrafiltração com água tratada

63

Figura 5.2 - Valores de turbidez e condutividade do permeado produzido pelo processo de ultrafiltração no ensaio de 28/02/2005. 64

Figura 5.3 - Variação das vazões de alimentação, permeado e concentrado na unidade de ultrafiltração ao longo do ensaio com água da Represa Guarapiranga em 28/02/2005. 65 Figura 5.4 - Variação da vazão de permeado e da taxa de recuperação de água em função da pressão de operação, para o ensaio com água tratada 66

Figura 5.5 - Variação da taxa de fluxo de permeado normalizada pela pressão, em função da pressão de operação da unidade 67 Figura 5.6 - Variação da vazão de permeado e da taxa de recuperação de água em função da pressão de operação, para o ensaio com água do Reservatório Guarapiranga 68

Figura 5.7 - Recuperação da vazão de permeado após paradas não previstas 70

Figura 5.8 - Variação da perda de carga na membrana da unidade piloto antes da implantação dos procedimentos operacionais para melhoria de desempenho, no período de 07 a 21 de outubro de 2005 75 Figura 5.9 - Variação da perda de carga na membrana da unidade piloto após a implantação dos procedimentos operacionais para a melhoria de desempenho, no periodo de 26 de maio a 30 de junho de 2006 75 Figura 5.10 - Vazão de permeado e taxa global de recuperação de água pela unidade pilto PROSAB-04, ao longo de sua operação. 76 Figura 5.11 - Desempenho da unidade piloto no periodo de 03 a 10/09/2007, sem a dosagem de hipoclorito de súdio, mas com o procedimento de paradas periódicas 
Figura 5.12 - Desempenho da unidade piloto no período de 28/09 a 05/10/2007, com o início da dosagem de hipoclorito de sódio e paradas periódicas

Figura 5.13 - Desempenho da unidade piloto no periodo de 16/11 a 05/12/2007, sem a realização das paradas periódicas, mas com dosagem de hipoclorito de sódio.

Figura 5.14 - Resultados da vazão de permeado obtida durante o período de 29/08/2007 a 22/12/2008 na unidade piloto PROSAB-05

Figura 5.15 - Dados de recuperação global de água na unidade piloto PROSAB-05 89

Figura 5.16 - Turbidez média obtida pelo analisador de processo na operação da unidade piloto PROSAB-05 92

Figura 5.17 - Diagrama esquemático do processo de avaliação e caracterização de riscos ambientais associados aos desreguladores ....... 101 Figura 5,18 - Comparação do custo de tratamento dè água pelos processos de ultrafiltração, convencional e convencional com carvão ativado . 106 Figura 5.19 - Composição dos custos do sistema de ultrafiltração PROSAB04 106

Figura 5.20 - Planilha de entrada de dados para cálculo do sistema de ultrafiltração. 107

Figura 5.21 - Planilha com os resultados do dimensionamento do sistema de ultrafiltração. 107

Figura 5.22 - Planilha do dimensionamento do sistema de limpeza quimica e cálculo do consumo de reagentes 108

Figura 5.23 - Planilha dos custos associados ao sistema de ultrafiltração 108 Figura 5.24 - Planilha com o custo de investimento da unidade de ultrafiltração 108

Figura 5.25 - Planilha com os custos de operação 108 Figura 5.26 - Custo do tratamento de água por ultrafiltração PROSAB-05 109 


\section{LISTA DE TABELAS}

Tabela 3.1 - Valores típicos para taxa de fluxo em membranas. 10

Tabela 3.2 - Associação de membranas enroladas em espiral em série por vaso de pressão e a taxa de recuperação de água 11 Tabela 3.3 - Variáveis de qualidade da água bruta para ensaios de micro e ultrafiltração.

Tabela 3.4 - Dados de produção de fertilizantes, defensivos agrícolas e detergentes sintéticos e outros produtos no Brasil, em 2006. 23 Tabela 3.5 - Dados sobre atendimento no abastecimento de água e coleta e tratamento de esgotos, por região geográfica do país, em 2006. 25 Tabela 3.6 - Excreção diária, em microgramas, de estrogênios pelos seres humanos 32

Tabela 3.7 - Estimativa da carga de alguns estrógenos lançada no meio ambiente por seres humanos 36 Tabela 3.8 - Substâncias químicas e tecnologias de tratamento avaliadas no projeto desenvolvido pela EPA 38 Tabela 3.9 - Resultados do monitoramento de algumas variáveis de qualidade da água do Reservatório Guarapiranga, no ponto de captação da SABESP 40

Tabela 4.1 - Características dos equipamentos utilizados para a realização das análises 48 Tabela 4.2 - Variáveis de qualidade utilizadas para avaliar o desempenho da unidade piloto de ultrafiltração 55 Tabela 5.1- Caracterização físico-química de amostras de água bruta da Represa Guarapiranga coletadas nos dias 15/2/2005 e 22/02/2005 para realização dos ensaios no CIRRA. 62

Tabela 5.2 - Modificações na unidade piloto ao longo da operação. 69 Tabela 5.3 - Dados sobre as operações de limpeza química da unidade piloto PROSAB-04 
Tabela 5.4 - Resultados das análises de amostras da água bruta, realizadas pelo CIRRA (Agosto de 2005 a Abril de 2006)

Tabela 5.5 - Resultados das análises de amostras do permeado, realizadas pelo CIRRA (Agosto de 2005 a Abril de 2006)

Tabela 5.6 - Resultados das análises de amostras da água bruta, realizadas pela SABESP (Setembro de 2005 a Março de 2006).

Tabela 5.7 - Resultados das análises de amostras do permeado, realizadas pela SABESP (Setembro de 2005 a Março de 2006) 79

Tabela 5.8 - Resultados do ensaio para remoção de etinilestradiol pelo sistema de ultrafiltração

Tabela 5.9 - Dados de operação da unidade pilto PROSAB-05

Tabela 5.10 - Resultados das análises das amostras de água bruta para as variáveis utilizadas no controle da eficiência de remoção de contaminantes pela piloto PROSAB-05

Tabela 5.11 - Resultados das análises para amostras de permeado para as variáveis para controle da eficiência de remoção de contaminantes pela piloto PROSAB-05. 91

Tabela 5.12 - Resultados do monitoramento de nonilfenol na unidade piloto PROSAB-05 93

Tabela 5.13 - Resultados do monitoramento de estrogênios na unidade piloto PROSAB-05

Tabela 5.14- Resultados do monitoramento de etinilestradiol na unidade piloto PROSAB-05

Tabela 5.15 - Resultados das análises de nonilfenol para os ensaios na unidade piloto PROSAB-05 95

Tabela 5.16 - Resultados das análises de 17-beta-estradiol para os ensaios na unidade piloto PROSAB-05 96

Tabela 5.17 - Resultados das análises de etinilestradiol para os ensaios na unidade piloto PROSAB-05 96

Tabela 5.18 - Resultado do monitoramento de nonilfenol 99

Tabela 5.19 - Resultados do monitoramento de estrogênios 99 
Tabela 5.20 - Valores de CENO para Nonilfenol, 17-beta-Estradiol e

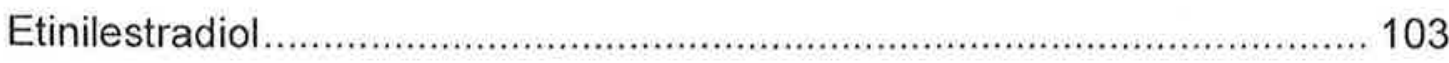
Tabela 5.21 - Relação entre as concentraçöes máximas dos desreguladores endócrinos identificados nos mananciais da RMBH e RMSP e valores da CENO. 103

Tabela 5.22 - Proposta para caracterização de riscos associados à presença de desreguladores endócrinos em mananciais de abastecimento 104 


\section{LISTA DE ABREVIATURAS}

CAS - Chemical Abstract Service.

CETESB - Companhia de Tecnologia Ambiental do Estado de São Paulo CIRRA - Centro Internacional de Referência em Reúso de Água CNPq - Conselho Nacional de Desenvolvimento Científico e Tecnológico COT - Carbono Orgânico Total

CUFSA - Centro Universitário Fundação Santo André

DE - Desregulador Endócrino

DTI - Desenvolvimento Tecnológico e Industrial

EPA - Agência Americana de Proteção Ambiental (Environmental Protection Agency)

EPUSP - Escola Politécnica da Universidade de São Paulo

FINEP - Financiadora de Estudos e Projetos

IC - Iniciação Científica

IPCS - International Programme on Chemical Safety

MON - Materia Orgânica Natural

NMP - Número mais porvável

OMS - Organização Mundial de Saúde

PROSAB - Programa de Pesquisa em Saneamento Básico

$\mathrm{RMBH}$ - Região Metropolitana de Belo Horizonte

RMSP - Região Metropolitana de São Paulo

SABESP - Companhia de Saneamento Básico do Estado de São Paulo

THM - Trihalometanos

UC - Unidade de cor

UFOP - Universidade Federal de Ouro Preto

UNT - Unidade nefelométrica de turbidez

UT - Unidade de turbidez

VMP - Valor máximo permitido

WHO - World Health Organization 



\section{INTRODUÇÃO}

Atualmente, regiões com alto indice de urbanização vêm sofrendo com os problemas de escassez de água, resultado de uma demanda elevada e dos problemas de poluição dos corpos d'água.

Devido à ocupação desordenada dos espaços urbanos, inclusive áreas de mananciais, as principais fontes utilizadas para abastecimento humano passam a ter a sua qualidade comprometida, seja pelo lançamento de esgotos domésticos, industriais ou devido às cargas difusas. Tais despejos, por sua vez, constituem uma grande ameaça aos consumidores da água proveniente desses mananciais, principalmente devido à ampla gama de compostos químicos lançados e que não são removidos pelos processos geralmẹnte utilizados para o tratamento da água.

Além dos contaminantes tradicionalmente contemplados na legislação relativa à qualidade da água para abastecimento humano, uma nova classe de contaminantes tem despertado preocupação, a dos desreguladores endócrinos. Estes contaminantes são importantes, pois em concentrações muito baixas são capazes de provocar alterações no sistema endócrino de organismos vivos (WHO, 2002).

Em muitos paises a preocupação com esta nova classe de contaminantes já resultou no desenvolvimento de várias pesquisas e projetos sobre o tema, inclusive com o desenvolvimento de diretrizes para regulamentação do registro, distribuição e uso de substâncias com potencial de interferir no sistema endócrino de organismos vivos (CEC, 2007; CEC, 2004).

O avanço tecnológico ocorrido ao longo das últimas décadas colocou no mercado processos alternativos de tratamento de água. Os processos de separação por membranas, microfiltração, ultrafiltração, osmose reversa e a eletrodiálise, os quais eram restritos a aplicações muito específicas, principalmente para produção de água com elevado grau de pureza utilizada na indústria farmacêutica, eletrônica e nucle:ar, ou dessalinização da água do mar para produção de água potável.

Este acontecimento foi resultado, principalmente, da ampliação da escala de produção, possibilitando que o custo de equipamentos baseados nesta tecnologia se 
tornasse competitivo em relação aos sistemas tradicionalmente utilizados (MIERZWA, et al., 2008; ZACERKOWNY, 2007).

Em vários países da Europa, nos Estados Unidos e na China, além de outros países, onde as pesquisas e estudos sobre a tecnologia de separação por membranas têm avançado muito, a utilização dos processos de separação por membranas para tratamento de água já é uma opção consolidada (MICKLEY, 2006; BENTAMA, et al., 2004; NICOLAISEN, 2003; HOFMAN, et al., 1998; Ma, et al., 1998; WILBERT, et al., 1998; JACANGELO, TRUSSELL, WATSON, 1997).

No Brasil, a utilização de tecnologias de separação por membranas ainda é muito incipiente, com aplicaçōes especificas em processos industriais, em geral, para produção de água com elevado grau de qualidade nas indústrias farmacêuticas, ou para processos de separação ou concentração na indústria alimentícia.

Este panorama reforça a necessidade do desenvolvimento de uma pesquisa sobre o desempenho de processos de separação por membranas para a avaliação do potencial da utilização desta tecnologia na produção de água potável, a partir de mananciais que apresentam problemas de qualidade.

Além disto, com o melhor conhecimento do potencial dos processos de separação por membranas para tratamento de água, será possivel o desenvolvimento de novas áreas de pesquisa no país, especificamente sobre a sintese de membranas e fabricação de equipamentos para tratamento de água e efluentes. 


\section{OBJETIVOS}

\section{Geral:}

- Avaliar o desempenho do processo de ultrafiltração, utilizando-se membranas enroladas em espiral, no tratamento de água para abastecimento público para verificar a viabilidade técnica e econômica de sua utilização nas condições nacionais.

\section{Específicos:}

- Avaliar e discutir os atuais problemas de qualidade dos mananciais para abastecimento;

- Avaliar o desempenho operacional do processo de ultrafiltração para tratamento de água para abastecimento;

- Avaliar a presença de alguns desreguladores endócrinos em mananciais da RMSP e a sua relevância para o abastecimento de água, por meio de uma avaliação preliminar de riscos;

- Realizar uma avaliação preliminar de custos do processo de ultrafiltração com membranas enroladas em espiral para tratamento de água de abastecimento. 


\section{REVISÃO DA LITERATURA}

\subsection{Sistema convencional de tratamento de água para abastecimento}

O sistema corvencional de tratamento de água passou a ser amplamente utilizado a partir do final do Século XIX é começo do Século XX, a partir da constatação científica que organismos microscópicos presentes na água podiam transmitir doenças (OKUN, 2003; EPA, 2000). Inicialmente o sistema convencional de tratamento de água envolvia apenas as etapas de filtração e desinfecção e com o passar do tempo foram se tornando cada vez mais complexos, em decorrência dos elevados niveis de urbanização e industrialização, verificados em muitas regiões do Planeta.

O tratamento convencional físico-químico consiste nos processos de coagulação, floculação, sedimentação, filtração e desinfecção com cloro, tendo como principais objetivos a remoção de sólidos em suspensão e inativação de microrganismos.

A coagulação visa neutralizar as cargas elétricas das partículas, através da adição de compostos químicos que apresentam, em geral, cargas positivas (MIERZWA e HESPANHOL, 2001 a). Após o processo de coagulação, a água contendo partículas desestabilizadas é submetida ao processo de floculação, cujo objetivo é promover "choques" entre as partículas para que elas se agrupem, formando assim flocos maiores, para, posteriormente, sedimentarem nos decantadores. Para o processo de desinfecção o cloro e seus derivados podem ser destacados como principais produtos utilizados em estações de tratamento de água para consumo humano (EPA, 1999 a). Contucio, a presença de materia orgânica natural (MON), nos mananciais, como resultado da degradação natual da vegetação e animais mortos, associada ao processo de desinfecção com cloro, chamou a atenção para os contaminantes quimicos, pelo potencial de geração de compostos orgânicos 
clorados, denominados de Trihalometanos (THM), subprodutos da desinfecção (OKUN, 2003).

A preocupação com os trihalometanos se deve ao potencial de danos à saúde humana pela exposição de longo prazo, principalmente o desenvolvimento de cânceres, o que conduziu ao desenvolvimento de padrões de qualidade de água mais restritivos.

Como conseqüência do potencial de formação de THM, resultado da reação química entre a MON presente na água e o cloro, principal agente de desinfecção, e maior restrição da legislação, os sistemas convencionais de tratamento de água tiveram que ser adaptados para enfrentar este novo desafio (EPA, 1999 b). O processo proposto para enfrentar este problema foi denominado de "coagulação melhorada", do inglês "enhanced coagulation".

O processo de coagulação melhorada refere-se ao processo empregado para possibilitar uma melhor remoção das substâncias precursoras dos subprodutos da desinfecção, oụ seja, a matéria orgânica natural (EPA, 1999 b). Para isto, é necessário modificar as condições do processo de coagulação e substituir os produtos químicos tradicionalmente utilizados no sistema convencional. O controle da eficiência do processo passa a ser feita pelo monitoramento, além de variáveis como turbidez e cor, da concentração de carbono orgânico total (COT). Outro aspecto importante é que o consumo de produtos químicos é significativamente superior ao do processo convencional, o que implica em maior produção de lodo e maiores custos de tratamento.

Com a ocupação desordenada das várzeas dos mananciais, fato que ocorre em muitos dos reservatórios de abastecimento, as fontes de água potável estão se tornando comprometidas e, conseqüentemente, com dificuldades em atender os padrões de potabilidade exigidos. Tais ocupações contribuem para o surgimento de outros problemas de qualidade de água, como a eutrofizaçäo, resultado do excesso de nutrientes nos corpos d'água, com potencial de desenvolvimento de florações de algas tóxicas, como as cianobactérias (BARTRAM et. al., 1999).

O fenômeno de eutrofização também pode resultar em prołlemas operacionais nas estaçöes convencionais de tratamento de água, com a necessidade de alteração das condições de operação, como pré-xidação (LI et al., 2009; CHEN, YEH e TSENG, 2009; CHEN e YEH, 2005), substituição e/ou otimização da dosagem de produtos quimicos (CHENG e CHI, 2003; HRUDEY et al., 1999), com o risco de 
perda de eficiência no tratamento e conseqüentemente da qualidade da água produzida.

É importante considerar, ainda, os problemas associados aos demais tipos de poluentes que podem estar presentes nos mananciais de água para abastecimento, como os produtos farmacêuticos e de higiene pessoal e a classe dos desreguladores endócrinos, amplamente pesquisados na atualidade (TERNES, GIGER e JOSS, 2006), e que serão abordados neste trabalho.

Isto demonstra a relevância do desenvolvimento de pesquisas e estudos sobre processos alternativos ao sistema convencional de tratamento, o qual passa a ser insuficiente para assegurar o fornecimento de água para abastecimento público, principalmente em regiões críticas de poluição.

Assim, técnicas mais modernas como, por exemplo, os processos de separação por membranas, podém ser uma opção, pois além de remover partículas em suspensão da água, têm capacidade para remover microorganismos, bactérias, vírus e até mesmo substâncias orgânicas e inorgânicas dissolvidas (MIERZWA e HESPANHOL, 2001 b).

Além disso, as membranas apresentam as seguintes vantagens em relação ao processo de tratamento convencional:

- Não necessitam de produtos químicos para a remoção dos contaminantes;

- A qualidade da água produzida é pouco influenciada pela qualidade da água bruta;

- Se constituem de unidades compactas, exigindo menor espaço para implantação;

- Possuem características operacionais mais simples.

Com isso, o processo de separação por membranás pode ser urna alternativa adequada para substituição, ou complementação, dos processos convencionais de tratamento de água para abastecimento público. 


\subsection{Tecnologia de separação por membranas}

A tecnologia de separação por membranas envolve a utilização de membranas sintéticas, porosas ou semipermeáveis, orgânicas ou inorgânicas, em uma configuração adequada, para separar de um fluído, partículas sólidas de pequeno diâmetro, bactérias, vírus, moléculas orgânicas, compostos iônicos de baixo peso molecular e até gases. Para tratamento de água os processos de separação por membranas que mais se destacam são (MIERZWA e HESPANHOL, 2005):

- Microfiltração;

- Ultrafiltração;

- Nanofiltração;

- Osmose Reversa; e

- Eletrodiálise.

O que difere cada um destes processos são a capacidade de separação de contaminante e o tipo e intensidade da força motriz utilizada para promover a separação, além da forma de separação do contaminante. $\mathrm{Na}$ microfiltração, ultrafiltração, nanofiltração e osmose reversa, a pressão hidráulica é utilizada para promover a separação entre a água e os contaminantes e é a água que atravessa a membrana. Já no processo de eletrodiálise, a separação é obtida por uma diferença de potencial elétrico aplicado entre as membranas e, neste caso, são os contaminantes que atravessam a membrana.

A Figura 3.1 apresenta de maneira esquemática a capacidade de separação dos processos de separação por membranas que utilizam a pressão hidráulica como força motriz (MIERZWA e HESPANHOL, 2005). 


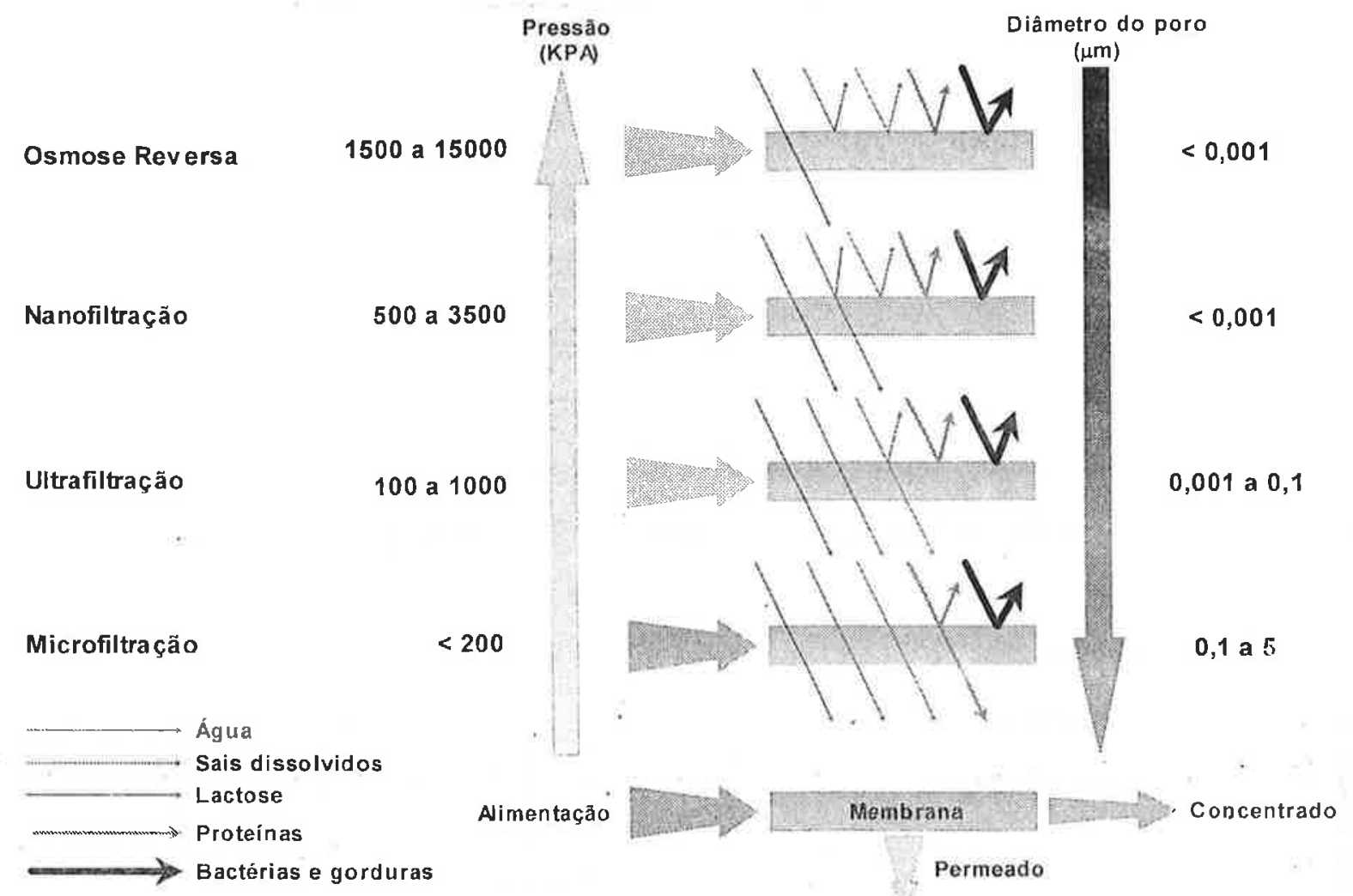

Figura 3.1. - Capacidade dos principais processos de separação por membranas que utilizam pressão hidráulica como força motriz

Muitas vezes os processos de separação por membranas são comparados com os processos de filtração convencional, contudo, várias características fazem com que estes processos sejam distintos, podendo-se destacar os seguintes aspectos:

- O fluxo de água é paralelo às membranas, ou seja, não é necessário que todo o fluido a ser tratado passe através da membrana;

- São eficientes para a separação de partículas sólidas e compostos orgânicos e inorgânicos dissolvidos, inclusive gases;

- A pressão de operação de alguns dos sistemas de separação por membranas é significativamente maior que nos processos de filtração convencional.

Nos processos de separação por membranas sempre estarão envolvidos três fluxos distıntos, a alimentaçäo, o concentrado e o permeado ou purificado. A Figura 3.2 ilustra os fluxos envolvidos nos processos de separação por membranas na prática. 


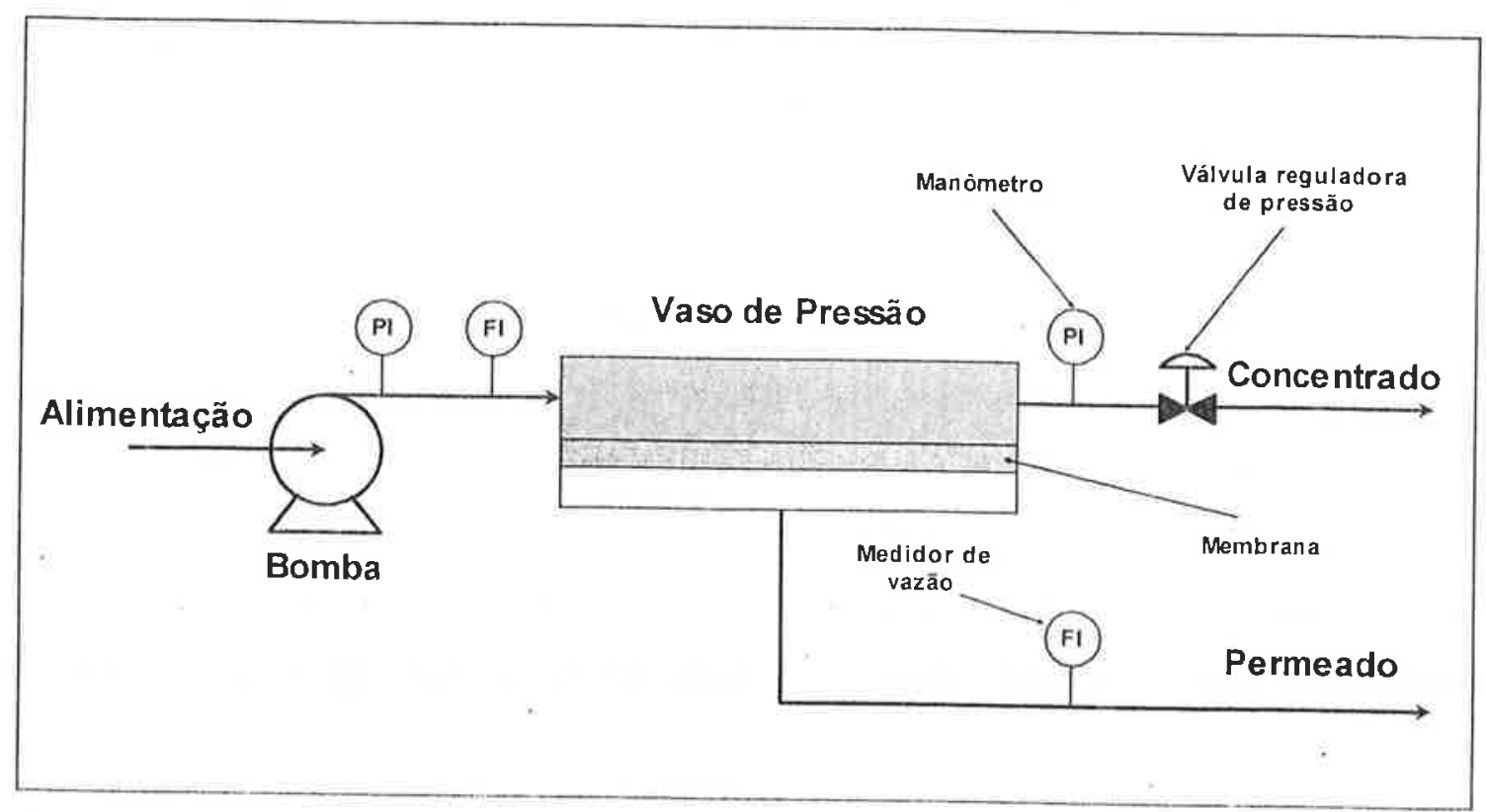

Figura 3.2 - Representação esquemática do funcionamento dos processos de separação por membranas na prática.

Dependendo do processo selecionado a conversão da alimentação em permeado ou purificado pode ser superior a $95 \%$ e a rejeição de contaminantes pode ser superior a $99 \%$ (MIERZWA e HESPANHOL, 2005).

As membranas utilizadas nos equipamentos de tratamento de água podem apresentar configurações variadas, por exemplo, placas planas, fibras ocas, tubulares e enroladas em espiral. Comercialmente, a configuração tipica das membranas de osmose reversa e nanofiltração é a enrolada em espiral, para as membranas de micro e ultrafiltração existem também as configurações, tubular e fibra oca ou capilar, enquanto para a eletrodiálise são utilizadas membranas planas. Dados especificos sobre cada uma das configurações disponiveis podem ser obtidos em literatura relacionada ao tema (MIERZWA e HESPANHOL, 2005; EPA, 2005; SCHNEIDER E TSUTIYA, 2001; WAGNER, 2001, WILBERT et al, 1998; AWWA, 1996), ou então, mediante consulta aos fornecedores de membranas.

Como qualquer outra tecnologia para tratamento de água, os processos de separação por membranas também apresentam vantagens e limitações. O conhecimento, principalmente, das limitações dos processos de separação por membranas é de fundamental importância para que a utilização destes processos possa resultar no máximo benefício possivel, levando-se em consideração fatores técnicos e econômicos. 
3.2.1. Projeto de sistemas de separação por membranas, que utilizam pressão hidráulica como força motriz

O desenvolvimento do projeto de sistemas de separação por membranas é feito com base nas características da água de alimentação, na qualidade a ser obtida, na vazão a ser produzida, na capacidade de produção da membrana selecionada e na taxa de recuperação estabelecida.

Com relação à capacidade de produção das membranas, na Tabela 3.1 são apresentados alguns valores para as taxas de fluxo dos tipos de membranas disponiveis.

Tabela 3.1 - Valores típicos para taxa de fluxo em membranas



A taxa de recuperação de água nos sistemas de separação por membranas é função da configuração da membrana e do arranjo selecionado, variando de menos de $10 \%$ por passagem, quando a operação é em fluxo tangencial, ou de até $100 \%$, quando se opera com filtração total ("dead end"). Assim é necessário estudar arranjos que permitam uma maior recuperação, o que é feito colocando-se membranas em série ou trabalhando-se com a recirculação de concentrado. No caso especifico de membranas enroladas em espiral, é possivel fazer associações de membranas e vasos de pressão em série.

Na Tabela 3.2 são apresentados dados relacionados à quantidade de membranas eriroladas em espiral que podem ser colocadas em série em un mesmo vaso de pressão e a taxa de recuperação de água obtida por vaso. 
Tabela 3.2 - Associação de membranas enroladas em espiral em série por vaso de pressão e a taxa de recuperação de água

\begin{tabular}{l|c|cccc}
\hline \multicolumn{2}{c|}{ Processo } & MF & UF & NF & OR \\
\hline \multirow{2}{*}{ Número de membranas por vaso } & Faixa & 1 a 2 & 1 a 4 & 1 a 6 & 1 a 8 \\
& Típico & 2 & 3 & 6 & 6 \\
\hline Taxa de recuperação de água (\%) & & 10 a 19 & 10 a 34 & 10 a 47 \\
\hline \multicolumn{2}{l|}{ Adaptado de Wagner, 2001. }
\end{tabular}

Outro aspecto de grande relevância nos processos de separação por membranas refere-se aos materiais de fabricação. Isto é mais importante no caso das membranas poliméricas. Duas características de grande interesse em tratamento de água, associadas ao tipo de polímero utilizado na fabricação das membranas, são:

- Potencial para a formação de depósitos m o potencial de formação de depósitos está associado com a afinidade ou não do polímero pela água, ou seja, hidrofilicidade ou hidrofobicidade. Membranas hidrofilicas têm uma menor propensão para a formação de depósitos, o que irá resultar em uma maior produtividade;

- Resistência a agentes oxidantes $\rightarrow$ alguns tipos de polímeros não toleram agentes oxidantes. Membranas fabricadas com esses polímeros não podem ser expostas aos agentes de oxidação como, por exemplo, cloro e seus derivados.

Por natureza, a maioria dos polimeros apresenta certo grau de hidrofobicidade e, na prática, o critério para a seleção do material da membrana é escolher aquele que é o menos hidrofóbico possível.

Com relação à resistência aos agentes de oxidação, em alguns casos é possível utilizar membranas fabricadas com materiais poliméricos que toleram determinados niveis de agentes de oxidação, ressaltando-se que esta condição acaba sendo restrita aos processos de microfiltração e ultrafiltração.

A utilizaçäo dos processos de separação por membranas exige, na maioria dos casos, sistemas de pré-tratamento, de modo a melhorar o desempenho das membranas, ao mesmo tempo em que as protegem. Para os processos de micro e ultrafiltração, as exigências com relação ao pré-tratamento são menoies e podem restringir-se à utilização de sistemas de filtração para evitar a obstrução da passagem de fluído no canal de alimentação. Já para os processos de nanofiltração, 
osmose reversa e eletrodiálise, as exigências são maiores, visto que estes são utilizados para a separação de contaminantes solúveis.

\subsection{Processos de separação por membranas para tratamento de água de abastecimento}

Ainda hoje, a tecnologia mais amplamente utilizada para tratamento de água para abastecimento é o sistema convencional, contemplando as etapas de coagulação, floculação, sedimentação, filtração e desinfecção. Contudo, em países desenvolvidos, como Estados Unidos da América, Canadá e Inglaterra, a crescente preocupação com os subprodutos da desinfeç̧ão e com microrganismos específicos fez com que novas tecnologias passassem a ser consideradas, dentre as quais os processos de separação por membranas, (EPA, 2005; JACANGELO, TRUSSELL, WATSON, 1997).

De acordo com Jacangelo, Trussell e Watson (1997), a ampliação do uso dos processos de separação por membranas é resultado do aumento do número e restrições das normas sobre qualidade da água para abastecimento.

O estabelecimento, nos Estados Unidos da América, da norma sobre tratamento aprimorado de água de superfície ("Long Term Enhanced Surface Water Treatment Rule"), identificou os processos de separação por membranas, microfiltração, ultrafiltração, nanofiltração e osmose reversa, como opções de tratamento para atingir os niveis exigidos para a remoção de criptosporídeos (EPA, 2005).

Outra norma que merece ser destacada é a que trata dos subprodutos da desinfecção ("Stage 2 Disinfection Byproducts Rule"), a qual estabelece limites de concentraçäo para os subprodutos da desinfeç̧ão na água para abastecimento público, como Trihalometanos (THMs) e Ácidos Haloacéticos (AHA). Neste caso, os processos de separação por membranas, principalmente a UF, a NF e a OR, podem remover da água, antes da etapa de desinfecção, os precursores dos. THMs e AHA, ou seja, a matéria orgânica natural, além de outros compostos orgânicos sintéticos (JACANGELO, TRUSSELL, WATSON, 1997). 
Fatos que demonstram a ampliação do interesse pelos processos de separação por membranas são os pedidos de verificação de tecnologias para a Agência Americana de Proteção Ambiental (USEPA).

A USEPA tem um programa de verificação de tecnologias com o objetivo de divulgar novas tecnologias ambientais através da verificação do desempenho e disseminação de informações. Várias empresas fabricantes de equipamentos têm solicitado a USEPA, através do Programa de Verificação de Tecnologias Ambientais, a emissão de parecer para certificação de seus equipamentos (NSF, 2003, 2002, $2000 \mathrm{a}, \mathrm{b}, \mathrm{c})$.

Além disto, é importante considerar, também, as questões de mercado e investimento em pesquisa e desenvolvimento. Por exemplo, a construção de um gráfico do retorno ou benefícios em função dos investimentos em pesquisa em desenvolvimento, mostra que, para as tecnologias convencionais, é necessário um alto investimento para um pequeno avanço em termos de inovação. Por outro lado, o investimento em novas tecnologias, como em processos de separação por membranas, pode resultar em avanços expressivos, conforme ilustra a Figura 3.3 (MALLEVIALLE, ODENDAAL, WISNER, 1996).

Outro indicador da relevância do uso dos processos de separação por membranas para tratamento de água é a quantidade de pesquisas associadas a este tema.

Em 1996, Nakatsuka, Nakate e Miyano, estudaram o tratamento de água potável utilizarido um sistema de ultrafiltração com membranas de fibra oca (NAKATSUKA, NAKATE e MIYANO, 1996). No estudo desenvolvido, a partir de água de um rio, foi feita a avaliação do desempenho do sistema de ultrafiltração, operando com fluxo tangencial e contralavagens periódicas, utilizando membranas de acetato de celulose e de polietersulfona.

Como resultado do estudo foi verificado que as membranas hidrofílicas, neste caso de acetato de celulose, apresentavam maior fíx de água e que a qualidade da água produzida, por todas as membranas avaliadas, era mantida praticamente constante, mesmo com uma grande variação da qualidade da água de alimentação. Doyen (1997) fez uma avaliação das incvações sobre o processo de ultrariltração para a produção de água potável em grande escala. Foi feita uma revisão sobre as propriedades das membranas, tipos de módulos existentes e modos de operação dos sistemas. 


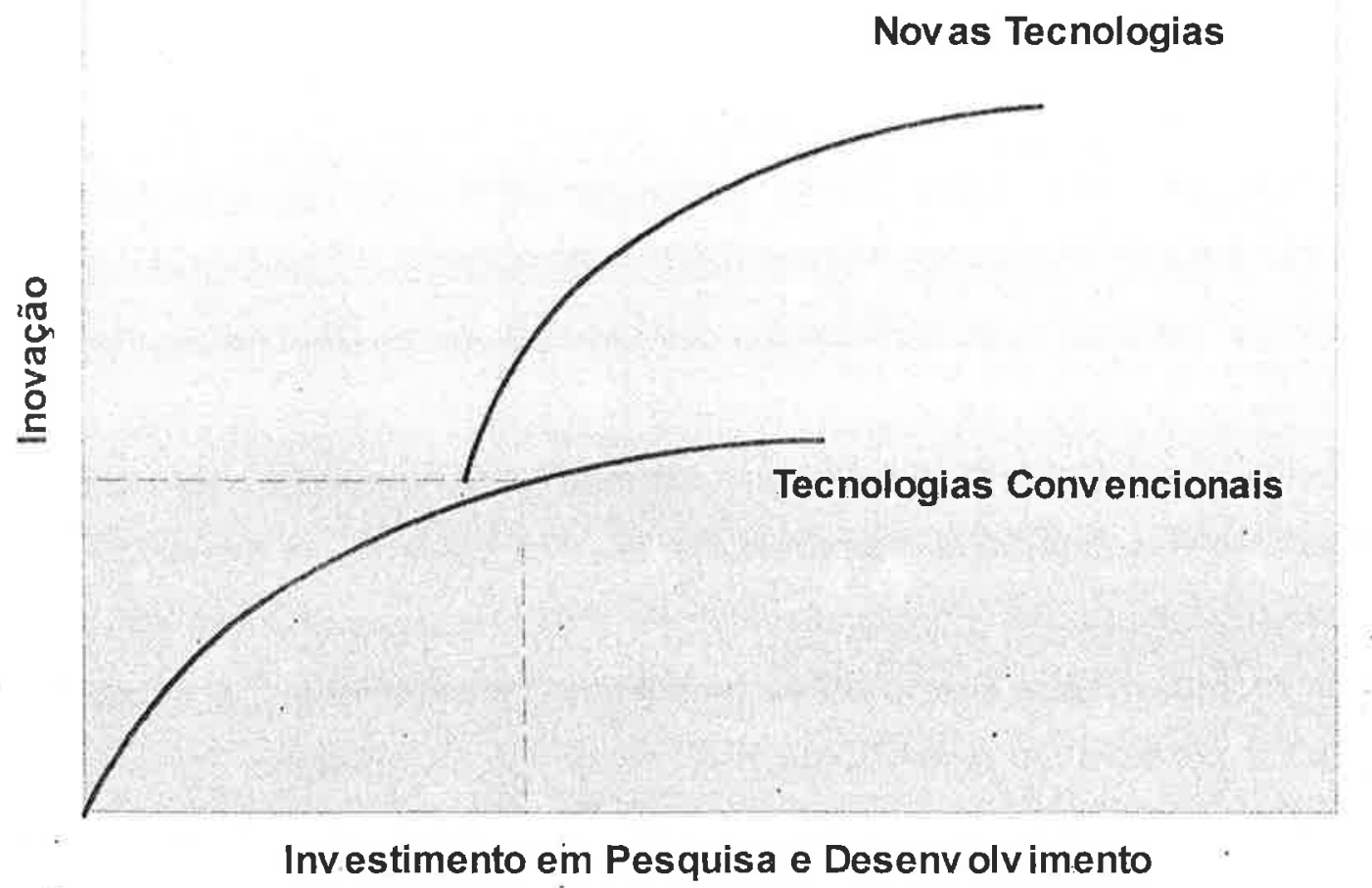

Figura 3.3 - Representação do ganho em inovação em função do investimento em pesquisa e desenvolvimento

As conclusões da avaliação feita por Doyen (1997) indicavam o crescimento potencial da utilização do processo de ultrafiltração para tratamento de água, destacando os avanços sobre as melhorias das características das membranas, do projeto dos módulos e das condições operacionais do sistema.

Pianta e colaboradores (1998) desenvolveram uma pesquisa sobre a utilização de micro e ultrafiltração para tratamento de água de abastecimento a partir de águas de nascentes cársticas. Nesta pesquisa os aspectos relacionados à variação da qualidade da água bruta, induziram a utilização de sistemas flexíveis e confiáveis de tratamento, visando garantir a qualidade da água para abastecimento público. Assim foram estudados os processos de micro e ultrafiltração em escala piloto, por um período de 15 e 12 meses, respectivamente, para remoção de material particulado e alguns compostos orgânicos específicos (PIANTA et al., 1998). A Tabela 3.3 mostra as variáveis de qualidade da água bruta utilizada nos ensaios piloto. 
Tabela 3.3 - Variáveis de qualidade da água bruta para ensaios de micro e ultrafiltração

\begin{tabular}{l|ccc}
\hline \multirow{2}{*}{\multicolumn{1}{c|}{ Variáveis }} & \multicolumn{3}{c}{ Valores } \\
\cline { 2 - 4 } & \multicolumn{3}{|c}{ Periodo Seco } \\
Média & $\begin{array}{c}\text { Mínimo e } \\
\text { Máximo }\end{array}$ & $\begin{array}{c}\text { Em } \\
\text { eventos de } \\
\text { chuva }\end{array}$ \\
\hline Turbidez (UNT) & 1,45 & $0,1-4,6$ & 130 \\
Carbono Orgânico Total $\left(\mathrm{mg} . \mathrm{L}^{-1}\right)$ & 0,9 & $0,6-1,4$ & 6,5 \\
Carbono Orgânico Dissolvido $\left(\mathrm{mg} \cdot \mathrm{L}^{-1}\right)$ & 0,8 & $0,6-1,2$ & 5,1 \\
ABS UV 254 $\mathrm{nm}\left(\mathrm{m}^{-1}\right)$ & 1,4 & $1,2-1,7$ & 16,9 \\
Tetracloroeteno $\left(\mu \mathrm{g} \mathrm{L}^{-1}\right)$ & 10 & $1-18$ & 80 \\
Tricloroeteno $\left(\mu \mathrm{g} . \mathrm{L}^{-1}\right)$ & 6 & $1-10$ & 40 \\
Atrazina $\left(\mathrm{ng} . \mathrm{L}^{-1}\right)$ & 60 & $<10-150$ & 1400 \\
\hline Oocistos de criptosporídeos $\left(\mathrm{n}^{0} / 20 \mathrm{~mL}\right)$ & 3,2 & $<1-5$ & - \\
\hline Fonte: Pianta et al., 1998 & & &
\end{tabular}

Noṣ ensaios com a unidade piloto de microfiltração foi verificado um bom desempenho para baixos valores de turbidez na água de alimentação e que elevados valores de turbidez provocavam o entupimento da membrana.

Para possibilitar a remoção de matéria orgânica natural e outros contaminantes orgânicos foi feita a dosagem de carvão ativado em pó, obtendo-se resultados satisfatórios, tanto em termos de quantidade de água produzida, como de qualidade. Em relação à unidade piloto de ultrafiltração foi verificada a influência da turbidez da água de alimentação sobre o fluxo através da membrana. Com a utilização de carvão ativado em pó, a turbidez da água de alimentação deixou de exercer influência significativa sobre o desempenho da membrana. Fazendo-se ajustes na dosagem de carvão ativado em pó foi observada uma redução significativa na concentração de tetracloroeteno, tricloroeteno e Atrazina, atingindo-se eficiências de remoção entre $75 \%$ e $90 \%$ (PIANTA et al., 1998).

A necessidade de utilizar carvão ativado em pó no sistema de ultrafiltração foi resultado do tipo de membrana selecionada, com peso molecular de corte de $100.000 \mathrm{~g} \cdot \mathrm{mol}^{-1}$.

Com o objetivo de ampliar a capacidade de uma estação de tratamento de água de Amsterdã, Hofman e colaboradores (1998), desenvolveram uma pesquisa para avaliar o potencial de utilização do processo de ultrafiltração.

O principal objetivo da pesquisa foi avaliar o desempenho do processo de ultrafiltração para a remoção de fosfatos, sólidos em suspensão, incluindo os colóides, e também microrganismos. 
Como se tratava de um manancial superficial, a qualidade da água bruta apresentou variações significativas. Foram avaliados dois tipos de membrana de ultrafiltração de configuração em fibra oca e peso molecular de corte entre 150.000 e $200.000 \mathrm{~g}^{\mathrm{mol}}{ }^{-1}$ (HOFMAN et al., 1998).

Os resultados do teste em escala piloto demonstraram que o processo de ultrafiltração teria grande potencial para a ampliação do sistema de tratamento de água de Amsterdã, pois foi possivel manter a operação do sistema estável, produzindo uma água de excelente qualidade.

Clever e colaboradores (2000) desenvolveram um estudo em escala piloto para o tratamento de água de rio por ultrafiltração e osmose reversa visando à produção de água de processo, ressaltando-se que apenas o processo de ultrafiltração foi avaliado. Durante o período de realização dos ensaios foram avaliados o escoamento tangencial e o escoamento perpendicular ("dead end"), com membranas hidrofílicas operando com contralavagens periódicas.

No sistema operando com escoamento tangencial, o fluxo de permeado através das membranas variou entre 60 e $80 \mathrm{~L} \cdot \mathrm{h}^{-1} \cdot \dot{m}^{-2}$, enquanto que a taxa de recuperação de água se manteve entre $75 \%$ e $90 \%$. Já no sistema operando com escoamento perpendicular, a produção de permeado permaneceu entre 40 e $70 \mathrm{~L} \cdot \mathrm{h}^{-1} \cdot \mathrm{m}^{-2}$, com uma taxa de recuperação de água entre $55 \%$ e $80 \%$ (CLEVER et al., 2000). Com relação à qualidade da água produzida, para os dois modos de escoamento, a turbidez foi inferior a 0,1 UNT.

Em 2002, Arnal e colaboradores desenvolveram um estudo sobre o projeto e a construção de sistemas de potabilização de água por membranas, corn aplicação em países em desenvolvimento (ARNAL et al., 2002).

Neste estudo foi avaliado o desempenho de um sistema de ultrafiltração com membrana enrolada em espiral e peso molecular de corte de $100.000 \mathrm{~g} \cdot \mathrm{mol}^{-1}$, para tratamento de água para abastecimento, com foco na qualidade microbiológica da água produzida.

A unidade piloto foi operada por um periodo de 300 horas, obtendo-se um desempenho satisfatório em relação à produção e qualidade da água. A vazão média de permeado foi de $239,5 \mathrm{~L} . \mathrm{h}^{-1}$, com a unidade operando com uma pressão hidráulica de 400 a $450 \mathrm{kPa}$, enquanto a eficiência de remoção de microrganismos foi de $100 \%$. 
Outro estudo desenvolvido por Arnal e colaboradores (2004), também teve como objetivo verificar o desempenho de membranas de ultrafiltração para a remoção de microrganismos. Neste estudo foram avaliadas quatro membranas, com diferentes capacidades de retenção de contaminantes, peso molecular de corte de 10.000 , $30.000,50.000$ e $100.000 \mathrm{~g} \cdot \mathrm{mol}^{-1}$, sendo uma de poliacrilonitrila $\left(50.000 \mathrm{~g} \cdot \mathrm{mol}^{-1}\right)$ e as demais de polietersulfona.

Os resultados mostraram que todas as membranas testadas eram eficientes para a retenção de microrganismos e que a permeabilidade das membranas com peso molecular de corte acima de $30.000 \mathrm{~g} \cdot \mathrm{mol}^{-1}$ foi bastante similar, ressaltando-se que a membrana de poliacrilonitrila teve um melhor desempenho em comparação à de polietersulfona (ARNAL et al., 2004).

Finalizados os estudos em escala piloto, em 2004 foi instalada uma unidade de potabilização de água pelo processo de ultrafiltração, em uma área rural do Equador

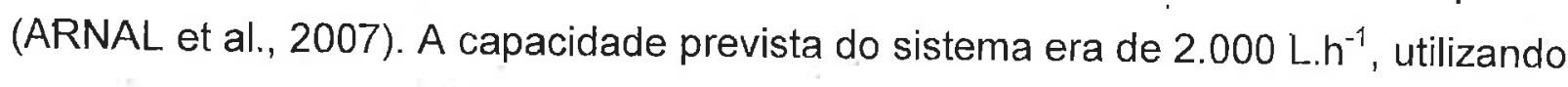
uma membrana de ultrafiltração enrolada em espiral, com peso molecular de corte de (150.000 g.mol $\left.{ }^{-1}\right)$, operando com pressão de, aproximadamente, $250 \mathrm{kPa}$, sem a utilização de bomba, em função da carga hidráulica disponível. Os resultados do monitoramento de seis meses de operação da unidade demonstraram a viabilidade do processo, obtendo-se eficiências de remoção de $67 \%$ e $100 \%$ para turbidez e coliformes totais e termotolerantes.

Domany e colaboradores (2002) pesquisaram, em laboratório, a remoção de substâncias húmicas da água para abastecimento pelo processo de ultrafiltração. Nos estudos foram utilizadas membranas com peso molecular de corte de 5.000, $6.000,15.000$ e $100.000 \mathrm{~g} \cdot \mathrm{mol}^{-1}$, obtendo uma eficiência de remoção de substâncias húmicas entre $85 \%$ a $90 \%$ para uma solução sintética e entre $62 \%$ a $69 \%$, para águas naturais.

Uma inovação na área de processos de separação por membranas foi o desenvolvimento de membranas enroladas em espiral com a possibilidade de contralavagem.

Com base nesta nova tecnologia, Lipp e colaboradores (2005), realizaram uma pesquisa na Alemanha para tratamento de água de reservatórios, utilizando membranas de micro e ultrafiltração. Durante três anos, os pesquisadores avaliaram cinco tipos diferentes de membranas, utilizando água bruta ou pré-tratada de um reservatório da região norte da Floresta Negra na Alemanha. 
Pelos resultados da pesquisa foi verificado que o desempenho de membranas enroladas em espiral com contralavagem era similar ao das membranas de fibra oca, tornando esta tecnologia uma opção para aplicações futuras.

As membranas de UF avaliadas tinham um peso molecular de corte de 50.000, 100.000 e $150.000 \mathrm{~g} \cdot \mathrm{mol}^{-1} \mathrm{e}$ as de microfiltração apresentavam diâmetros de poro de 0,1 e $0,15 \mu \mathrm{m}$ (LIPP et al., 2005).

Com enfoque nos problemas atuais de qualidade de água, Yoon e colaboradores (2006), estudaram os processos de separação por membranas para a emoção de compostos causadores de alterações no sistema endócrino, fármacos e produtos de higiene pessoal.

Na pesquisa foi avaliada, em laboratório, a eficiência de remoção de 52 compostos com diferentes propriedades físico-quimicas, pelos processos de nanofiltração e ultrafiltração, utilizando membranas com pesos moleculares de corte de $600 \mathrm{~g}^{\mathrm{mol}}{ }^{-1}$ e $8.000 \mathrm{~g} \cdot \mathrm{mol}^{-1}$, respectivamente. A membrana de nanofiltração apresentou maior remoção dos contaminantes, com eficiências entre $44 . \%$ e $93 \%$, em comparação com a membrana de ultrafiltração, cuja remoção foi inferior a $40 \%$ (YOON et al, 2006).

Outro estudo sobre a utilização de sistemas de ultrafiltração em espiral com contra lavagem para tratamento de água foi feito por Rojas e colaboradores (2008), utilizando uma membrana enrolada em espiral da empresa Trisep, operando submersa. A unidade operou continuamente, por um período de 180 dias, sem que ocorressem problemas de perda de capacidade, obtendo eficiências de remoção de $96,3 \%, 38,1 \%$ e $100 \%$ para turbidez, substâncias com absorção de radiação ultravioleta em $254 \mathrm{~nm}$ e microrganismos, respectivamente.

Os exemplos apresentados demonstram a relevância dos processos de separação por membranas para tratamento de água para abastecimento, ressaltando que não foram relatados os casos onde o processo de osmose reversa é utilizado, por já ser uma tecnologia bem consolidada.

Um levantamento feito Mickley (2006), para a avaliação da disposição final do concentrado gerado em sistemas de separação por menbranas, mostrou que haviam sido instaladas nos Estados Unidos da América, até 2002, 422 unidades municipas com capacidade superior a $95 \mathrm{~m}^{3} \cdot \mathrm{dia}^{-1}$, sendo que os sistemas de microfiltração e ultrafiltração começaram a ser instalados a partir de 1993. A Figura 3.4 mostra a distribuição das unidades de separação por membranas por tipo de 
tecnologia (MICKLEY, 2006). A capacidade total de projeto das unidades é de, aproximadamente, $45 \mathrm{~m}^{3} \cdot \mathrm{s}^{-1}$, suficiente para abastecer 19,4 milhões de pessoas.



Figura 3.4 - Distribuição das unidades de separação por membranas nos EUA

\subsection{Contaminantes orgânicos presentes em microquantidades em mananciais de água para abastecimento público}

O avanço tecnológico ocorrido a partir da $2^{\circ}$ Grande Guerra Mundial colocou no mercado uma ampla variedade de substâncias ou compostos químicos utilizados para os mais variados usos como, por exemplo, formulação ou como intermediários de muitos produtos utilizados no nosso dia-a-dia, contribuindo para a melhoria da qualidade de vida do ser humano.

O desenvolvimento de medicamentos, produtos de higiene pessoal, defensivos agrícolas e aditivos alimentares, entre outros, trouxe muitos beneficios para a sociedade. Contudo, um aspecto que deve ser considerado é que, após o seu uso, ou mesmo nas etapas associadas à sua produção, esses acábam atingindo o meio 
ambiente na forma de resíduos sólidos, efluentes líquidos, emissões gasosas e, até mesmo, durante a sua utilização ou pelo lançamento acidental ou indiscriminado.

Muitos dos produtos e substâncias químicas utilizadas pelos seres humanos, quando presentes no meio ambiente, são potencialmente prejudiciais à fauna, à flora e ao próprio Homem, o que constitui um grande fator de risco.

Um fenômeno que teve expansão em várias regiões do Planeta, resultante da alteração do equilibrio de sistemas aquáticos pelo lançamento de poluentes para o ambiente, foi a eutrofização. Em decorrência da eutrofização há, em muitos casos, a proliferação de algas capazes de liberar para a água substâncias tóxicas, aos seres humanos, denominadas de cianotoxinas, que mesmo em concentrações muito baixas, podem resultar em morte.

Em relação aos produtos químicos sintéticos, Harrison, Holmes e Humfrey (1997) relataram que muitos estudos de laboratório indicaram que compostos químicos presentès no meio ambiente têm potencial de causar alterações no equilíbrio hormonal dos seres humanos, resultando em uma série de problemas de saúde.

Segundo Singer (1949, apud AMARAL MENDES, 2002), o primeiro efeito sobre a saúde humana devido a substâncias químicas, foi a redução na contagem de espermas dos pilotos de aviões pulverizadores de Diclorodifeniltricloroetano (DDT). Estes relatos mostram a relevância da presença de determinadas substâncias químicas no ambiente em decorrência dos efeitos potenciais na saúde humana.

A situação é mais preocupante quando são levados em consideração os grandes centros urbanos. A razão para isto está diretamente associada à variedade e quantidade de produtos químicos utilizados diariamente, uma vez que esses têm como destino final os cursos d'água, seja através dos esgotos tratados nas estações, ou pelo lançamento direto.

Por esta razão é necessário avaliar as implicações da presença de certas substâncias; quimicas no meio ambiente, principalmente nos mananciais de agué que recebem esgotos tratados, ou in natura, drenagem de águas pluviais e efluentes industriais e que são, ainda, utilizados para abastecimento público.

Para contribuir com este tema, são apresentadus e discutidos, a seguir, os principais aspectos relacionados aos contaminantes orgânicos preserites em microquantidades em mananciais de água para abastecimento público, incluindo o seu comportamento nos sistemas de tratamento de água e esgotos. 
3.4.1. Panorama sobre substâncias químicas disponíveis e sua presença em mananciais de água

Para que seja possivel verificar a relevância da discussão sobre a presença de contaminantes orgânicos em mananciais de água para abastecimento é necessário conhecer a realidade sobre as substâncias químicas existentes, bem como sobre o potencial que possuem de atingir os corpos d'água.

Um dado relevante para uma primeira avaliação é a quantidade de substâncias químicas existentes e quantas dessas substâncias, efetivamente, têm potencial de estarem presentes no meio ambiente. Tais informações podem ser obtidas no Serviço de Compêndio de Substâncias Químicas (CAS), órgão que faz o registro de todas as substâncias químicas desenvolvidas e utilizadas no mundo. Através de uma consulta à página elètrônica do CAS, verificou-se que, em fevereiro de 2009 , existiam mais de 42,5 milhões de substâncias orgânicas e inorgânicas registradas e destas cerca de 27.8 milhões estavam disponíveis çomercialmente (CAS, 2009), ressaltando-se que estes números só tendem a aumentar.

As substâncias químicas disponiveis comercialmente são utilizadas para diversas finalidades, inclusive como matéria-prima e princípios ativos nas indústrias de medicamentos, produtos de higiene pessoal, defensivos agrícolas, alimentos e desinfetantes, entre outras.

A Pesquisa Industrial de 2006 (IBGE, 2006), apresenta dados sobre os principais produtos fabricados e comercializados no Brasil. Nesta publicação os produtos são agrupados por classes de aplicação, dentre as quais se encontram:

- Fertilizantes;

- Medicamentos para uso humano;

- Medicamentos para uso veterinário;

- Inseticidas;

- Fungicidas;

- Herbicidas;

- Outros defensivos agrícolas;

- Sabões, sabonetes e detergentes sintéticos;

- Produtos de limpeza e polimento; 
- Artigos de perfumaria e cosméticos.

Em termos financeiros, a produção destas classes de aplicações atingiu o valor de, aproximadamente, 58,7 bilhões de Reais, no ano de $2006,4,4 \%$ do valor da produção de todo parque industrial brasileiro. No gráfico da Figura 3.5 é apresentada a participação no valor de produção de cada uma das classes de aplicações destacadas.



Figura 3.5 - Participação no valor de produção de algumas classes de atividades

Destaca-se que na pesquisa do IBGE não são apresentados os valores relacionados à quantidade produzida para todas as classes de aplicações e categorias de produtos. Contudo, é possivel obter os dados de produção sobre alguns produtos especificos, o que pode contribuir para uma melhor compreensão da presença de certos contaminantes químicos no meio ambiente. Na Tabela 3.4 são apresentados os dados de produção de fertilizantes, defensivos agrícolas e detergentes sintéticos (IBGE, 2006).

Com relação aos defensivos agrícolas presentes em mananciais, o potencial de contaminação está diretamente associado à forma de utilização dessas substâncias e aos fenômenos de transporte envolvidos, como drenagem do escoarnento superficial de água de irrigação e águas pluviais e percolação no solo, o que compromete a qualidade da água subterrânea. 
Para os demais contaminantes, a sua presença nos corpos d'água depende da forma de utilização e descarte, além da existência ou não de sistemas de coleta e tratamento de esgoto e também a eficiência de remoção no sistema de tratamento.

Tabela 3.4 - Dados de produção de fertilizantes, defensivos agrícolas e detergentes sintéticos e outros produtos no Brasil, em 2006.

\begin{tabular}{|c|c|c|}
\hline Produto & Quantidade & $\begin{array}{l}\text { Valor da Produção } \\
(\mathrm{R} \$)\end{array}$ \\
\hline $\begin{array}{l}\text { Adubos ou fertilizantes de origem } \\
\text { animal ou vegetal, inclusive } \\
\text { misturados. }\end{array}$ & $74.615 .000 \mathrm{~kg}$ & $123.491 .000,00$ \\
\hline $\begin{array}{l}\text { Adubos ou fertilizantes com fósforo } \\
\text { e potássio. }\end{array}$ & $1.375 .571 .000 \mathrm{~kg}$ & $770.101 .000,00$ \\
\hline $\begin{array}{l}\text { Adubo ou fertilizantes com NPK. } \\
\text { Inseticidas para uso na agricultura.. }\end{array}$ & $\begin{array}{l}16.922 .761 .000 \mathrm{~kg} \\
.79 .546 .000 \mathrm{~kg}\end{array}$ & $\begin{array}{l}9.940 .070 .000,00 \\
1.635 .105 .000,00\end{array}$ \\
\hline $\begin{array}{l}\text { Inseticidas para usos doméstico, } \\
\text { institucional e/ou industrial. }\end{array}$ & $30.225 .427 \mathrm{~kg}$ & $340.533 .000,00$ \\
\hline Fungicidas para uso na agricultura. & $82.459 .000 \mathrm{~kg}$ & $1.488 .801 .000,00$ \\
\hline $\begin{array}{l}\text { Herbicidas para usos doméstico e } \\
\text { industrial. }\end{array}$ & $84.712 \mathrm{~kg}$ & $5.606 .000,00$ \\
\hline $\begin{array}{l}\text { Herbicidas para uso na agricultura. } \\
\text { Amaciantes }\end{array}$ & $253.874 .000 \mathrm{~kg}$ & $3.120 .453 .000,00$ \\
\hline $\begin{array}{l}\text { lmaclantes } \\
\text { tecidos. } \\
\text { Detergentes ou sabões líauidos }\end{array}$ & $397.986 .000 \mathrm{~L}$ & $616.424 .000,00$ \\
\hline $\begin{array}{l}\text { inclusive produtos para lavagem de } \\
\text { pisos e vidros. }\end{array}$ & $684.971 .000 \mathrm{~L}$ & $1.449 .020 .000,00$ \\
\hline $\begin{array}{l}\text { Preparações tensoativas para } \\
\text { lavagem e limpeza. }\end{array}$ & 353.397.689 L & $379.427 .000,00$ \\
\hline $\begin{array}{l}\text { Sabões em pó, flocos, palhetas, } \\
\text { grânulos ou outras formas. }\end{array}$ & $1.158 .061 .000 \mathrm{Kg}$ & $2.660 .026 .000,00$ \\
\hline $\begin{array}{l}\text { Dentifrícios, pastas e cremes } \\
\text { dentais. }\end{array}$ & $199.197 .693 \mathrm{~kg}$ & $1.992 .997 .000,00$ \\
\hline Xampus para cabelos. & $208.596 .091 \mathrm{~L}$ & $700.019 .000,00$ \\
\hline
\end{tabular}

O destaque dado aos sistemas de coleta e tratamento de esgotos é justificado pelo fato de que a maioria das substâncias quimicas, utilizadas em nosso dia-a-dia, ter como destino final os esgotos, de maneira direta ou indireta. Sobre a eficiência de remoção nos sistemas de tratamento, ainda não existem informações precisas relacionadas a cada tipo de contaminante potencialmente presente nos esgotos, seja pelos elevados custos das análises, ou pela dificuldade de selecionar as variáveis que devem ser avaliadas.

Informações sobre coleta e tratamento de esgotos estão disponiveis em publicações de alguns órgãos do governo, como IBGE e Programa de Modernização do Setor de 
Saneamento, através do Sistema Nacional de Informações sobre Saneamento (PMSS, 2007), e também em páginas eletrônicas de empresas de saneamento básico do país. Utilizando as fontes mencionadas, são apresentados na Tabela 3.5 os dados gerais sobre coleta e tratamento de esgotos no Brasil, o que dará subsídios para inferir sobre o potencial da presença de contaminantes químicos em mananciais, inclusive utilizados para abastecimento público.

Pelos dados apresentados na Tabela 3.5, verifica-se que os indices de coleta e tratamento de esgotos nas principais regiões brasileiras são muito baixos, ou seja, de $47,2 \%$ para coleta e $29,6 \%$ para tratamento, indicando que uma quantidade significativa de esgotos in natura é lançada no ambiente. Este é um forte indicativo da presença potencial de inúmeras substâncias nos corpos d'água receptores desses esgotos, inclusive mananciais utilizados para abastecimento público. Mesmo nos casos onde ocorre o tratamento de esgotos, é importante considerar que não existem dados suficientes sobre a eficiência de remoção de muitas substâncias químicas, potencialmente presentes.

Os elementos apresentados permitem concluir que a presença de vários contaminantes orgânicos em mananciais utilizados para abastecimento é uma condição real, seja devido à drenagem de áreas agrícolas, no caso de defensivos agrícolas, ou pelo lançamento de esgotos, no caso de medicamentos, produtos de higiene pessoal e detergentes sintéticos. Contudo, deve ser ponderado se a concentração com que estes contaminantes estão presentes na água é suficiente para resultar em danos à saúde humana e ao próprio meio ambiente.

3.4.2. Riscos associados aos contaminantes orgânicos potencialmente presentes em mananciais de água para abastecimento

Como já mencionado, uma nova classe de contaminantes presentes no meio ambiente tem despertado a preocupação de profissionais e pesquisadores das áreas, ambiental, de tratamento de água e saúde, a qual é denominada de desreguladores ou disruptores endócrinos. 


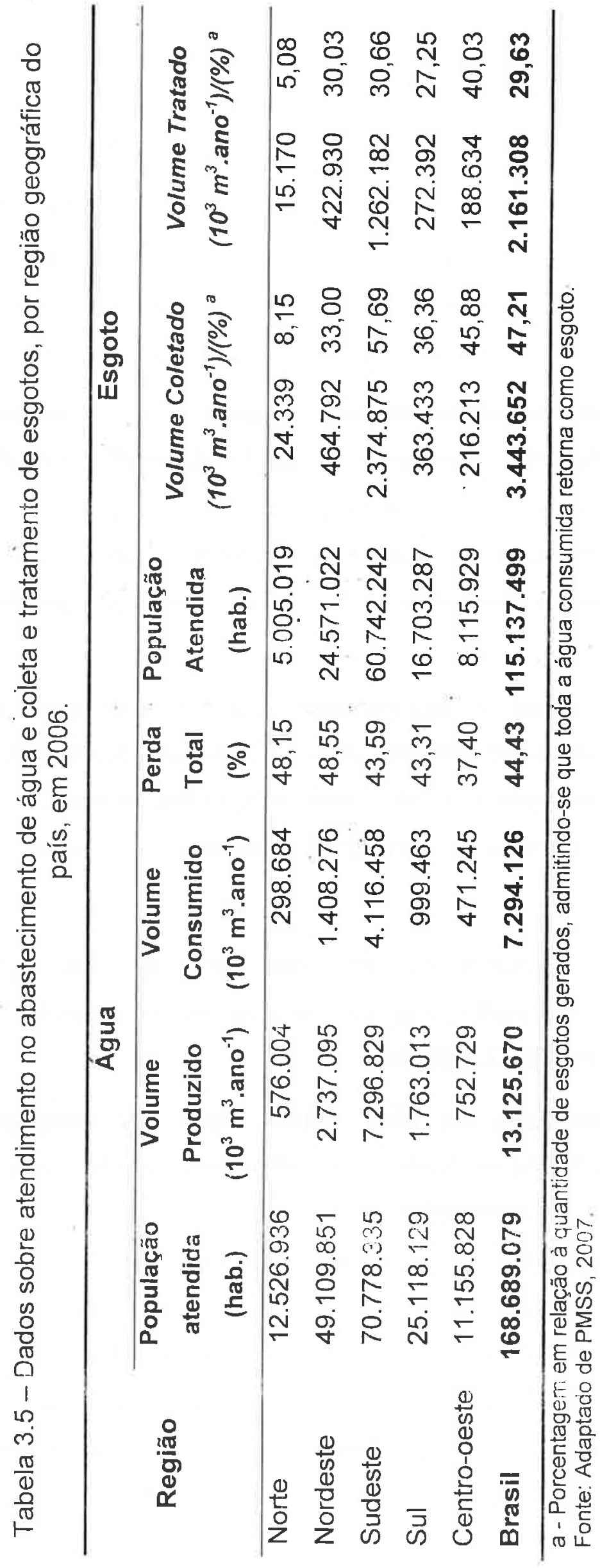


Um desregulador ou "disruptor" endócrino é uma substância ou mistura exógena que altera as funções do sistema endócrino e, conseqüentemente, causa danos em um organismo sadio, em seus descendentes, ou em outros grupos de organismos vivos (WHO, 2002).

O sistema endócrino é muito complexo e seria muito difícil descrevê-lo completamente, destacando-se três eixos endócrinos principais, os quais funcionam de maneira muito similar (WHO, 2002):

- Hipotálamo-ptuitário-adrenal, ligado ao metabolismo de carbohidratos, proteinas e gorduras, efeito antiinflamatório e modulação de respostas ao estresse;

- Hipotálamo-pituitário-gonodal, ligado ao sistema reprodutivo;

- Hiopálamo-pituitário-tieroidal, ligado à atividade metabólica como um todo.

A função principal do sistema endócrino é manter a homeostase dos organismos vivos, de maneira a evitar variações bruscas nos niveis de hormônios / respostas em decorrência de sinais, internos ou externos ao organismo, com base no princípio da "gangorra", conforme demonstrado na Figura 3.6.

Quando se considera os impactos potenciais dos desreguladores endócrinos nas funções corporais, devem ser considerados os seguintes pontos críticos (WHO, 2002):

- A exposição na fase adulta pode ser compensada pelos mecanismos de homeostase, de maneira a não resultar em efeitos significativos ou detectáveis;

- A exposição durante a fase de programação do sistema endócrino pode resultar em uma mudança permanente da função ou sensibilidade para os sinais de estímulo ou inibição;

- A exposição a um mesmo nivel de sinal endócrino em diferentes estágios do desenvolvimento, ou diferentes estações do ano, no caso de animais, pode produzir diferentes efeitos; 
- Em decorrência da comunicação entre os diferentes sistemas endócrinos os efeitos da exposição podem ocorrer de maneira imprevisivel e em um sistema diferente daquele que recebeu o sinal;

- Em decorrência da imprevisibilidade dos efeitos associados aos desreguladores endócrinos é necessário ter cuidado na extrapolação de resultados de avaliações in vitro da atividade hormonal das substâncias para a condição in vivo.


Figura 3.6 - Representação do funcionamento do sistema endócrino com base no princípio da "gangorra" (WHO, 2002)

Uma abordagem bastante ampla sobre os desreguladores endócrinos, na época ainda não tratados por esta designação, foi apresentada por Rachel Carson, com a publicação do livro Silent Spring (CARSON, 1962). Da publicação do livro até o presente, a situação se tornou mais complexa em função do grande nủmero de novas substâncias quimicas desenvolvidas e utilizadas pelos seres humanos. 
Várias publicações têm apresentado dados com indícios dos efeitos de determinadas substâncias químicas sobre organismos vivos, inclusive sobre o Homem.

Em 1997 Harrison, Holmes e Humfrey chamavam a atenção sobre efeitos adversos na saúde reprodutiva e na fecundidade de animais e humanos. Foi destacada por estes pesquisadores, tendências para desenvolvimento de cânceres testicular no homem e de mama nas mulheres, bem como a redução na contagem de espermas no homem, além de outros problemas resultantes da exposição aos compostos químicos presentes no meio ambiente, naturais ou sintéticos. Os autores concluem que é necessário desenvolver programas de pesquisa e monitoramento para identificar com maior precisão as possíveis substâncias que podem atuar como desreguladores endócrinos e também avaliar a exposição dos seres humanos e outros animais a essas substâncias.

Uma revisão sobre estrógenos e andrógenos mimetizadores e antagonistas, feita por Sonnenschein e Soto (1998), corrobora para a hipótese de que certas substâncias químicas têm efeito adverso sobre a saúde humana e de outros organismos vivos. Neste artigo, os autores relataram a feminilização de peixes machos nas proximidades dos pontos de lançamento de esgotos em rios da Inglaterra, tendo como causa, provável, os alquilfenóis resultantes da degradação de detergentes sintéticos, durante o processo de tratamento de esgotos.

Em 2002, Amaral Mendes escreveu um artigo sobre desreguladores endócrinos como o principal desafio médico relatando que existem evidências substanciais sobre atuação de certas substâncias químicas, como pesticidas e outros compostos, no sistema endócrino e reprodutivo, destacando que os efeitos podem ser atribuídos à capacidade das substâncias em:

a) mimetizar os efeitos de hormônios endógenos;

b) antagonizar o efeito de hormônios endógenos,

c) desregular a síntese e metabolismo de hormônios endógenos;

d) desregular a síntese de receptores de hormônios. 
Em um artigo publicado na revista Trends in Biotechnology, Jones, Lester e Voulvoulis (2005), chamam a atenção para os potenciais problemas relacionados à presença de medicamentos no meio ambiente relatando sobre o risco associado ao desenvolvimento de patógenos resistentes a antibióticos. Os autores citam como exemplo, a identificação de bactérias com genes resistentes a alguns antibióticos em biofilmes inoculados com água potável na Alemanha.

Em 1997, com base na resolução WHO 50.13, o Programa Internacional sobre Segurança Química, pertencente à Organização Mundial da Saúde, Programa Ambiental das Nações Unidas e Organização Internacional do Trabalho, assumiu a responsabilidade para desenvolver uma avaliação global sobre o conhecimento científico relativo aos desreguladores endócrinos (WHO, 2002). O desenvolvimento da avaliação sobre os desreguladores endócrinos foi motivado pelo grande número de pesquisas e estudos, em muitos casos divergentes, relacionados ao tema. Como conclusões gerais da avaliação foi apontado que, embora certas substâncias químicas possam interferir com os processos hormonais, as evidências que a saúde humana tem sido afetada pela exposição a substâncias endocrinologicamente ativas ainda são muito fracas. Contudo, existem evidências suficientes para concluir que efeitos adversos mediados pelo sistema endócrino ocorreram em algumas espécies selvagens (WHO, 2002).

Um aspecto a ser considerado sobre as evidências de efeitos adversos dos desreguladores endócrinos sobre a vida selvagem é o fato das pesquisas terem sido feitas em locais onde os niveis de contaminação são elevados. Isto não elimina a possibilidade de ocorrência de efeitos adversos onde as concentrações de desreguladores endócrinos são baixas, pois muitas substâncias podem ter a sua concentração aumentada pelo processo de bióacumulação e amplificação biológica, quando tais substâncias entram na cadeia alimentar.

Evidências da presença no meio ambiente e de efeitos potenciais dos desreguladores endócrinos têm sido relatadas em vários trabalhos 
desenvolvidos, principalmente, em países da Europa e nos Estados Unidos da América, ressaltando-se que nestes países as condições de saneamento básico, em especial da coleta e tratamento de esgotos, são melhores do que as encontradas no Brasil.

\subsection{Presença de contaminantes orgânicos em mananciais de água para abastecimento}

Por se tratar de um tema relativamente novo, os principais estudos sobre a presença, em mananciais, de contaminantes orgânicos com potencial de causar perturbações no sistema endócrino, limitam-se aos países com maior disponibilidade de recursos.

Em alguns trabalhos disponíveis são apresentados dadós muito pontuais sobre o Brasil, ressaltando-se que as investigações foram feitas por pesquisadores internacionais e que a avaliação se restringiu à análise de amostras de esgoto bruto e tratado.

No trabalho desenvolvido por Ternes e colaboradores (TERNES et al., 1999), procurou-se avaliar o comportamento e a ocorrência de estrógenos em estações de tratamento de esgotos da Alemanha, do Brasil e do Canadá, além da presença em rios e cursos d'água da Alemanha e do Canadá.

Para o estudo foram coletadas amostras compostas diárias do afluente e efluente de uma estação de tratamento de esgotos próxima a frankfurt ná Alemanha (23 a 30 de novembro de 1997), e da uma estação no Rio de Janeiro (16 a 20 de junho de 1997). Além disto, foram analisadas amostras de esgoto tratado de 16 estações na Alemanha (20 a 27 de novembro de 1997), e 10 no Canadá (03 a 13 de novembro de 1997). Na Alemanha também foram analisadas amostras de 5 rios e outros 9 cursos d'água. Os compostos analisados foram: 
- Estrona;

- $17 \beta-$ Estradiol;

- Mestranol;

- $17 \alpha$-Etinilestradiol;

- $17 \beta$-Estradiol - 17 - valerato;

- $16 \alpha$ - Hidroxiestrona;

- $17 \beta$-Estradiol - 17 - acetato.

No esgoto bruto da estação de tratamento no Rio de Janeiro foram detectados os estrogênios naturais $17 \beta$-estradiol e estrona, nas concentrações de $21 \mathrm{ng} \cdot \mathrm{L}^{-1}$ e $40 \mathrm{ng} . \mathrm{L}^{-1}$, além do $17 \alpha$-etinilestradiol em menor concentração. A eficiência de remoção no sistema de tratamento. foi de $78 \%$ para o $17 \alpha$-etinilestradiol, $83 \%$ para a estrona e $99,9 \%$ para o 17ß-estradiol (TERNES et al., 1999). Na estação de tratamento de esgotos da Alemanha também foi constatada a presença de $17 \beta$-estradiol e estrona no efluente bruto, porém em menor concentração que na estação do Rio de Janeiro. Foi verificado, no entanto, que a remoção de estrona e $17 \alpha$-etinilestradiol foi menor.

Com relação às descargas de efluentes das estações de tratamento da Alemanha e do Canadá, os principais compostos que puderam ser identificados foram estrona, 17 $\beta$-estradiol, 16 $\alpha$-hidroxiestrona e $17 \alpha$ etinilestradiol, na faixa de nanogramas por litro.

No caso das amostras de rios e cursos d'água da Alemanha, a estrona foi o único composto identificado, com concentrações variando entre $0,7 \mathrm{e}$ 1,6 ng. L-1 (TERNES et al., 1999).

Um estudo realizado pelo United States Geological Survey (USGS) mostrou que uma ampla variedade de produtos quimicos da classe dos desreguladores endócrinos está presente em baixas concentraçöes em corpos d'água próximos a áreas de intensa urbanização e de produção animal (USGS, 2002).

No programa desenvolvido pelo USGS foram coletadas amostras de 139 corpos d'água em 30 estados americanos, para a identificação e 
quantificação de substâncias químicas da classe dos desreguladores endócrinos, sendo que os resultados mais representativos foram para as regiões altamente urbanizadas e com elevada produção de gado.

Dentre os compostos químicos identificados estão o 4-nonilfenol (metabólito de detergentes não iônicos), o N-N-dietiltoluamida (repelente de insetos) e o triclosan (desinfetante antimicrobiano), entre outros (USGS, 2002). O gráfico da Figura 3.7 mostra os principais contaminantes identificados, as concentrações médias e a freqüência de detecção.

Em 2002, Ying, Kookana e Ru publicaram uma revisão sobre a ocorrência e destino de esteróides hormonais no meio ambiente (YING, KOOKANA e RU, 2002). Neste artigo os autores apresentam informações sobre os níveis de estrógenos em esgotos, resíduos animais e em águas superficial e subterrânea.

Em relação ao potencial para a presença de estrógenos nos esgotos, uma informaçăo bastante útil refere-se à quantidade de estrogênios excretadọs diariamente pelos seres humanos (Tabela 3.6), mostrando a relevância desta fonte.

Tabela 3.6 - Excreção diária, em microgramas, de estrogênios pelos seres humanos

\begin{tabular}{|c|c|c|c|c|}
\hline Categoria & $\begin{array}{c}17 \beta \\
\text { estradiol }\end{array}$ & Estrona & Estriol & $\begin{array}{c}17 \alpha- \\
\text { etinilestradiol }\end{array}$ \\
\hline Homens & 1,6 & 3,9 & 1,5 & $\ldots$ \\
\hline Mulheres férteis & 3,5 & 8 & 4,8 & - \\
\hline $\begin{array}{l}\text { Mulheres na } \\
\text { menopausa }\end{array}$ & 2,3 & 4 & 1 & - \\
\hline Mulheres grávidas & 259 & 600 & 6.000 & $\ldots$ \\
\hline Mulheres & - & $\ldots$ & - & 35 \\
\hline
\end{tabular}

Fonte: Ying, Kookana e Ru, 2002.

Boyd et al (2003) desenvolveram um estudo para avaliar a presença de fármacos e produtos de higiene pessoal em águas superficiais e tratadas na Louisiana (EUA), e Ontário (Canadá). 




Figura 3.7 - Principais contaminantes identificados em cursos d'água nos Estados Unidos da América. 
No estudo foram avaliadas onze substâncias químicas, tendo sido encontradas no efluente da estação de tratamento da Louisiana o Naproxen (analgésico antiinflamatório), em concentrações variando entre $81^{\circ}$ a $106 \mathrm{ng} \cdot \mathrm{L}^{-1}$ e 0 Triclosan (desinfetante antimicrobiano), em concentrações variando entre 10 e $21 \mathrm{ng} \cdot \mathrm{L}^{-1}$. Com relação à presença de contaminantes químicos em águas superficiais, o Naproxen foi detectado tanto na Louisiana, quanto em Ontário, em concentrações variando entre 22 e $107 \mathrm{ng} \cdot \mathrm{L}^{-1}$ (BOYD et al, 2003).

Em Portugal (CEREJEIRA et al., 2003) e Espanha (CARABIASMARTÍNEZ et al., 2003), foi detectada a presença de herbicidas e inseticidas em mananciais superficiais, a maioria com valores constantes e abaixo do valor máximo permitido (VMP) pela União Européia. Apesar de não representar uma tendência, foi constatada variação sazonal de concentração, com os maiores níveis registrados na primavera, justamente após aplicação dọ produto, com resíduos de alguns defensivos agrícolas com valores acima do VMP europeu. Tais resultados, ainda que pontuais, sugerem uma relação entre a estação do ano e a ocorrência de contaminação por herbicidas, como uma função das atividades agrícolas em cada época do ano.

Um projeto conduzido pela União Européia, POSEIDON, entre janeiro de 2001 e junho de 2004, para desenvolver estratégias de avaliação e melhorar o desempenho para a remoção de produtos farmacêuticos e de higiene pessoal nas estações de tratamento de água para abastecimento e esgotos, permitiu concluir que estas substâncias são um grande problema para os países da Europa (TERNES, 2004).

Avaliando-se as informações apresentadas, é possivel concluir que a presença de contaminantes pertencentes à classe dos desreguladores endócrinos em mananciais de água é uma realidade, mesmo em países que dispões de uma infra-estrutura adequada de coleta e tratamento de esgotos.

A hipótese formulada é comprovada pelos resultados de uma pesquisa desenvolvida nos Estados Unidos da América, onde foram detectados 
traços de diferentes fármacos, na água potável de 24 Regiões Metropolitanas importantes (MEMBRANE TECHNOLOGY, 2008), indicando que estes contaminantes não são eficientemente removidos pelos processos de tratamento empregados.

Em um trabalho desenvolvido por Soares e colaboradores (2008), é relatado que a eficiência de remoção do nonilfenol, um composto químico resultante da degradação dos detergentes a base de alquilfenol polietoxilado, em estações de tratamento de água é muito variável, entre $13 \%$ e $99 \%$, dependendo do processo de tratamento empregado.

Como no Brasil os serviços de coleta e tratamento de esgotos ainda são precários e as atividades agrícolas são intensas pode-se inferir que além da presença de compostos orgânicos da classe dos desreguladores endócrinos em mananciais de água, as suas concentrações podem ser maiores do que aquelas observadas em países desenvolvidos.

Apenas para efeito de ilustração, utilizando-se os dados da'Tabela 3.6 e da contagem da população em 2007 (IBGE, 2007) é possivel obter uma estimativa da carga anual de alguns estrógenos, lançada no meio ambiente apenas pelos seres humanos e as suas concentraçōes nos esgotos, conforme apresentado na Tabela 3.7.

No estudo de Ghiselli (2006), na Região Metropolitana de Campinas-SP, para a avaliação da presença de desreguladores endócrinos e produtos farmacêuticos e de higiene pessoal, foi identificada a presença, em mananciais e na água tratada, de diversas substâncias como o nonilfenol e estrogênios naturais e sintéticos, além de diversos fármacos, em concentrações na faixa de $n g \cdot L^{-1}$ a $\mu g \cdot L^{-1}$.

Em uma pesquisa desenvolvida para a avaliação da ocorrência de perturbadores endócrinos em três mananciais de abastecimento da Região Metropolitana de Belo Horizonte, Moreira (2008) identificou a presença de nonilfenol (44 a $1.900 \mathrm{ng} \cdot \mathrm{L}^{-1}$ ), de 17- $\beta$-estradiol (3 a $54 \mathrm{ng} . \mathrm{L}^{-1}$ ), e de Etinilestradiol $\left(1,5\right.$ a $\left.36 \mathrm{ng} \cdot \mathrm{L}^{-1}\right)$. Também foi feita, neste estudo, a avaliação da presença destas substâncias na água tratada dos três mananciais estudados, constatando que os processos e 
operações unitárias empregados nas estações de tratamento não são eficientes para remover tais contaminantes.

Tabela 3.7 - Estimativa da carga de alguns estrógenos lançada no meio ambiente por seres humanos

\begin{tabular}{|c|c|c|c|c|c|}
\hline \multirow{2}{*}{ Categoria } & \multirow{2}{*}{$\begin{array}{c}\text { Quantidade } \\
\text { (milhōes) }\end{array}$} & \multicolumn{4}{|c|}{ Carga anual (kg) } \\
\hline & & $\begin{array}{c}17 \beta- \\
\text { estradiol }\end{array}$ & Estrona & Estriol & $\begin{array}{c}17 \alpha- \\
\text { etinilestradiol }\end{array}$ \\
\hline $\begin{array}{l}\text { Homens } \\
\text { entre } 15 \text { e } \\
60 \text { anos }\end{array}$ & 58,4 & 34,11 & 83,13 & 31,97 & 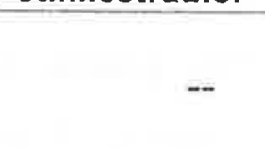 \\
\hline $\begin{array}{l}\text { Mulheres } \\
\text { entre } 15 \text { e } \\
49 \text { anos }\end{array}$ & $47,1^{\mathrm{a}}$ & 60,17 & 137,53 & 85,52 & $198,56^{b}$. \\
\hline Mulheres & 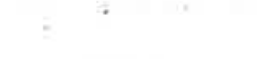 & & & & \\
\hline $\begin{array}{l}\text { acima de } \\
49 \text { anos }\end{array}$ & 17,4 & 14,61 & 25,40 & 6,35 & $\therefore$ \\
\hline $\begin{array}{l}\text { Mulheres } \\
\text { grávidas }^{\mathrm{c}}\end{array}$ & 2,8 & 196,76 & 455,62 & $4.537,21$ & 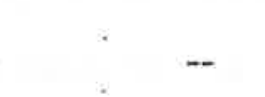 \\
\hline Total & & 305,65 & 701,68 & $4.661,05$ & 198,56 \\
\hline $\begin{array}{l}\text { Concentraç } \\
\text { potencial } \\
\left(\mathrm{ng} \cdot \mathrm{L}^{-1}\right)^{\mathrm{d}}\end{array}$ & $\begin{array}{l}\text { ão } \\
\text { os esgotos }\end{array}$ & 41,9 & 96,2 & 639,0 & 27,2 \\
\hline $\begin{array}{l}\text { a - aqui foram } \\
\text { b - foi consid } \\
\text { Online, 2008). } \\
c \text { - o número } \\
\text { com menos de } \\
d \text { - foi utilizado }\end{array}$ & $\begin{array}{l}\text { desconsideradas } \\
\text { rado que apena } \\
\text { de mulheres grá } \\
\text { um ano e um pe } \\
\text { o volume anual }\end{array}$ & $\begin{array}{l}\text { as mulheres } 9 \\
33 \% \text { das mL } \\
\text { das foi consio } \\
\text { odo de excrec } \\
\text { e água consul }\end{array}$ & $\begin{array}{l}\text { lrávidas. } \\
\text { llheres utiliz } \\
\text { derado equi } \\
\text { ção de } 9 \text { me } \\
\text { mido, Tabel }\end{array}$ & $\begin{array}{l}\text { am anticon } \\
\text { alente ao } r \\
\text { ses. }\end{array}$ & $\begin{array}{l}\text { cionais (Paraná } \\
\text { ero de crianças }\end{array}$ \\
\hline
\end{tabular}

Os dados apresentados demonstram a relevância dessa nova classe de contaminantes, conhecidos como desreguladores endócrinos, destacando-se a importância do desenvolvimento de pesquisas especificas sobre procedimentos analíticos para a sua identificação e quantificação e sobre a capacidade das tecnologias de tratamento de água atualmente utilizadas para a sua remoção. 


\subsection{Remoção no tratamento}

Com base no conceito de múltiplas barreiras, os sistemas de tratamento de água para abastecimento se constituem no instrumento final para assegurar a produção de uma água adequada do ponto de vista de saúde pública.

As tecnologias tradicionalmente utilizadas para tratamento de água apresentam capacidade limitada para possibilitar a remoção ou destruição de substâncias ou compostos orgânicos, que possuem potencial de geração de subprodutos com maior toxicidade, principalmente nas etapas de pré-oxidação ou desinfecção (OKUN, 2003).

Em um estudo desenvolvido por Stackelberg e colaboradores (2004), foi constatado que muitos compostos químicos, como medicamentos, fragrâncias e plastificantes, entre outros, podem passar inalterados pelos processos de tratamento de esgotos e de água para abastecimento. Neste trabalho foi relatada a presença de 25 compostos químicos, com freqüência superior a $50 \%$, nas amostras de água coletadas na saída do sistema de tratamento de água convencional, dentre os 106 que foram analisados (STACKELBERG et al, 2004).

Jones, Lester e Voulvoulis (2005), também relatam a presença de alguns produtos farmacêuticos na água de abastecimento em diversos países. Mesmo que as concentrações estejam na faixa de nanogramas por litro, o aspecto mais importante é que estas substâncias passam incólume por sistemas convencionais de tratamento de água, possibilitando a exposição dos consumidores, o que é um fator de risco à sua saúde.

Considerando-se que no Brasil a maioria das estações de tratamento de água para abastecimento público utiliza sistema convencional, a presença potencial de uma ampla gama de compostos orgânicos na água potável não pode ser desprezada, o que requer uma maior atenção por parte de pesquisadores e profissionais que atuam na área de tratamento de água para abastecimento, principalmente nos grandes centros urbanos 
As crescentes evidências dos efeitos de muitas substâncias quimicas sobre o sistema endócrino do ser humano e outros organismos vivos fizeram a Agência Americana de Proteção Ambiental desenvolver um programa para determinar quais substâncias quimicas poderiam ser relevantes, além de avaliar as tecnologias capazes de remover tais substâncias da água (EPA, 2001). No programa foram avaliadas as substâncias químicas e tecnologias apresentadas na Tabela 3.8.

Tabela 3.8 - Substâncias químicas e tecnologias de tratamento avaliadas no projeto desenvolvido pela EPA

\begin{tabular}{|c|c|c|}
\hline \multicolumn{2}{|c|}{ Substâncias químicas } & \multirow{2}{*}{ Tecnologias } \\
\hline Grupo & Substância / Composto & \\
\hline Pesticidas & $\begin{array}{l}\text { DDT } \\
\text { Endosulfan } \\
\text { Metoxicloro }\end{array}$ & \\
\hline Compostos Clorados & $\begin{array}{l}\text { PCB } \\
\text { Dioxinas } \\
\text { Furanos }\end{array}$ & $\begin{array}{c}\text { Carvão ativado } \\
\text { granular }\end{array}$ \\
\hline $\begin{array}{l}\text { Alquilfenóis e } \\
\text { Alquilfenóis } \\
\text { polietoxilados }\end{array}$ & $\begin{array}{l}\text { Nonilfenol } \\
\text { Octilfenol }\end{array}$ & $\begin{array}{l}\text { Coagulação e filtração } \\
\text { Abrandamento com cal }\end{array}$ \\
\hline Aditivos plásticos & $\begin{array}{c}\text { Bisfenol A } \\
\text { Dietilftalato } \\
\text { Di-2-etilhexilftalato }\end{array}$ & \\
\hline
\end{tabular}

Fonte: EPA, 2001.

Como resultado do programa, a EPA concluiu que o processo de adsorção em carvão ativado granular é o mais eficiente para a remoção dos contaminantes avaliados. Uma exceção foi feita para as dioxinas, que não são solúveis em água, podendo estar apenas adsorvidas nas partículas presentes, indicando que os processos de coagulação filtração seriam eficientes para a sua remoção.

Além do processo de adsorção em carvão ativado, outras tecnologias de tratamento têm sido avaliadas e sugeridas para a remoção dessa nova classe de contaminantes (VON GUNTEN et al., 2006). Dentre as tecnologias sugeridas estão os processos de separação por membrana's e a oxidação com ozônio. 


\subsection{Comprometimento da qualidade da água dos mananciais da Região Metropolitana de São Paulo}

Para justificar a utilização de tecnologias alternativas de tratamento de água para abastecimento público é necessário dispor de um panorama relativo à qualidade das águas dos mananciais disponíveis.

Em particular, para a Região Metropolitana de São Paulo - RMSP pode ser utilizado, como exemplo, o Reservatório Guarapiranga, um dos principais mananciais de abastecimento de água da região.

O Reservatório Guarapiranga possui um perímetro de $85 \mathrm{~km}$, área superficial de 33,91 km² e capacidade de armazenagem de 194 milhões de metros cúbicos de água. Em 1927, passou a ser utilizado como manancial para abastecimento público da cidade de São Paulo e, atualmente, contribui com cerca de. $20 \%$ da água de abastecimento da RMSP (CETESB, 2003).

Segundo a Companhia de Tecnologia de Saneamento Ambiental do Estado de São Paulo (2003), é estimada a presença de 622 mil hảbitantes no entorno do Reservatório Guarapiranga, com prevalência de subhabitações nas regiões mais próximas às margens do reservatório. Com isso, desde o final da década de 1960, o reservatório vem sofrendo um contínuo processo de degradação. Durante a década de 1970, o Estado passou a definir políticas públicas para a proteção de mananciais, mas que ainda não resultaram em efeitos perceptiveis no panorama descrito.

Apesar da água do Reservatório Guarapiranga ser utilizada para abastecimento, em sua Bacia são lançados esgotos domésticos e efluentes líquidos industriais. Devido ao grande aporte de carga orgânica contendo fósforo, um acentuado processo de eutrofização tem ocorrido nos últimos anos, agravando os problemas de qualidade da água do reservatório. A partir de 1982, fenômenos de floração de algas têm sido recorrentes, afetando negativamente o sistema de tratamento para 
abastecimento público. A Companhia Estadual de Saneamento Básico (SABESP) passou, então, a utilizar sulfato de cobre como algicida para controle de algas no reservatório (CETESB, 2003).

Para constatar os problemas associados à degradação da qualidade da água do Reservatório Guarapiranga foi feito um levantamento na base de dados da CETESB, sobre algumas variáveis físico-quimicas indicadoras da qualidade da água do reservatório no ponto de captação da SABESP, Tabela 3.9. Os resultados apresentados, claramente, demonstram a deterioração da qualidade da água do manancial, influenciada pela ocupação humana.

Tabela 3.9 - Resultados do monitoramento de algumas variáveis de - qualidade da água do Reservatório Guarapiranga, no ponto de captação da SABESP.

\begin{tabular}{|c|c|c|c|c|c|c|c|c|}
\hline \multirow{2}{*}{ Variável } & \multirow{2}{*}{ Ano } & \multicolumn{7}{|c|}{ Meses do ano } \\
\hline & & Jan & Mar & Mai & Jul & Set & Nov & Média \\
\hline \multirow{5}{*}{$\begin{array}{l}\text { Carbono Orgânico } \\
\text { Dissolvido }\left(\mathrm{mg}^{-1} \mathrm{~L}^{-1}\right)\end{array}$} & 2003 & 4,91 & 5,06 & 5,60 & 3,90 & 6,79 & 5,08 & 5,22 \\
\hline & 2004 & 6,57 & 5,55 & 5,42 & 4,40 & 5,31 & 4,84 & 5,35 \\
\hline & 2005 & 6,35 & 6,75 & 6,55 & 5,61 & 5,70 & 7,55 & 6,42 \\
\hline & 2006 & 5,68 & 5,74 & 6,81 & 3,04 & 4,21 & 5,02 & 5,08 \\
\hline & 2007 & 5,87 & 6,84 & 4,74 & 5,10 & 4,07 & 6,30 & 5,49 \\
\hline \multirow{5}{*}{$\begin{array}{l}\text { Condutividade } \\
\text { Elétrica }\left(\mu \mathrm{S} . \mathrm{cm}^{-1}\right)\end{array}$} & 2003 & 141 & 133 & 131 & 149 & 173 & 160 & 148 \\
\hline & 2004 & 143 & 122 & 130 & 126 & 154 & 164 & 140 \\
\hline & 2005 & 132 & 110 & 113 & 123 & 138 & 134 & 125 \\
\hline & 2006 & 125 & 114 & 109 & 117 & 134 & 133 & 122 \\
\hline & 2007 & 114 & 112 & 117 & 132 & 140 & 160 & 129 \\
\hline \multirow{5}{*}{ Turbidez (UT) } & 2003 & 0,3 & 1,2 & 2,5 & 2,0 & 3,2 & 4,2 & 2,2 \\
\hline & 2004 & 3,3 & 0,8 & 1,9 & 0,4 & 0,4 & 2,8 & 1,6 \\
\hline & 2005 & 3,2 & 2,6 & 1,3 & 2,2 & 3,1 & 2,3 & 2,4 \\
\hline & 2006 & 1,4 & $<1,0$ & 2,5 & 1,6 & 1,9 & 1,6 & 1,8 \\
\hline & 2007 & 3,2 & 2,0 & 3,2 & 3,0 & - & 4,3 & 3,1 \\
\hline \multirow{5}{*}{$\begin{array}{l}\text { Fósforo total } \\
\left(m g \cdot L^{-1}, \text { como } P\right)^{\text {tal }}\end{array}$} & 2003 & 0,04 & 0,05 & 0,04 & 0,11 & 0,22 & 0,23 & 0,12 \\
\hline & 2004 & 0,07 & 0,04 & $<0,03$ & 0,10 & 0,06 & 0,04 & 0,06 \\
\hline & 2005 & 0,07 & 0,05 & 0,04 & 0,04 & 0,05 & 0,06 & 0,05 \\
\hline & 2006 & 0,04 & $<0,02$ & 0,03 & 0,06 & 0,06 & 0,12 & 0,06 \\
\hline & 2007 & 0,07 & 0,04 & 0,09 & 0,07 & 0,05 & 0,04 & 0,06 \\
\hline \multirow{5}{*}{$\begin{array}{l}\text { Nitrogênio kjeldahl } \\
\left(\mathrm{mg}^{-1} \mathrm{~L}^{-1} \text { como } \mathrm{N}\right)\end{array}$} & 2003 & 0,36 & 0,53 & 1,45 & 0,65 & 1,11 & 2,56 & 1,11 \\
\hline & 2004 & 1,60 & 0,35 & 0,59 & 0,76 & 0,94 & 1,33 & 0,93 \\
\hline & 2005 & 0,77 & 0,94 & 0,38 & 0,90 & 0,69 & 1,58 & 0,88 \\
\hline & 2006 & 0,71 & 0,57 & 0,63 & 0,81 & 1,20 & 0,40 & 0,72 \\
\hline & 2007 & 0,55 & 0,82 & 0,69 & 0,82 & 0,85 & 1,01 & 0,79 \\
\hline
\end{tabular}

Fonte: CETESB, 2004, 2005, 2006, 2007 e 2008. 
A variável condutividade elétrica pode dar uma indicação do nível de comprometimento da qualidade da água do Reservatório Guarapiranga, pois, em geral, valores superiores a $100 \mu \mathrm{S} . \mathrm{cm}^{-1}$ indicam ambientes impactados (CETESB, 2002). Na Figura 3.8 é apresentada a evolução da variação da condutividade elétrica do Reservatório Guarapiranga de 1989 a 2007 (CETESB 2002, 2003, 2004, 2005, 2006, 2007 e 2008).

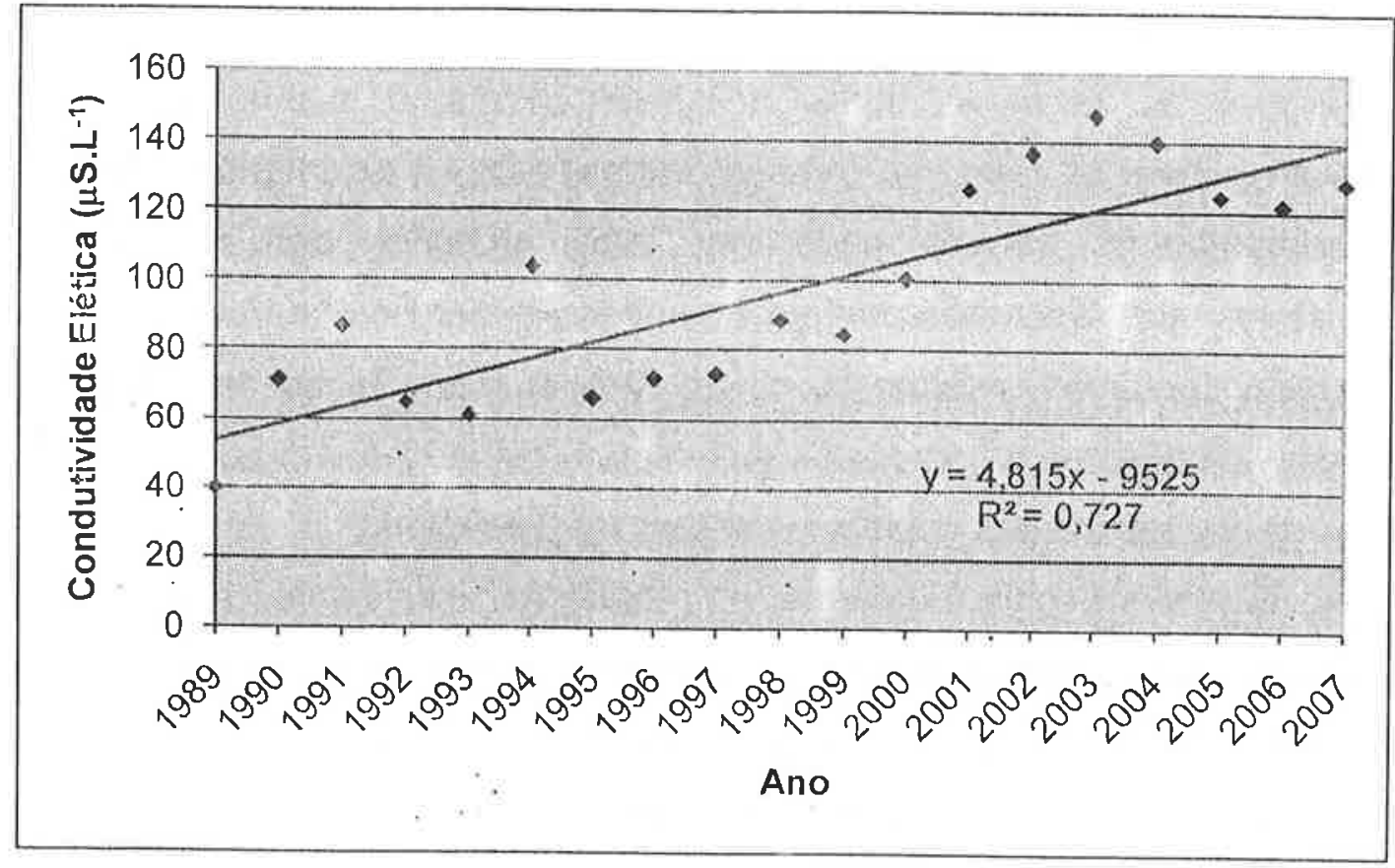

Figura 3.8 - Variação da condutividade elétrica da água do Reservatório Guarapiranga

Além da preocupação com os contaminantes apresentados, deve ser considerada, ainda, a presença potencial de outros contaminantes orgânicos como fármacos e produtos de higiene pessoal, que podem resultar em riscos para a saúde humana, conforme já discutido.

As condições observadas no Reservatório Guarapiranga indicam o comprometimento da qualidade das águas de mananciais próximos a áreas urbanas reforçando a necessidade de estudos para avaliação de tecnologias de tratamento que sejam capazes de atender aos desafios que ostão sendo impostos para o seior de saneamento ambiental.

Ressalta-se que a mesma condição observada no Reservatório Guarapiranga também pode ser observada em outros mananciais da 
RMSP, O que pode ser constatado pela avaliação dos dados disponibilizados pela CETESB.

\subsection{Tendências para o futuro}

Mantendo-se os atuais níveis de desenvolvimento e urbanização, a pressão sobre os recursos hídricos tenderá a ser mais intensa. Com os assentamentos urbanos cada vez mais próximos dos mananciais utilizados para abastecimento público, os baixos índices de tratamento de esgotos sanitários atualmente observados e a ampliação da oferta de - novas substâncias e compostos químicos, o abastecimento de água para as populações desses centros urbanos será um desafio.

Para que seja possivvel enfrentar os problemas relacionados à qualidade da água para abastecimento é necessário investir em pesquisas para avaliaçäo dos impactos que os compostos orgânicos presentes em microquantidades nos mananciais podem ter sobre a saúde humana e como eles se comportam nos sistemas de tratamento.

A colaboração entre instituições de pesquisa e companhias de abastecimento de água é de extrema importância para garantir que não sejam consolidadas posições extremas em relação a essa nova classe de contaminantes, que em última análise não atende aos interesses da sociedade como um todo.

Não se deve superestimar e muito meiios negligenciar os riscos potenciais que podem estar associados a esta ampla variedade de substâncias e compostos quimicos que atingem os nossos mananciais e, conseqüentemente, a água que é consumida.

O desenvolvimento tecnológico trouxe grandes benefícios para a hurnanidade, com inovações em várias áreas do conhecimento, inclusive para o tratamento de água. Assim, os desafios atuais devem ser enfrentados com todas as ferramentas disponiveis. 
No caso das tecnologias de tratamento de água, em muitas situações o sistema convencional é a opção mais adequada para possibilitar a obtenção de uma água segura para o consumo humano, enquanto em outras são necessárias tecnologias modernas e eficientes.

Além disto, deve-se considerar o desafio da expansão dos centros urbanos, o que acaba dificultando a adoção do conceito de sistemas centralizados de tratamento de água, principalmente pelos custos associados à rede de distribuição. A tendência atual é a adoção de sistemas descentralizados e, para isto, os processos de separação por membranas são uma opção bastante adequada (PETER-VARBANETS et al., 2008), principalmente pelo fato de ser um processo físico e poder ser facilmente automatizado, o que reduz os custos de operação desses sistemas.

Estar consciente dos principais problemas sobre a qualidade da água para abastecimento público e das opções disponiveis para enfrentá-los são, talvez, o maior desafio que deve ser superado pelos profissionais e pesquisadores ligados à área de saneamento básico, bem com as companhias que atuam no setor. 


\section{METODOLOGIA}

O presente estudo consolida os resultados obtidos com o desenvolvimento de dois projetos de pesquisa no âmbito do Programa de Pesquisa em Saneamento Básico - PROSAB, edital $n^{\circ}$ 04/2003 (PROSAB-04) e $n^{\circ}$ 05/2006 (PROSAB-05), com recursos da Financiadora de Estudos e Projetos - FINEP, Caixa Econômica Federal e Conselho Nacional de Desenvolvimento Científico e Tecnológico - CNPq. Trata-se de pesquisa pioneira no pais, sobre a aplicação da tecnologia de separação por membranas para tratamento de água de abàstecimento. $O$ Projeto desenvolvido no PROSAB-04 teve vigência de março/2004 a julho/2006 e o desenvolvido no PROSAB-05 de Agosto/2006 a novembro/2008.

Os dois projetos de pesquisa foram desenvolvidos a partir da montagem e operação de unidades pilotos, utilizando membranas de ultrafiltração enroladas em espiral. As unidades operaram em regime contínuo, junto à estação elevatória de água para a Estação Alto da Boa Vista, pertencente a SABESP, localizada próxima ao Reservatório Guarapiranga, conforme indicado na Figura 4.1.

No PROSAB-04 o principal objetivo do projeto de pesquisa foi avaliar o desempenho do sistema de ultrafiltração com relação à estabilidade de operação da membrana e a eficiência de remoção de alguns contaminantes de interesse para o tratamento de água para abastecimento público. Já no PROSAB-05 procurou-se obter uma melhor compreensão da influência de algumas condições operacionais no desempenho do sistema e a avaliação da eficência da membrana utilizada na remoçäo de alguns contaminantes orgânicos. 


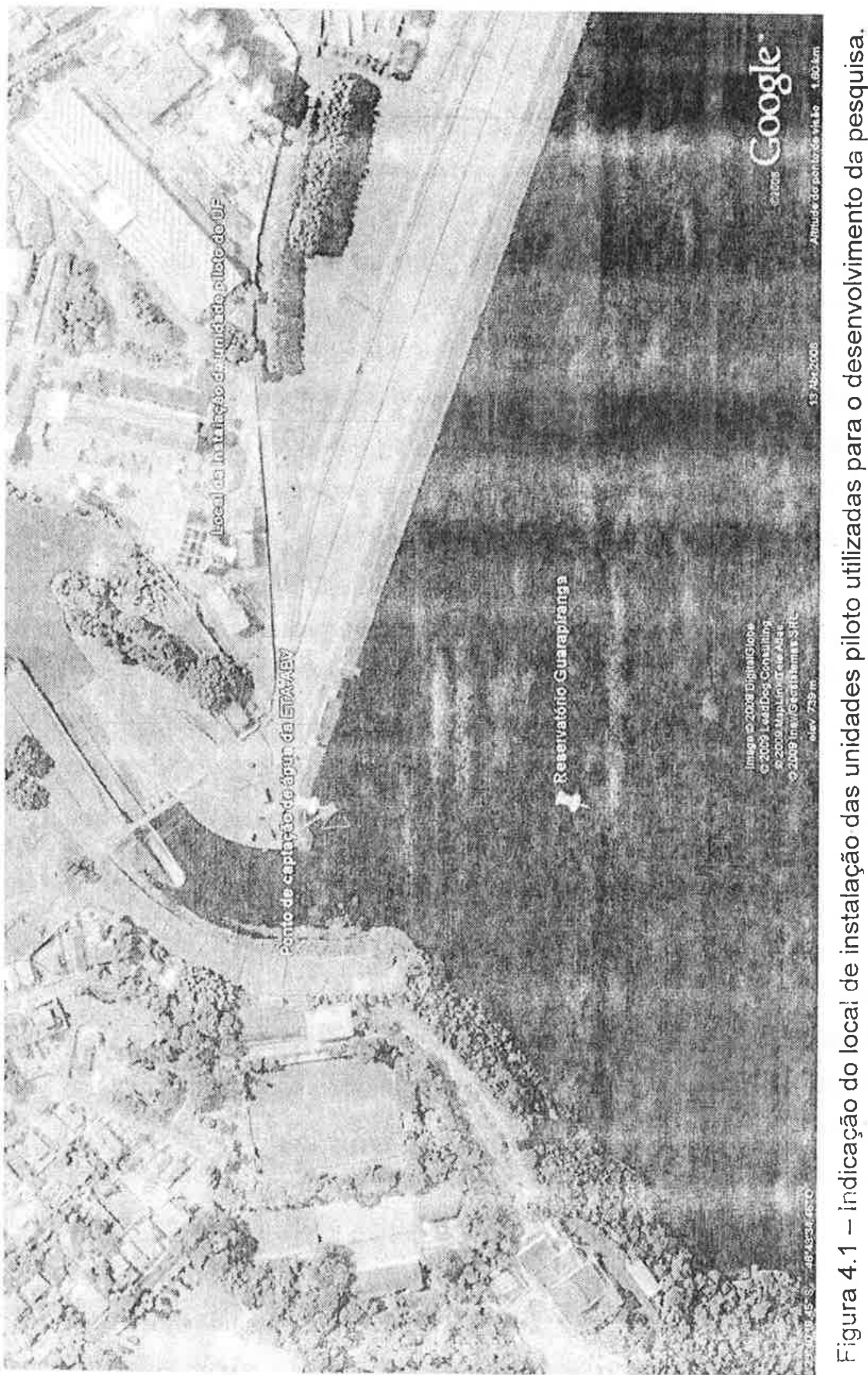




\subsection{Equipe, materiais e métodos - PROSAB-04}

O desenvolvimento deste projeto contou com a participação da equipe relacionada a seguir:

José Carlos Mierzwa Coordenador - Professor EPUSP;

Caio Pompeu Cavalhieri Estagiário - Aluno de graduação EPUSP;

Camilo Fragoso Giorgi Estágiário - Aluno de graduação EPUSP;

Luana Di Beo Rodrigues Bolsista DTI-CNPq, Pesquisadora;

Maurício Costa Cabra Bolsista DTI-CNPq, Pesquisador;

Maurício F. de F. Jardim Bolsista IC - CNPq / EPUSP;

Silvia M: C. de M. Carrara Bolsista DTI - CNPq, Pesquisadora;

Thiago Mathio

Bolsista IC - CNPq / EPUSP.

4.1.1. Avaliação preliminar do potencial de utilização de sistemas de UF

A avaliação preliminar de desempenho do processo de ultrafiltração foi realizada no laboratório do Centro Internacional de Referência em Reúso de Água - CIRRA/IRCWR, utilizando-se uma unidade piloto disponivel no local e água proveniente do Reservatório Guarapiranga, trazida por meio de caminhão tanque da SABESP.

Foram utilizadas membranas de ultrafiltração na configuração enrolada em espiral, fabricada pela empresa Osmonics, modelo GK-4040F, de filme fino composto e capacidade para separação de moléculas orgânicas coin peso molecular maior ou igual a $3.500 \mathrm{~g} \cdot \mathrm{mol}^{-1}$. A pressão de operação na membrana pode variar de 483 a $2.758 \mathrm{kPa}$, com uma taxa de produção de água, prevista pelo fabricante, de $28,26 \mathrm{~L} \cdot \mathrm{h}^{-1} \cdot \mathrm{m}^{-2}\left(25^{\circ} \mathrm{C}\right)$, 
para uma pressão de $517 \mathrm{kPa}$. A área de membrana por módulo é de $8,36 \mathrm{~m}^{2}$ (GE-Osmonics, 2006).

A unidade utilizada, que se encontra instalada no CIRRA, foi fornecida pela empresa Perenne Equipamentos e Sistemas de Água Ltda, sendo que nos ensaios preliminares foram utilizadas duas membranas instaladas em um único vaso de pressão.

A unidade piloto também dispõe de um sistema de pré-tratamento, constituído por filtro tipo bolsa, para retenção de partículas de até $50 \mu \mathrm{m}$, e um conjunto de filtros tipo cartucho, para retenção de partículas com até $5 \mu \mathrm{m}$ de diâmetro, cujo principal objetivo é assegurar que não ocorra entupimento dos canais de água de alimentação das membranas.

O monitoramento do desempenho do sistema foi realizado através de medidas de turbidez, $\mathrm{pH}$ e condutividade elétrica, análises das concentrações de nitrogênio amoniacal, fósforo total, ortofosfato e microcistinas, na água bruta, no permeado e no concentrado.

Todos os ensaios foram realizados seguindo os procedimentos estabelecidos pelo Standard Methods for the Examination of Water and Wastewater $20^{\text {th }}$ edition, com exceção da determinação de microcistinas.

A determinação de microcistinas na água foi feita pelo ensaio por imunosorbente com enzima conjugada (ELISA), utilizando-se kits adquiridos da empresa Beacon Analytical Systems, Inc., representada no Brasil pela empresa All Quality.

$\mathrm{Na}$ tabela 4.1 estão relacionados os equipamentos utilizados para a realização das análises de caracterização.

A amostra de água bruta do Reservatório Guarapiranga foi analisada para determinação dos parâmetros de controle, assim como para a realização dos ensaios na unidade piloto de ultrafiltração, cujos parâmetros de operação foram definidos na etapa de planejamento.

Antes do início do ensaio com a água do manancial foi feito um ensaio utilizando-se água da rede pública de abastecimento, visando obter a taxa de fluxo da membrana com água tratada, para efeito de comparação posterior. 
Tabela 4.1 - Características dos equipamentos utilizados para a realização das análises

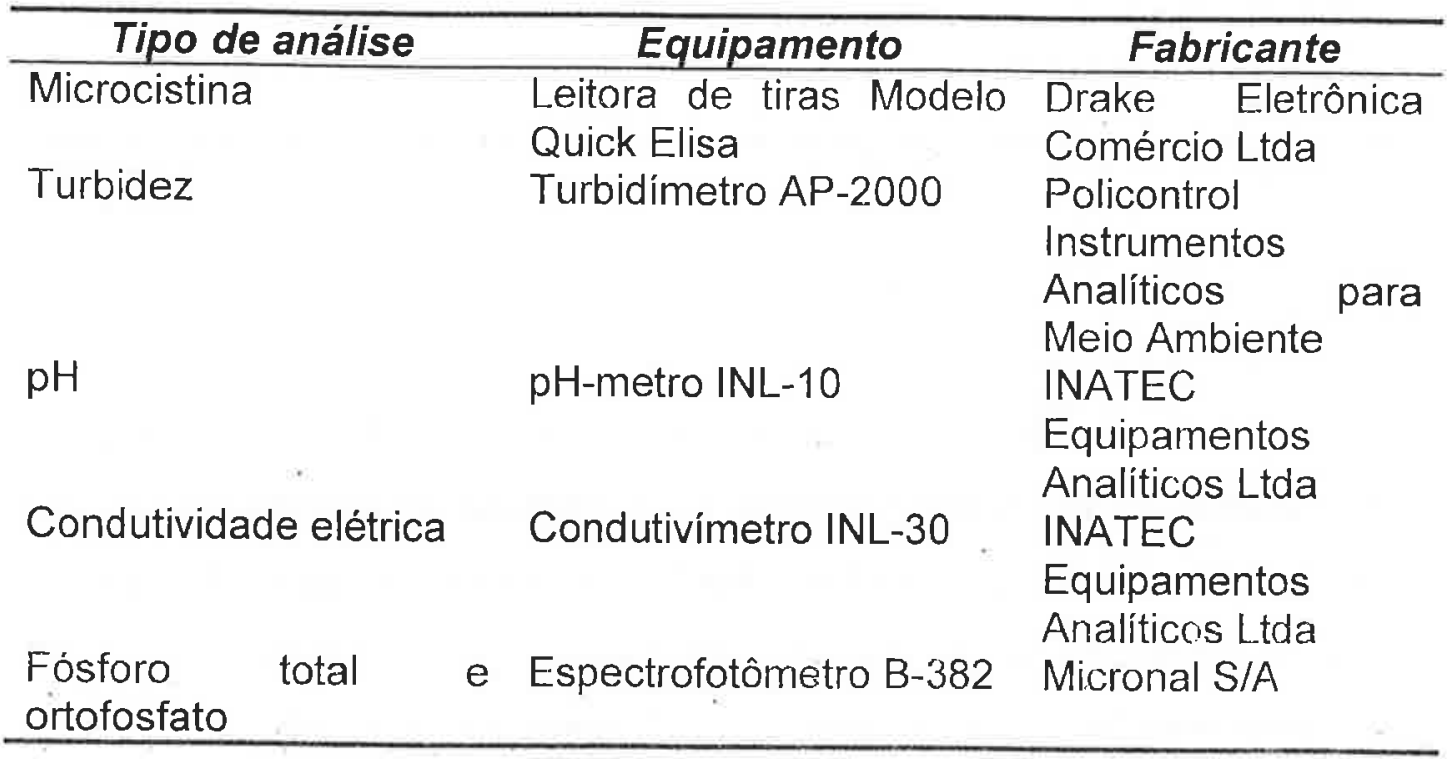

Durante a realização do ensaio na unidade piloto foram registradas as condições de operação do sistema, destacando-se as pressões de entrada e saída nos filtros cartucho e vaso de pressão e vazões de permeado, concentrado e de recirculação. A Figura 4.2 ilustra, esquematicamente, o arranjo utilizado nos ensaios, enquanto a Figura 4.3 mostra uma foto da unidade piloto utilizada.

\subsubsection{Avaliação na unidade piloto instalada no Reservatório Guarapiranga}

Com base nos resultados obtidos nos ensaios preliminares no laboratório do CIRRA, foi montada a unidade piloto junto à captação de água da SABESP, no Reservatório Guarapiranga. Na instalação piloto foi utilizada apenas uma membrana (GK-4040F), instalada em um vaso de pressão construido en material polimérico reforçado com fibra die vidio. o fluxograma de processo da unidade piloto está representado na Figura 4.4, com a indicação dos principais componentes. As Figuras 4.5 e 4.6 mostram detalhes da unidade piloto do PROSAB-04. 


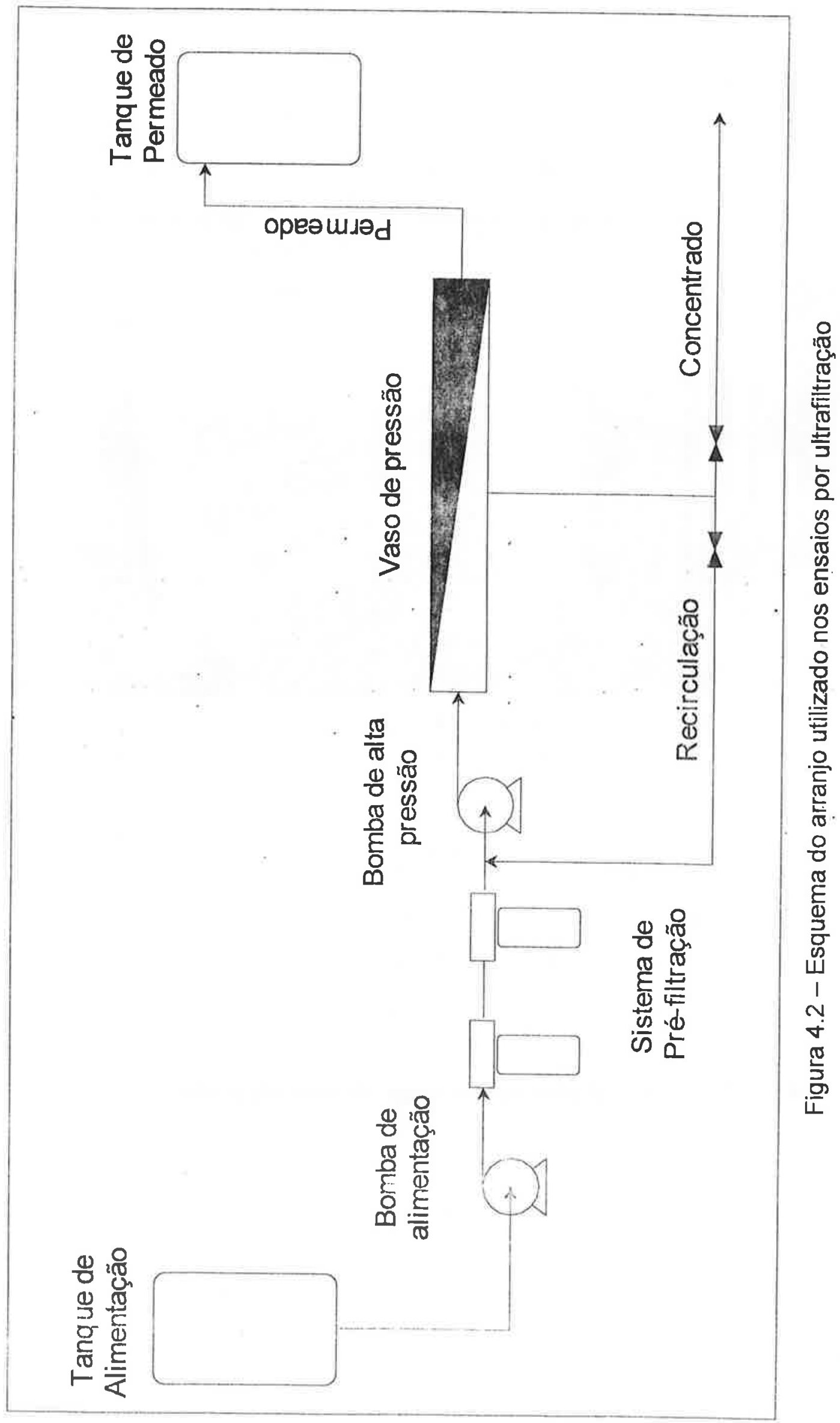




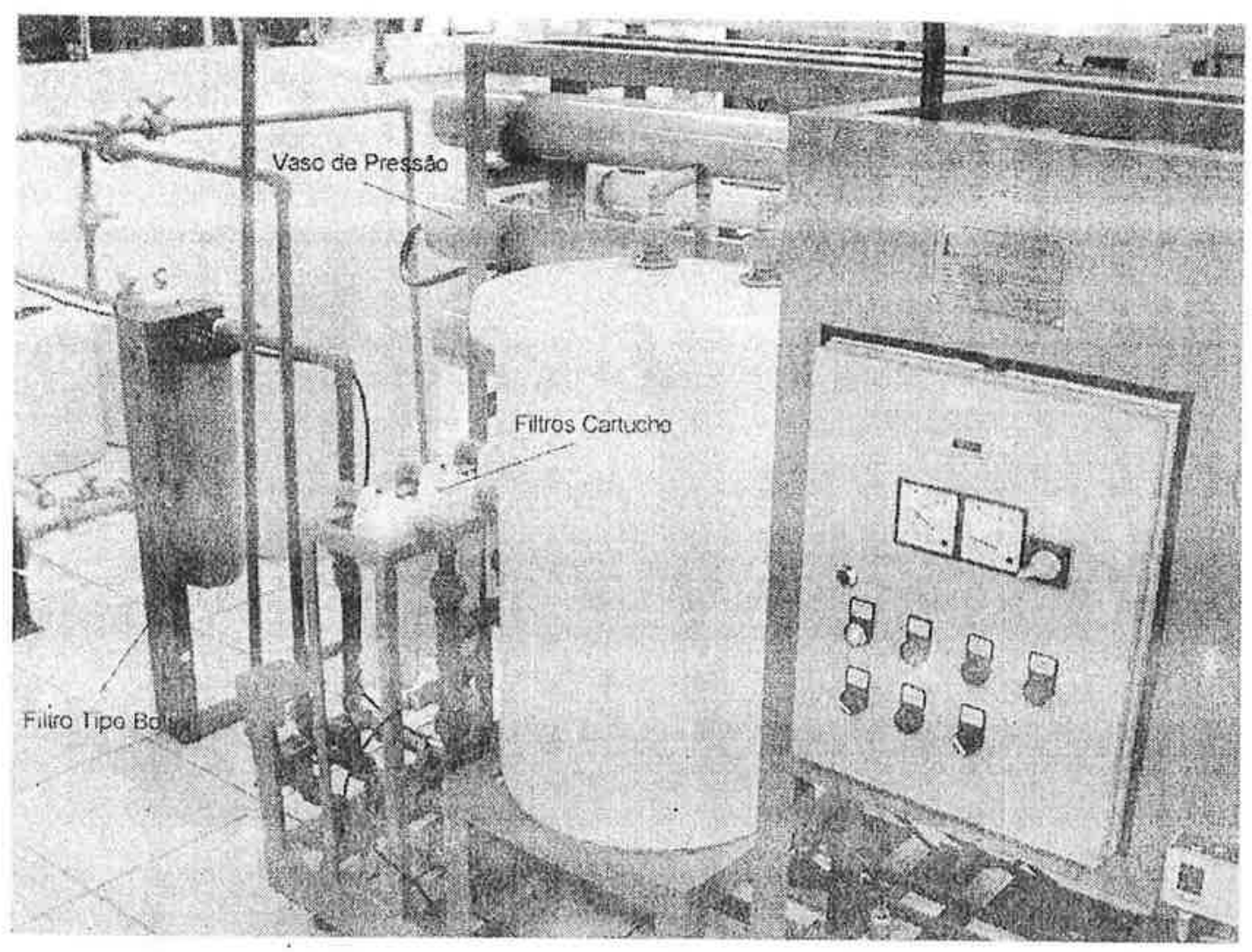

Figura 4.3 - Foto unidade ultrafiltração utilizada nos ensaios de laboratório

Deve ser observado que alguns dos componentes apresentados no fluxograma da Figura 4.4 foram instalados ao longo da operação da unidade piloto, pelos motivos que serão apresentados nos resultados.

\subsubsection{Condições operacionais da unidade piloto}

$\mathrm{Na}$ concepção da unidade piloto foi prevista a operação contínua, por meio da captação de água a partir da adutora de água bruta da elevatória do Reservatório Guarapiranga 


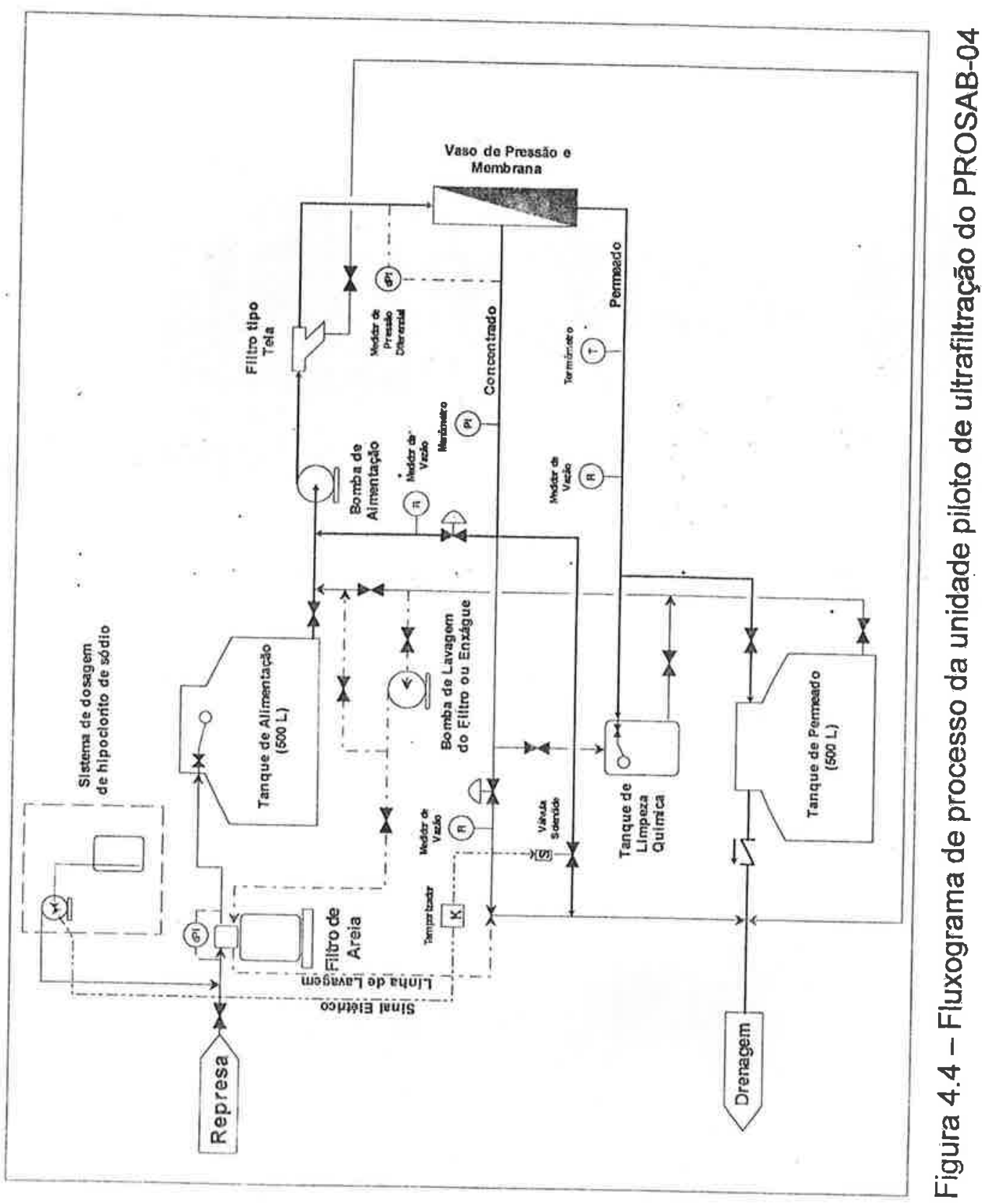






Figura 4.5 - Vista frontal da unidade piloto de ultrafiltração do PROSAB-04

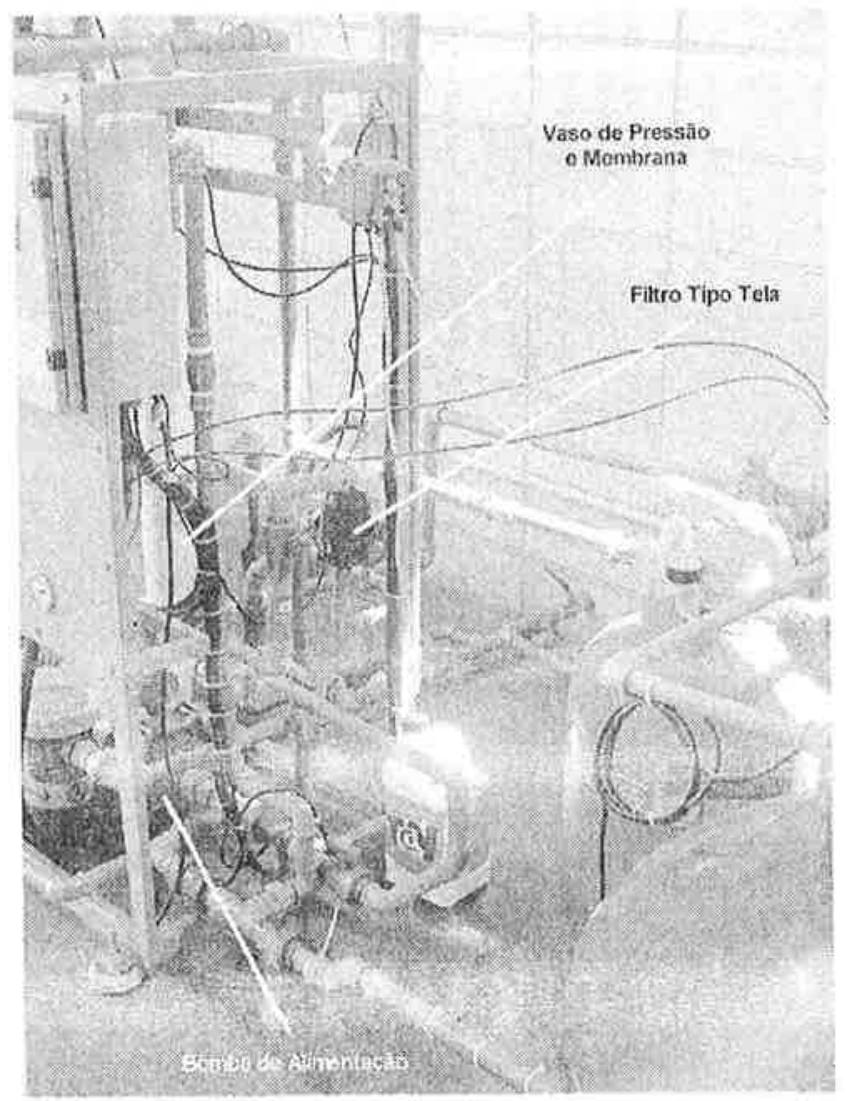

Figura 4.6 - Vista lateral da unidade piloto de ultrafiltração do PROSAB-04 
Antes de colocar a unidade em operação contínua, foi feito um ensaio para avaliar a taxa de produção de água do sistema em função da pressão aplicada na membrana, tanto para água tratada como para a água do Reservatório. A pressão nestes ensaios variou de 120 a 500 $\mathrm{KPa}$, sendo que para cada valor de pressão estabelecido foram coletados dados em intervalos de 5 minutos. A alteração da pressão foi feita a cada 30 minutos.

A água bruta é conduzida por tubulação de $25 \mathrm{~mm}$ de diâmetro para o tanque de alimentação com capacidade para $500 \mathrm{~L}$, construído em material polimérico, passando pelo filtro de areia, com área de filtração de $0,19 \mathrm{~m}^{2}$, modelo 19CFA4-M, da Jacuzzi.

Do tanque de alimentação, por bombeamento, a água passa pelo filtro tipo tela e deste alimenta o vaso de pressão onde se localiza a membrana de ultrafiltração. A pressão na membrana é controlada por meio de válvulas de descarga de concentrado instaladas na linha de recirculação e na linha de descarte de concentrado.

Para possibilitar uma maior recuperação de água pelo sistema, o concentrado é recirculado para a sucção da bomba de alimentação e somente uma parcela é descartada. Tanto na linha de recirculação como na de descarga de concentrado foram instalados medidores de vazäo do tipo rotâmetro.

O permeado deixa o vaso de pressão por uma tubulação central de 12 $\mathrm{mm}$ e segue para o tanque de permeado, passando pelo sensor de temperatura e por um medidor de vazão tipo turbina.

As operações de limpeza quimica, quando necessárias, foram realizadas promovendo-se, inicialmente, o enxágüe da membrana com o permeado produzido e posterior limpeza com solução de hidróxido de sódio e detergente, através da circulação da solução contida no tanque de limpeza química e enxágüe final com permeado.

Na fase inicial a unidade piloto foi operada com descarga contínua de concentrando, controlando-se a vazão por meio de uma válvula agulha instalada a montante do rotâmetro na respectiva linha. 
Para avaliar o desempenho do sistema, em intervalos regulares, a cada duas horas, eram registrados pelos operadores da SABESP, em planilha, os valores de temperatura, vazões de permeado e recirculação, vazão ou volume de concentrado descartado, pressão na membrana e perdas de carga na membrana e no filtro de areia.

Os dados da unidade piloto foram digitalizados em planilhas Excel, para posterior tratamento. Dados sobre a vazão do sistema foram normalizados para a temperatura de $25^{\circ} \mathrm{C}$, utilizando-se os dados relativos à viscosidade da água (Equação 4.1).

Vazão $_{25}{ }^{\circ} \mathrm{C}=$ Vazão $_{\top}{ }^{*}\left(\right.$ Viscosidade $_{T}$ Viscosidade $\left._{25^{\circ} \mathrm{C}}\right) \quad$ Equação (4.1). Onde:

Vazão $_{25^{\circ} \mathrm{C}} / \mathrm{T} \rightarrow$ vazão de permeado à temperatura de $25^{\circ} \mathrm{C}$ e a temperatura T, medida;

Viscosidade $_{25^{\circ}}$, $\mathrm{T} \rightarrow$ Viscosidade da água a $25^{\circ} \mathrm{C}$ e na temperatura medida.

A Figura 4.7 apresenta a curva de variação da viscosidade com a temperatura e a respectiva equação para o cálculo, obtida a partir dos dados disponiveis no Handbook of Chemistry and Physics (LIDE, 2009).

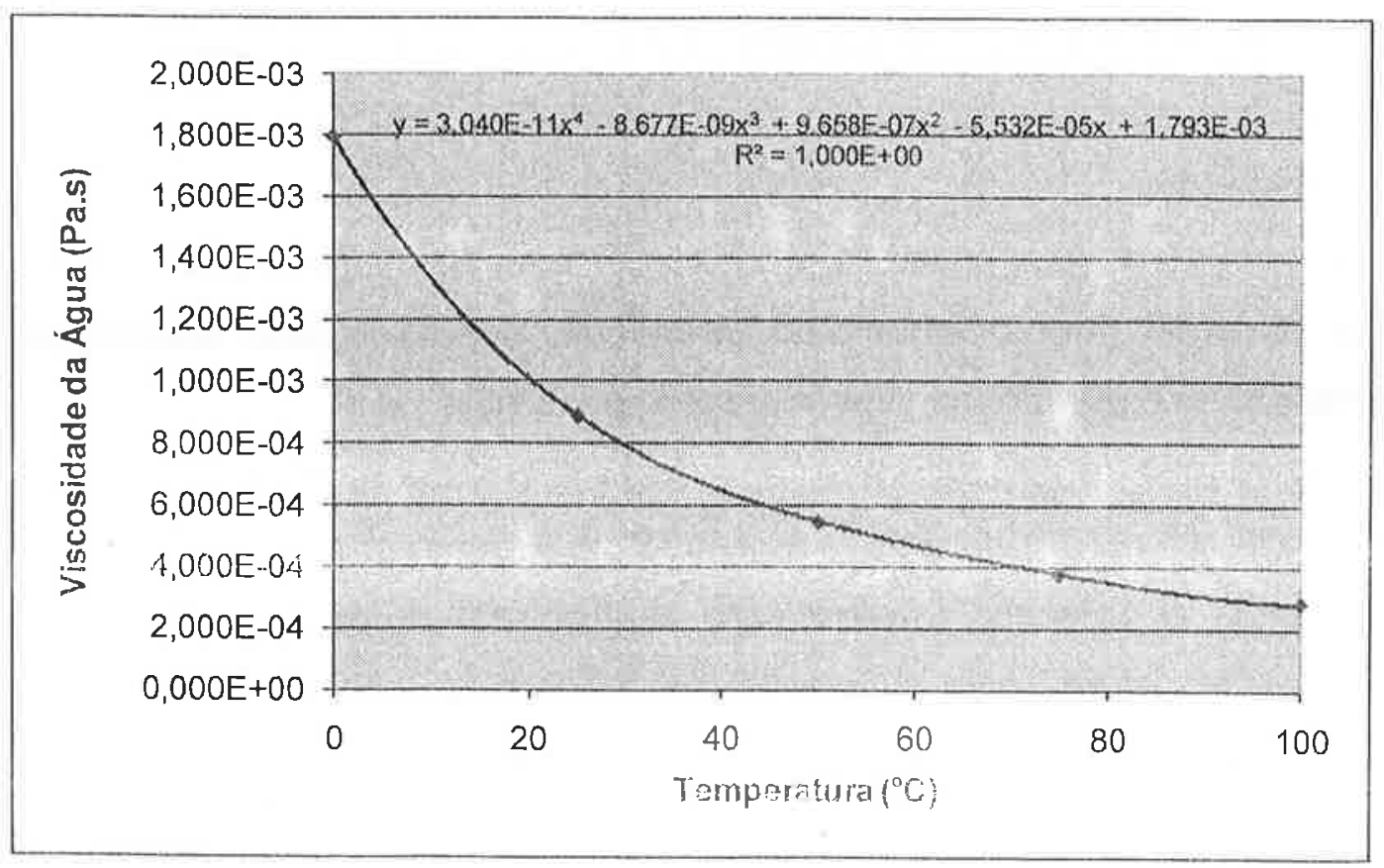

Figura 4.7 - Variação da viscosidade da água com a temperatura, para normalização da vazão de permeado 
Para o controle da eficiência da unidade piloto, em termos de remoção de contaminantes, foram coletadas amostras da água bruta, permeado e concentrado, para a realização de análises físico-químicas e microbiológicas, com freqüência semanal. As coletas eram feitas pela SABESP e pela equipe de pesquisa. As amostras coletadas pela equipe de pesquisa eram analisadas no laboratório do CIRRA, sendo que só foram realizadas análises de variáveis físicas e quimicas. As variáveis de qualidade para avaliação do desempenho do processo de ultrafiltração estão apresentadas na Tabela 4.2 .

Tabela 4.2 - Variáveis de qualidade utilizadas para avaliar o desempenho da unidade piloto de ultrafiltração

\begin{tabular}{|c|c|c|}
\hline Variável & $\begin{array}{l}\text { Analisados no } \\
\text { Laboratório do } \\
\text { CIRRA }^{a}\end{array}$ & $\begin{array}{l}\text { Analisados no } \\
\text { Laboratório da } \\
\text { SABESP }^{b}\end{array}$ \\
\hline 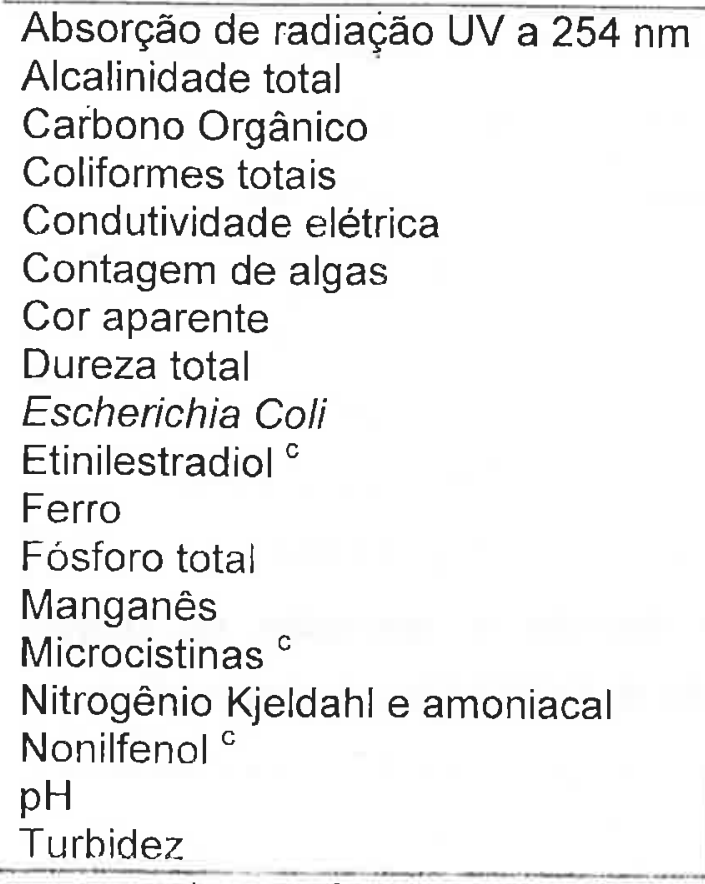 & $\begin{array}{l}X \\
X \\
X \\
X \\
X\end{array}$ & $\begin{array}{l}x \\
x \\
x\end{array}$ \\
\hline $\begin{array}{l}\text { a - quando não for especificado utiliz } \\
\text { Standards Methods for the Examination of } \\
2000 \text { ). } \\
\text { b-as análises foram realizadas pela SAB } \\
\text { utilizados para o controle da qualidade da á } \\
\text { - Análise pelo método de enzima conju } \\
\text { Kits da BEACON Analytical Systems Inc }\end{array}$ & $\begin{array}{l}\text { os procedim } \\
\text { ter and Wastew } \\
\text { seguindo-se os } \\
\text { de suas estaçõe. } \\
\text { e imunosorben }\end{array}$ & $\begin{array}{l}\text { estabelecidos no } \\
20^{\text {th }} \text { edition (APHA, } \\
\text { nos procedimentos } \\
\text { (SA), utilizando SE }\end{array}$ \\
\hline
\end{tabular}


As análises de Carbono Orgânico Total foram realizadas utilizando-se a técnica de combustão catalitica e detector de radiação infravermelha não dispersiva (NDIR), em um analisador modelo 5000A da Shimadzu, as medidas de absorção de radiação ultravioleta foram feitas em espectrofotômetro UVNisivel da Micronal, modelo B382, e as medidas de turbidez e cor utilizando-se equipamentos de bancada da Policontrol, AP2000 e Aquacolor.

\subsection{Equipe, materiais e métodos PROSAB-05}

O desenvolvimento deste projeto contou corn a participação da equipe relacionada a seguir:

José Carlos Mierzwa

Daniel Cursino da Cruz

Davi Costa Marques

Gabriele Malta Corrêa

Karine Raquel Landenberger

Luciana R. Valadares Veras

Maurício Costa Cabral da Silva

Raphael Rodrigues
Coordenàdor - Professor EPUSP;

Bolsista IC - CNPq / EPUSP;

Bolsista IC - CNPq / CUFSA;

Bolsista IC - CNPq / EPUSP;

Bolsista IC - CNPq / EPUSP;

Bolsista DTI - CNPq, pesquisadora;

Bolsista DTI - CNPq, pesquisador;

Bolsista IC - CNPq / EPUSP.

Com base nos resultados obtidos durante a operação do projeto desenvolvido no âmbito do edital $n^{\circ} 04$ do PROSAB, a unidade piloto de ultrafiltração foi modificada, principalmente com relação aos instrumentos de medição de vazão, pressão e temperatura, de maneira a possibilitar a aquisição automática dos dados. Adicionalmente, foi instalado um turbidimetro de processo na linha de permeado e um sistema de aquisição de dados automático Field Logger, da Novus Produtos Eletrônicos Ltda. Outra alteração foi a substituição da membrana modelo GK-4040F, por uma mebranas da GE-Osmonics, modelo PW-4040F, de




de 500 a $930 \mathrm{kPa}$ e taxa de fluxo de 15 a $40 \mathrm{~L} \cdot \mathrm{h}^{-1} \cdot \mathrm{m}^{-2}\left(25^{\circ} \mathrm{C}\right)$, com área util de $7,9 \mathrm{~m}^{2}$ (DESAL, 2006).

A Figura 4.8 apresenta o fluxograma de processo da unidade piloto e as Figuras 4.9 e 4.10 , as fotos da vista geral e lateral da unidade piloto. Neste projeto, também, procurou-se manter o sistema em operação contínua.

As linhas grossas na Figura 4.8 indicam o fluxo de água na operação normal do sistema, as linhas finas o fluxo na limpeza química e as tracejadas o fluxo para a contralavagem do filtro de areia.

Para a avaliação do desempenho da unidade piloto o Field Logger foi programado para fazer aquisições dos dados, em intervalos de um minuto no início dos testes e depois a cada três minutos, de pressão (PE), perda de carga no filtro de areia e na membrana (dPE), vazão de permeado (FE-1) e de recirculação (FE-2), temperatura (TE-1) e turbidez do permeado (AE-1). O sistema operou com descarga periódica de concentrado, através do controle por temporizador e válvula solenóide (S-1), com uma descarga de 10 segundos a cada 10 minutos. A medida da vazão de concentrado foi feita com base na medida do volume descartado e o número de descartes a cada hora. Além desta operação, o sistema foi programado para realizar interrupções em seu funcionamento a cada 24 horas, e, em seguida, descargas com duração de 2 minutos, com o auxílio de um temporizador (paradas periódicas). A utilização deste procedimento se mostrou eficiente, conforme será constatado pela análise dos resultados de desempenho.

Sempre que necessário a operação do sistema era interrompida para o processo de limpeza química, utilizando-se uma solução de hidróxido de sódio e detergente para limpeza e ácido peracético para a sanitização, com base no procedimento descrito para a pesquisa no PROSAB-04. 


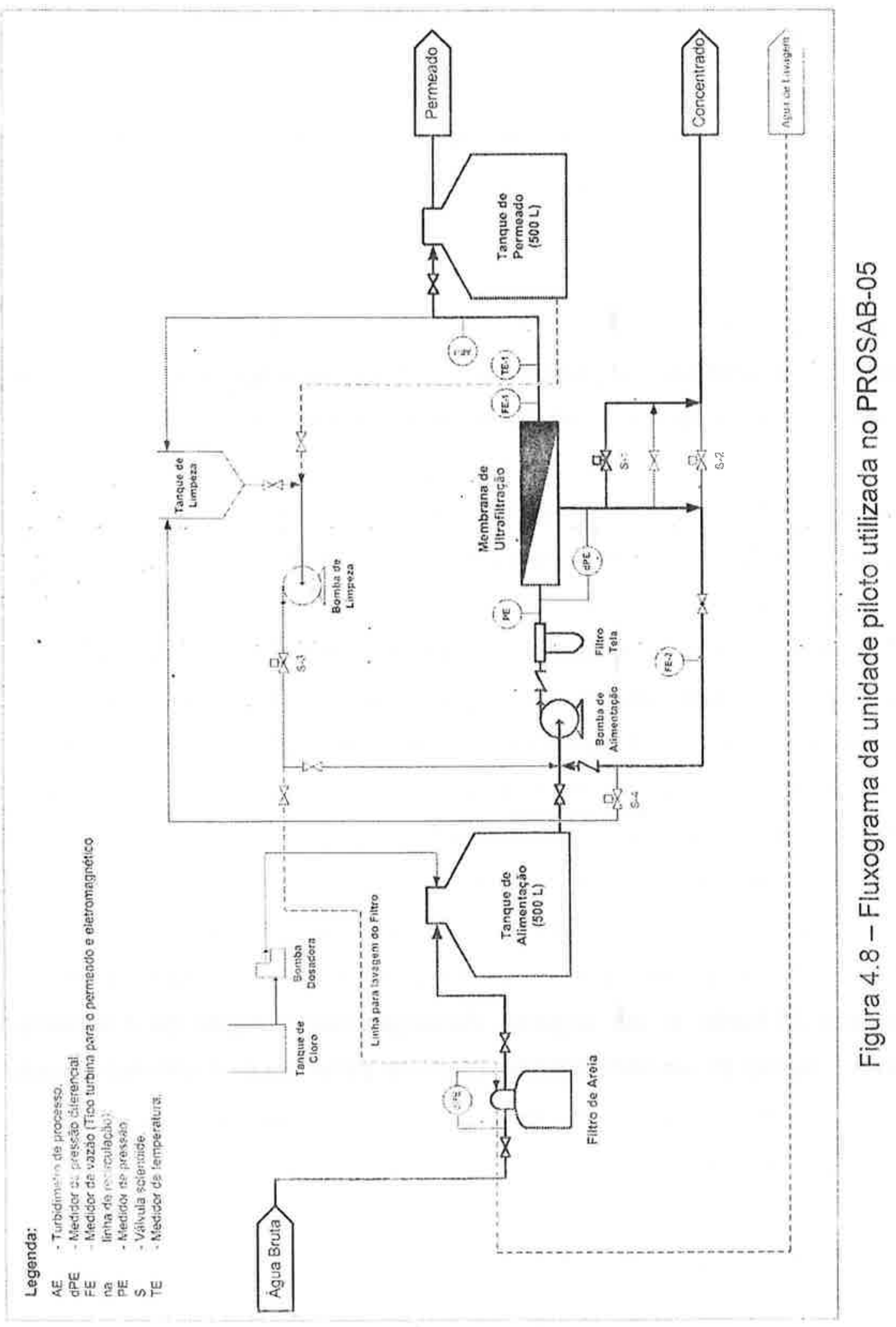




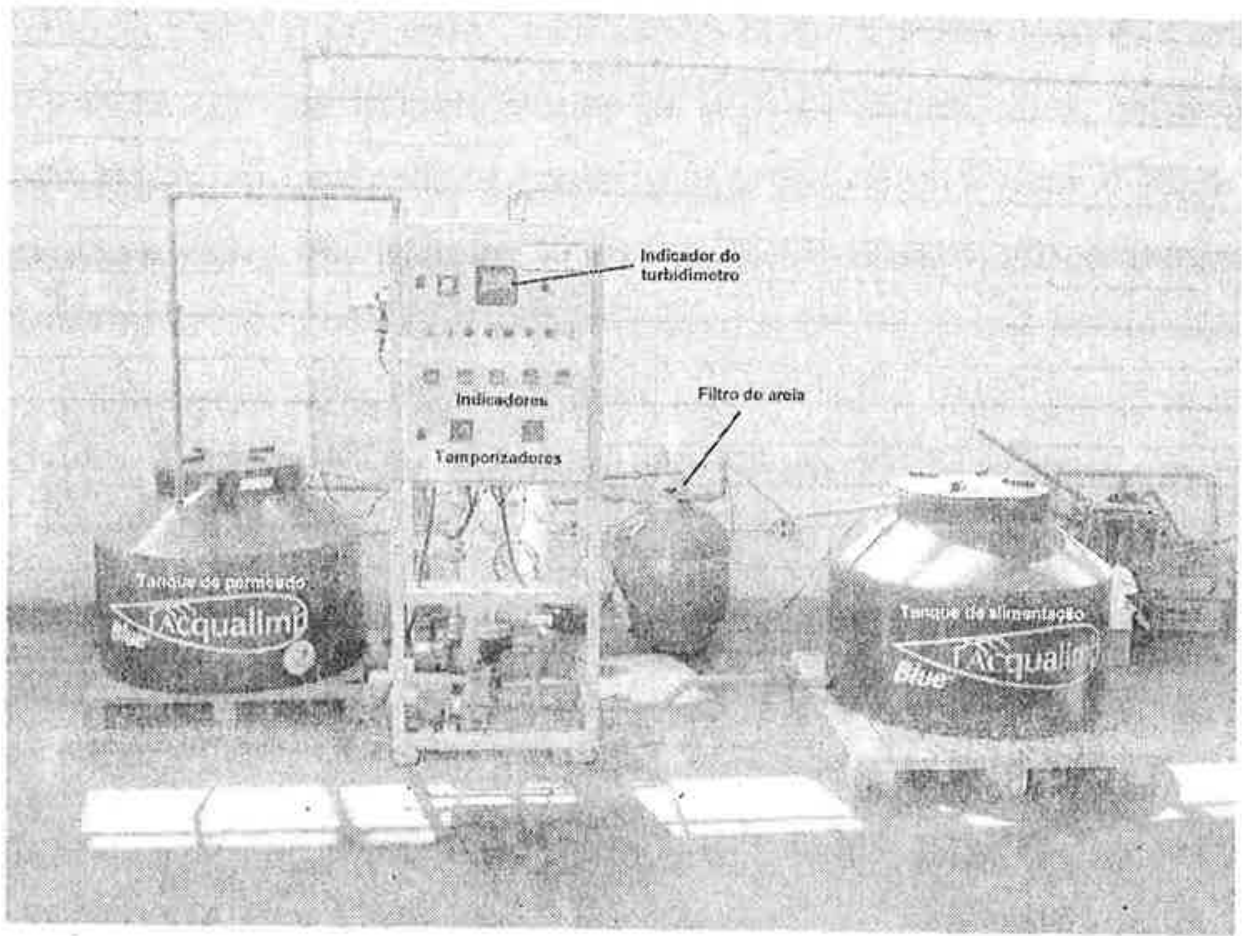

Figura 4.9 - Vista geral da unidade piloto do PROSAB-05



Figura 4.10 - Vista lateral da unidade piloto do PROSAB-05 
A avaliação da eficiência de remoção de contaminantes foi feita através da análise em laboratório de amostras periódicas da água bruta, permeado e concentrado, as quais foram realizadas no Laboratório de Saneamento da Escola Politécnica e no CIRRA, utilizando-se os procedimentos descritos no Standards Methods for the Examination of Water and Wastewater. $20^{\text {th }}$ edition. As variáveis analisadas foram:

- Absorção de Radiação UV em 254 nm;

- Alcalinidade;

- Carbono Orgânico Dissolvido;

- Coliformes totais;

- Condutividade elétrica;

- Cor aparente;

- Dureza;

- Escherichia Coli;

- $\mathrm{pH}$;

- Turbidez.

As análises de coliformes totais e Escherichia coli foram feitas utilizandose o método de reagente específico, Idexx - Colilert.

As análises de COT foram feitas pelo analisador TOC-V CPH, da Shimadzu, as de absorção de radiação UV em espectrofotômetro UV/Visivel UV-Mini 1240 da Shimadzu e as medidas de turbidez e cor aparente em equipamentos da Policontrol, AP-2000 e Acquacolor.

Além das variáveis relacionadas, também foram realizadas análises de estrogênios, $17 \alpha$-etinilestradiol e nonilfenol, inclusive em amostras de água da Represa Billings e do Rio Cotia, a montante da estação de tratamento de água operada pela companhia estadual.

As análises dos desreguladores endócrinos foram realizadas pelo método ELISA, utilizando-se kits da Abraxis, PN 590071 para estrogênios (Estrona, $17-\beta$-Estradiol Estriol), PN 59005 para etinilestadin e iN 590012 para nonilfenol. Para concentração de amostras foram seguidos os procedimentos indicados nos kits, sendo as análises feitas em leitora Quick Elisa da empresa Drake. Também foram feitos ensaios de 
intercalibração para estes micropoluentes com a Universidade Federal de Ouro Preto, que realizava as análises por cromatografia líquida de alto desempenho. 


\section{RESULTADOS E DISCUSSÃO}

5.1. Ensaios para a avaliação preliminar do processo de UF no laboratório do CIRRA

A Tabela 5.1 apresenta os valores de $\mathrm{pH}$, condutividade elétrica, demanda bioquímica de oxigênio e as concentrações de nitrogênio e fósforo da água coletada na Represa Guarapiranga, junto ao ponto de captação da Sabesp, para a realização dos ensaios no CIRRA.

Tabela 5.1- Caracterização físico-química de amostras de água bruta da Represa Guarapiranga coletadas nos dias 15/2/2005 e 22/02/2005 para realização dos ensaios no CIRRA

\begin{tabular}{ccccccc}
\hline Amostra & $\mathrm{pH}$ & $\begin{array}{c}\text { Condutividade } \\
\text { Elétrica }\left(\mu \mathrm{S} . \mathrm{cm}^{-1}\right)\end{array}$ & $\begin{array}{c}\text { Turbidez } \\
(\mathrm{uT})\end{array}$ & $\begin{array}{c}\text { Nitrogênio Amoniacal } \\
\left(\mathrm{mg} \mathrm{N}-\mathrm{NH}_{3} \cdot \mathrm{L}^{-1}\right)\end{array}$ & $\begin{array}{c}\text { Fósforo total } \\
\left(\mathrm{mg} \mathrm{PO}_{4} \cdot \mathrm{L}^{-1}\right)\end{array}$ & $\begin{array}{c}\text { Ortofosfato } \\
\left(\mathrm{mg} \mathrm{PO}_{4} \cdot \mathrm{L}^{-1}\right)\end{array}$ \\
\hline $\begin{array}{c}1 \\
(15 / 2 / 2005) \\
2\end{array}$ & 7,32 & 225 & 1,89 & 0,58 & $<0,08$ & $<0,08$ \\
$(22 / 2 / 2005)$ & 7,27 & 133 & 2,16 & 0,91 & $<0,08$ & $<0,08$ \\
\hline
\end{tabular}

Comparando-se os valores da Tabela $5.1 \mathrm{com}$ os da Tabela 3.9 , verificase que os resultados estão coerentes, com exceção d'o valor de condutividade elétrica da Amostra 01, que foi significativamente maior do que o reportado pela CETESB.

A Figura 5.1 apresenta os dados obtidos; no ensaio para a determinação da taxa de fluxo utilizando-se água da SABESP. A média para a taxa de fluxo de permeado foi de $35,3 \mathrm{~L} \cdot \mathrm{h}^{-1} \cdot \mathrm{m}^{-2}$, a uma pressão de $563,7 \mathrm{kPa}$ e temperatura de $29{ }^{\circ} \mathrm{C}\left(\mu=8,108 \times 10^{-04}\right)$. Com a normalização para $25^{\circ} \mathrm{C}$ 
( $\mu=8,899 \times 10^{-04}$ ) e pressão de $517 \mathrm{kPa}$, a taxa de fluxo é de $29,5 \mathrm{~L} . \mathrm{h}^{-1} \cdot \mathrm{m}^{-2}, 4,4 \%$ superior ao indicado pelo fabricante da membrana, mas dentro de uma faixa de variação aceitável, que é de $10 \%$.

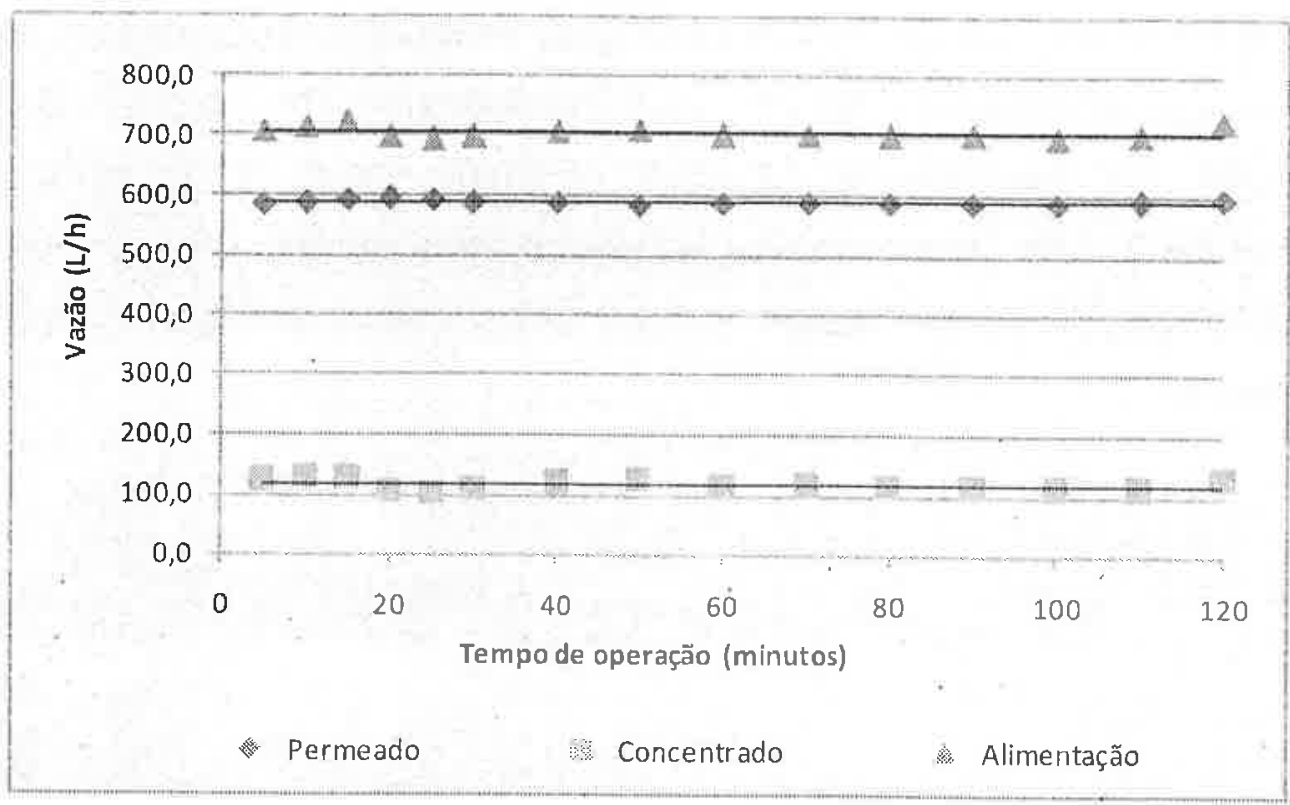

Figura 5.1 - Resultados do ensaio para a determinação da taxa de fluxo para a membrana de ultrafiltração com água tratada

Avaliando-se a Figura 5.1 verifica-se que o sistema se manteve estável em relação às vazões de permeado e concentrado, condição já esperada em função da qualidade da água utilizada no ensaio.

Na Figura 5.2 são apresentados os dados de variação da turbidez e da condutividade elétrica do permeado produzido a partir do processo de ultrafiltração da água da Represa Guarapiranga, no teste realizado no dia $28 / 02 / 2005$. A condutividade elétrica da água bruta era de $129,4 \mu \mathrm{S} . \mathrm{cm}^{-1}$ e a turbidez de 1,55 uT.

Pela análise do gráfico da Figura 5.2, pode ser constatado que houve uma elevada remoção de turbidez, que variou entre $78 \%$ e $89 \%$. Por outro lado, verifica-se um ligeiro aumento na condutividade elétrica do permeado produzido ao longo do tempo. Esta elevação foi mais significativa a partir das 12:20 h, após 1,5 holas de operaçăo, passando de 102,2 para $118,0 \mu \mathrm{S} . \mathrm{cm}^{-1}$, fato que pode justificado pela redução da

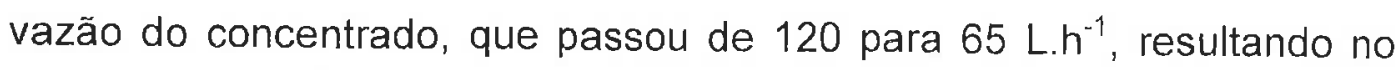
aumento da condutividade elétrica da água circulando pela membrana. 
Mesmo que as membranas de UF não sejam capazes de reter epécies dissolvidas de baixo peso molecular, observa-se, na Figura 5.2 que nos primeiros 90 minutos de operação a condutividade elétrica do permeado era ligeiramente inferior à da alimentação, indicando uma pequena taxa de rejeição de espécies iônicas, aproximadamente $22 \%$. Quando há um aumento da recuperação de água, também ocorre o aumento da concentração dos contaminantes circulando pelo sistema, mas a taxa de rejeição se mantém, resultando em uma maior passagem para o permeado.

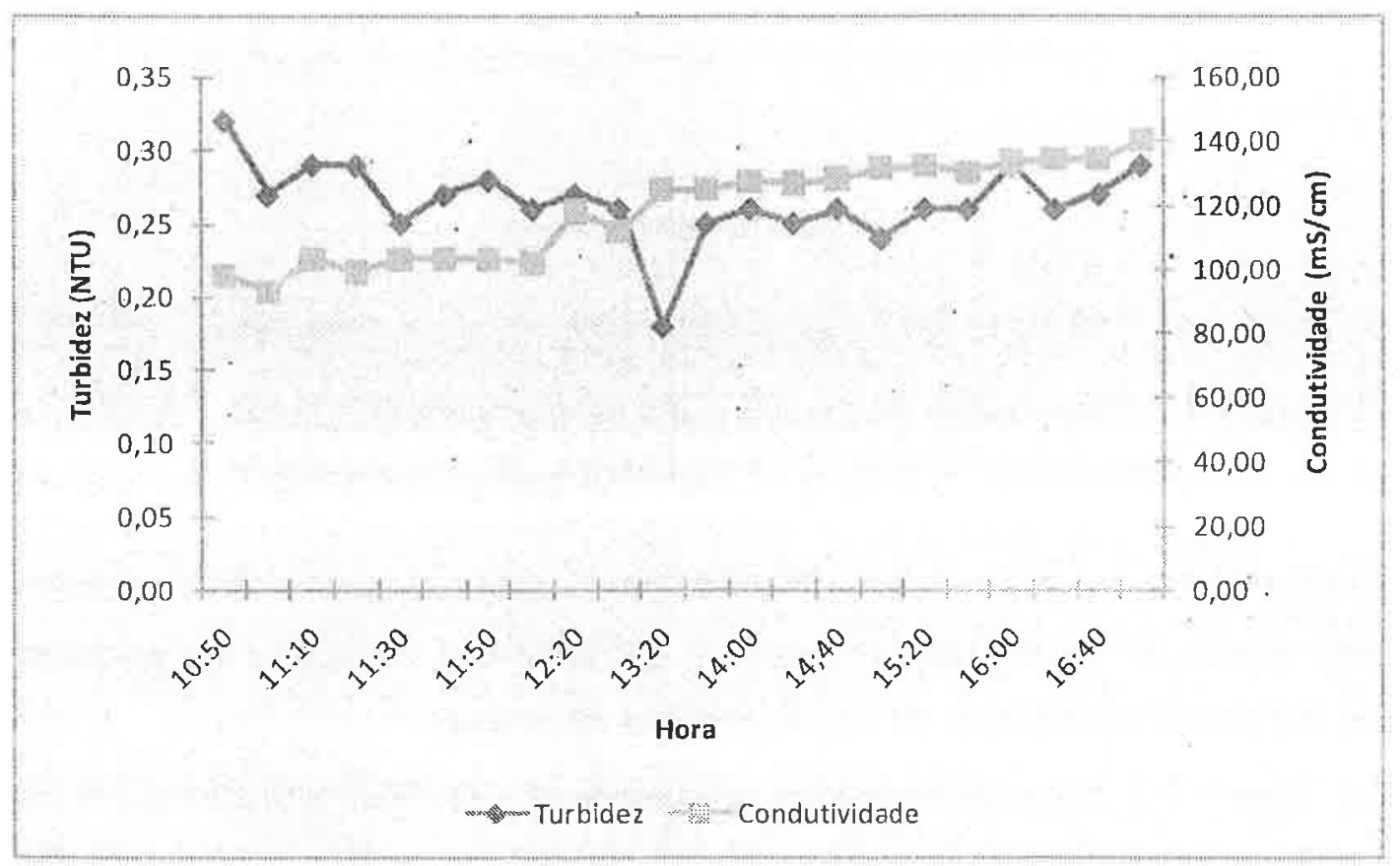

Figura 5.2 - Valores de turbidez e condutividade do permeado produzido pelo processo de ultrafiltração no ensaio de 28/02/2005.

A Figura 5.3 apresenta os dados sobre as vazões de alimentação, permeado e concentrado, podendo-se verificar que a vazão de água produzida foi mantida constante ao lungo do ensaio, o que é um bom indicativo para o desempenho da membrana. A recuperação de água no sistema foi próxima de $90 \%$ e a taxa de fluxo de permeado de $28,2 \mathrm{~L} \cdot \mathrm{h}^{-1} \cdot \mathrm{m}^{-2}$ a una pressão de $451 \mathrm{kPa}$ e temperatura de $27^{\circ} \mathrm{C}$. Lsta taxa de fluxo, quando comparada com aquela obtida no ensaio com água limpa é bastante satisfatória, principalmente se for considerado que a 
pressão de operação da unidade, durante a realização do ensaio, foi menor.

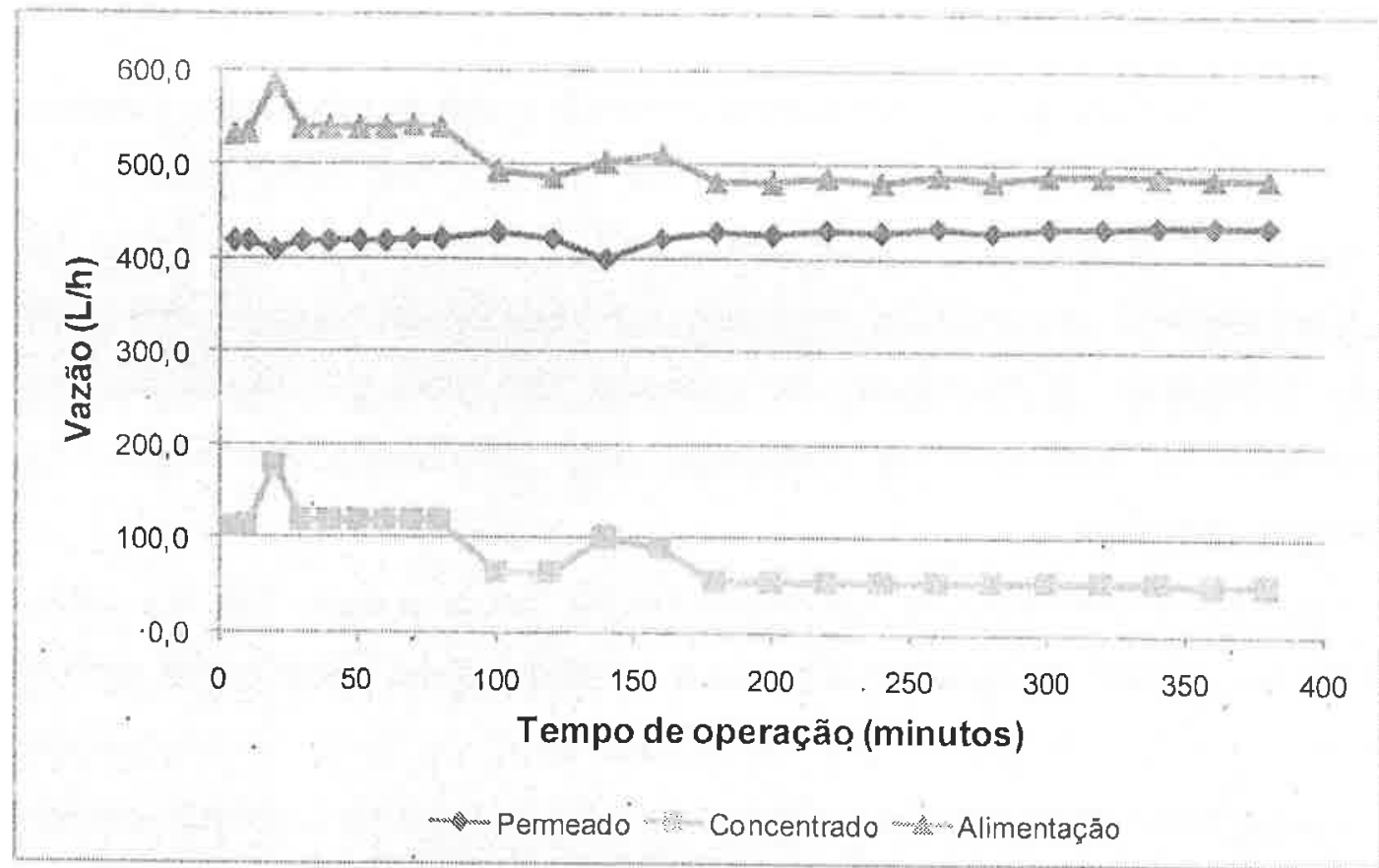

Figura 5.3 - Variação das vazões de alimentação, permeado e concentrado na unidade de ultrafiltração ao longo do ensaio com água da Represa Guarapiranga em 28/02/2005.

Com relação à turbidez (Figura 5.2), mesmo com o aumento da taxa de recuperação de água, não houve uma variação significativa no seu valor, indicando que a eficiência da membrana é mantida para esta variável.

A análise de microcistina na água bruta da Represa Guarapiranga, pelo método ELISA, resultou em um valor médio (triplicata), menor do que 0,1 $\mu \mathrm{g} \cdot \mathrm{L}^{-1}$, limite de detecção do método. No permeado da unidade de ultrafiltração, também, não foi detectada a presença de microcistina. Já no concentrado foi verificada a presença de microcistina na concentração de $0,24 \mu \mathrm{g} \cdot \mathrm{L}^{-1}$, constatando-se que a mesma foi relida pela membrana. Cabe observar que a presença de microcistina no concentrado da unidade de ultrafiltração pode ser devida as algas que foram retidas e depois sofreram lise celulat.

Os resultados obtidos foram bastante satisfatórios, dando subsidios para a concepção e montagem da unidade piloto, necessária à continuidade da pesquisa. 


\subsection{Resultados do desempenho da unidade piloto - PROSAB-04}

Após a montagem da unidade piloto, antes do início da operação contínua do sistema, foram realizados dois ensaios, um com água tratada da SABESP, realizado entre 30 e 31/05/2005, e outro com água bruta do Reservatório Guarapiranga, realizado em 06/06/2005, para a definição das condições de operação da unidade. Os ensaios consistiram na avaliação da produção de permeado pela membrana em função da pressão aplicada.

A Figura 5.4 apresenta os resultados do ensaio com água tratada, onde pode ser verificado que a vazão de permeado varia linearmente com a pressão, enquanto que a taxa de recuperação de água na membrana varia exponencialmente. Considerando-se que a máxima recuperação por passagem recomendada é de $10 \%$, para efeito de avaliação da produção de permeado deve ser considerada a pressão de $450 \mathrm{kPa}$, que resulta em

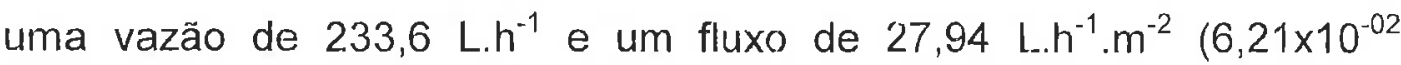
L. $\left.\mathrm{h}^{-1} \cdot \mathrm{m}^{-2} \cdot \mathrm{kPa}{ }^{-1}\right)$.



Figura 5.4 - Variação da vazão de permeado e da taxa de recuperação de água em função da pressão de operação, para o ensaio com água tratada 
Para verificar se a pressão de operação proposta está adequada pode ser feita a avaliação da variação do acréscimo da taxa de fluxo normalizada pela pressão, em função da pressão de operação, conforme apresentado na Figura 5.5.

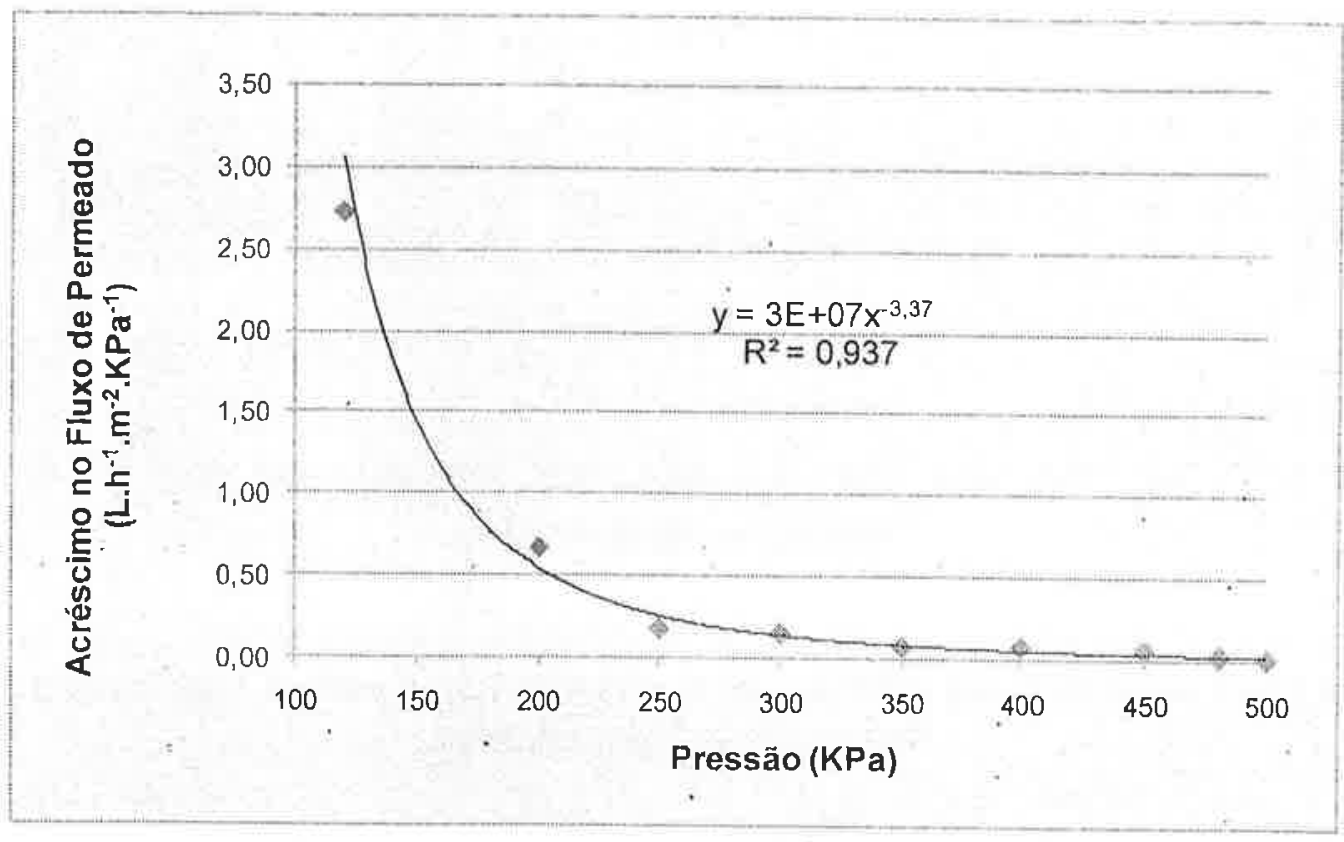

Figura 5.5 - Variação da taxa de fluxo de permeado normalizada pela pressão, em função da pressão de operação da unidade

Analisando-se a Figura 5.5 observa-se que o acréscimo na taxa de fluxo em função da pressão é reduzido, sendo que a partir de $400 \mathrm{kPa}$, praticamente não há mais acréscimo do fluxo de permeado. Não seria, assim, econômico operar a unidade com pressão superior a este valor.

A Figura 5.6 mostra os resultados dos ensaios com a água do Reservatório Guarapiranga, onde se observa o mesmo comportamento verificado no ensaio com água tratada. Considerando-se o critério de recuperação de água por passagem, a pressão de operação deve ser de $450 \mathrm{kPa}$, resultando em uma vazão de permeado de 230,1 L.h ${ }^{-1}$ e um fluxo de $27,52 \mathrm{~L} \cdot \mathrm{h}^{-1} \cdot \mathrm{m}^{-2}\left(6,12 \times 10^{-02} \mathrm{~L} \cdot \mathrm{h}^{-1} \cdot \mathrm{m}^{-2} \cdot \mathrm{kPa} \mathrm{a}^{-1}\right)$, ligeiramente inferior ao obtido com água tratada, o que já era esperado, pois em águas naturais existem substâncias que afetam de forma negativa o fluxo de água através da membrana. 


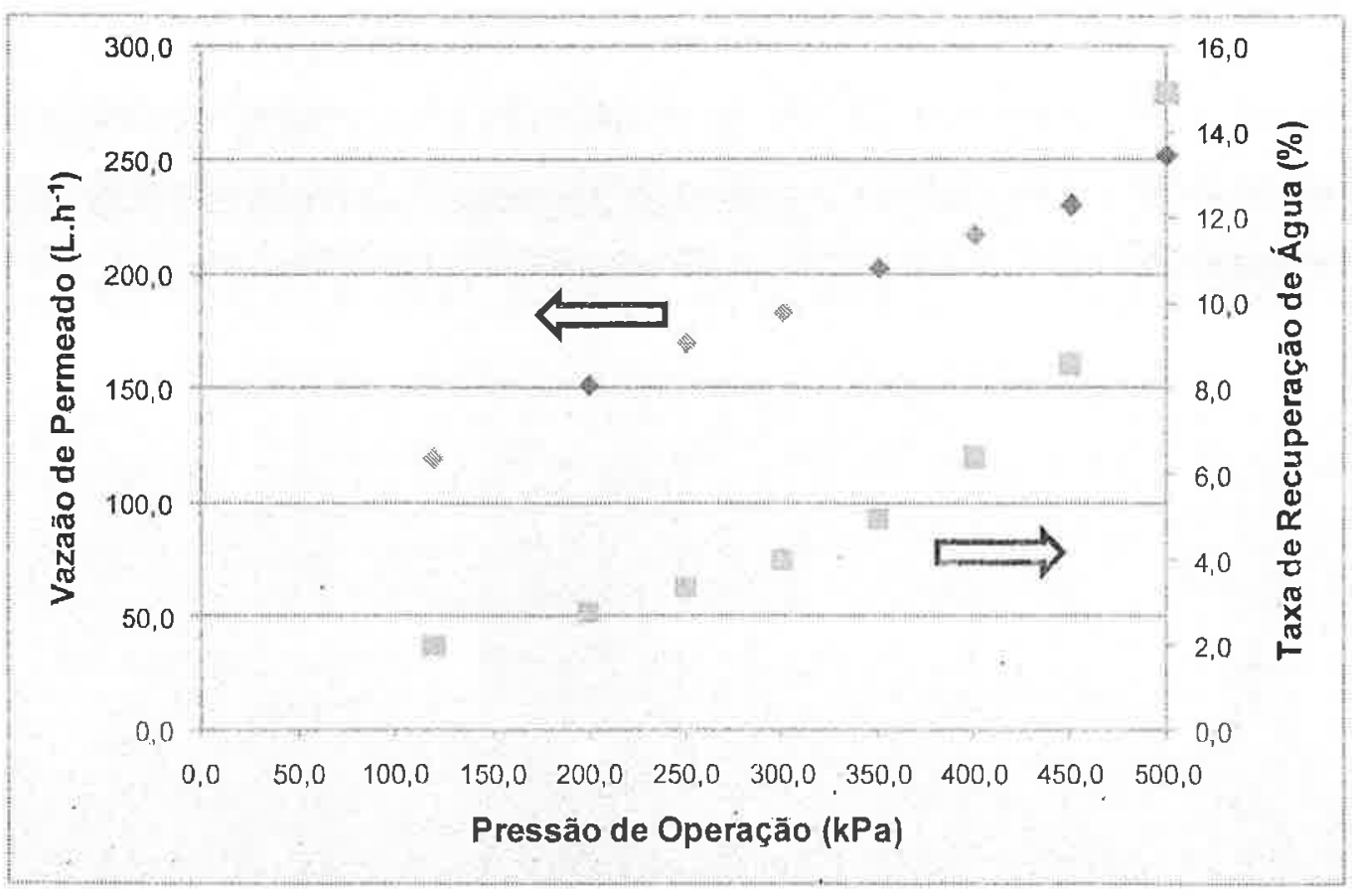

Figura 5.6 - Variação da vazão de permeado e da taxa de recuperação de água em função da pressão de operação, para o ensaio com água do Reservatório Guarapiranga

Com base nestes resultados, foi definido que a unidade piloto deveria operar com uma pressão de $450 \mathrm{kPa}$ e taxa de recuperação de água na membrana inferior a $10 \%$.

O início da operação da unidade piloto de forma contínua foi em 11/07/2005. Contudo em função de ajustes necessários, a operação contínua foi iniciada, efetivamente, a partir de 01/08/2005, sendo mantida a sua operação até 03/08/2006, totalizando 7.866 horas de operação continua. Na Tabela 5.2 são apresentadas as principais modificações implantadas na unidade piloto ao longo da operação.

A substituição do rotâmetro da linha de concentrado foi devido a problemas de escala, pois a escala do rotämetio insialado era de 0 a 100 L.minuto $^{-1}$, enquanto a vazão de concentrado situava-se na faixa de 20 a

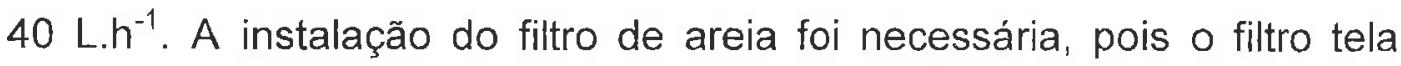
inicialmente previsto estava sendo colmatado muito apidamente. 
Tabela 5.2 - Modificações na unidade piloto ao longo da operação

\begin{tabular}{cl}
\hline \multicolumn{1}{c}{ Data } & \multicolumn{1}{c}{ Modificação } \\
\hline $02 / 08 / 2005$ & $\begin{array}{l}\text { Substituição do rotâmetro da linha de concentrado. } \\
25 / 08 / 2005\end{array}$ \\
& $\begin{array}{l}\text { Instalação do filtro de areia na linha de água bruta, antes do } \\
\text { reservatório de alimentação. }\end{array}$ \\
$07 / 10 / 2005$ & $\begin{array}{l}\text { Alteração do modo de descarte de concentrado de contínuo } \\
\text { para intermitente. }\end{array}$ \\
$24 / 10 / 2005$ & $\begin{array}{l}\text { Substituição da válvula solenóide de descarte de } \\
\text { concentrado de 1 polegada para 1/2 polegada. }\end{array}$ \\
$27 / 12 / 2005$ & $\begin{array}{l}\text { Instalação do sistema de dosagem de hipoclorito de sódio na } \\
\text { água bruta. }\end{array}$ \\
$13 / 04 / 2006$ & $\begin{array}{l}\text { Adoção do procedimento de paradas periódicas do sistema } \\
\text { a cada 24 horas, com a instalação de um temporizador para } \\
\text { controle. }\end{array}$ \\
Utilização do ácido peracético como agente de sanitização.
\end{tabular}

Devido à dificuldade em manter estável a descarga de concentrado ao longo da operação, foi adotado o procedimento de descarga intermitente, controlada por temporizador.

Ao longo da operação da unidade piloto constatou-se uma relação direta entre a perda de vazão de permeado e a perda de carga na membrana, devido, possivelmente, a formação de biofilme, de forma que foi instalado um sistema para dosagem de hipoclorito de sódio na água bruta, em concentração de $2,0 \mathrm{mg} \cdot \mathrm{L}^{-1}$.

Durante o acompanhamento da operação da unidade piloto, foi observado que, após interrupções não previstas, a vazão de permeado aumentava. Este fenômeno foi avaliado pela realização de alguns testes de parada e enxágue da membrana, comprovando a melhora na produção da unidade, como mostra a Figura 5.7. Isto levou a adoção do procedimento de paradas periódicas de forma automatizada.

Devido à probelmas relacionados à perda de fluxo na membrana e na recuperação da capacidade de produção da unidade após as operações de limpeza e sanitizaçāo, o uso de cioro como sanitizante foi substituido pelo ácido peracético, em uma concentração, na limpeza quimica, de $0,2 \%$ de peróxido de hidrogênio e $0,15 \%$ de ácido peracético. Foi utilizado o produto Proxitane 1512 da Peróxidos do Brasil Ltda. 
요

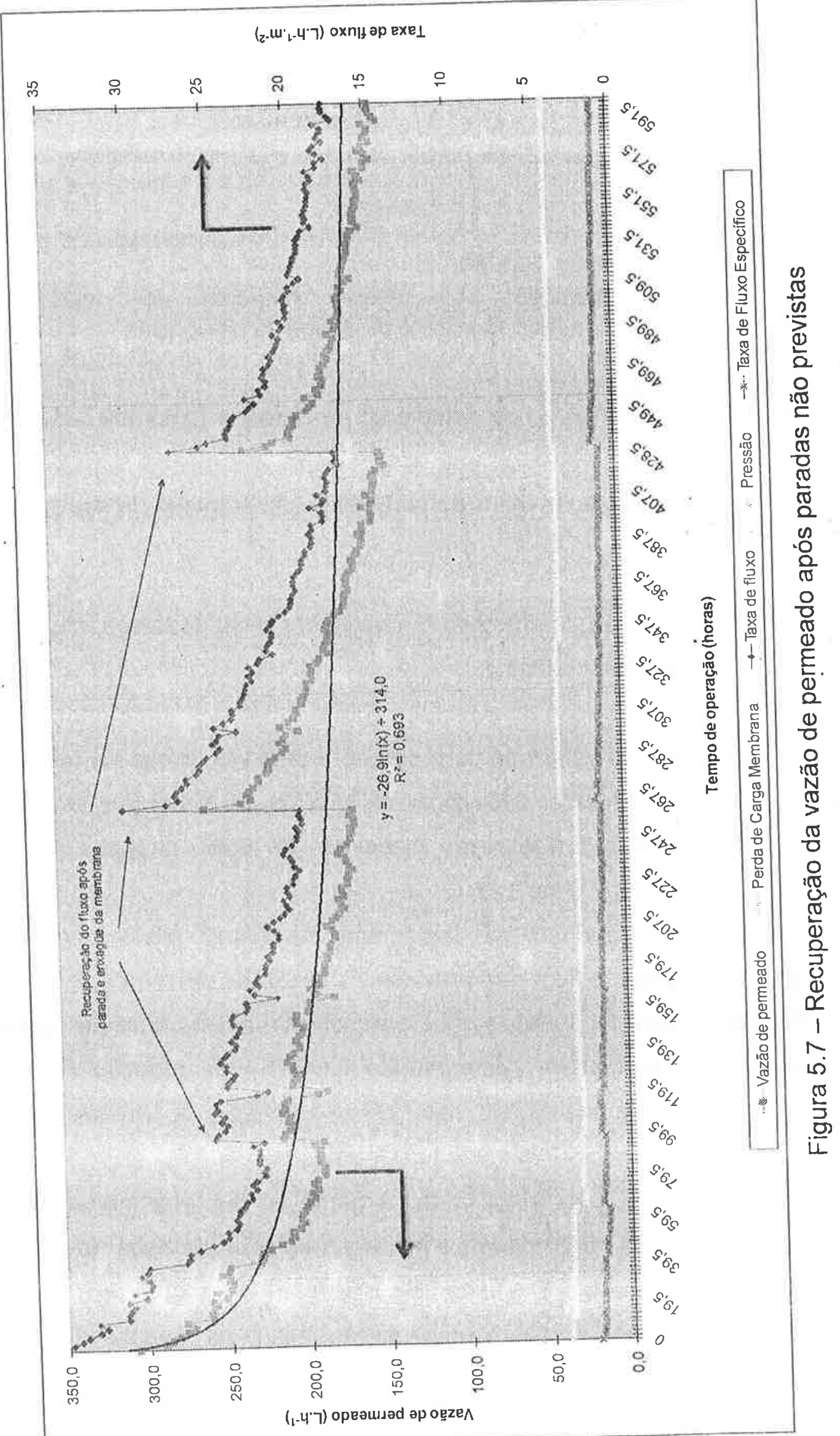


5.2.1. Desempenho operacional

Durante o período de operação da unidade piloto, a vazão normalizada média de permeado foi de 179,5 L.h ${ }^{-1}$ e a pressão de $418,3 \mathrm{kPa}$, com valores de vazão mínimo e máximo de 144,4 e 245,4 L.h ${ }^{-1}$ e taxa média de recuperação de água de $85 \%$.

A taxa de fluxo normalizada pela pressão, através da membrana, foi igual a $5,13 \times 10^{-02} \mathrm{~L} \cdot \mathrm{h}^{-1} \cdot \mathrm{m}^{-2} \cdot \mathrm{kPa}{ }^{-1}$. Comparando-se este valor com o obtido com água tratada da SABESP $\left(6,21 \times 10^{-02} \cdot \mathrm{h}^{-1} \cdot \mathrm{m}^{-2} \cdot \mathrm{kPa}^{-1}\right)$ e no primeiro teste com a água do Reservatório Guarapiranga $\left(6,12 \times 10^{-02} \mathrm{~L} \cdot \mathrm{h}^{-1} \cdot \mathrm{m}^{-2} \cdot \mathrm{kPa} \mathrm{P}^{-1}\right)$, verifica-se umá perda de fluxo de $17,4 \%$ e $16,2 \%$, respectivamente. Tal resultado já era previsto, por conta da intèração de contaminantes presentes na água com a membrana. Ressalta-se que a perda de vazão no período inicial da operação é mais significativa, devido à ocorrência de depósitos irreversíveis.

É importante observar que durante a operação da unidade piloto vários fatores podem ter contribuído para esta perda de fluxo, principalmente o fato da mesma não ter sido operada nas condições mais adequadas, desde o início. Contudo, apenas para efeito de comparação, para membranas de nanofiltração e osmose reversa, que operam em condições mais restritivas em relação à qualidade da água de alimentação, como critério de projeto, admiti-se uma perda de fluxo de $10 \%$ ao ano.

Um estudo desenvolvido por Barbot e Moulin (2008), sobre o tratamento de água para piscina pelo processo de ultrafiltração, porém com membranas de fibra oca, resultou em uma perda de fluxo nas membranas de $29,6 \%$, após 18 meses de operação, o que seria equivalente a uma perda de 20,9\% em um ano, calculada utilizando-se a Equação 5.1, admitindo-se que a perda anual é constante. 
$P_{t}=1-\left(1-P_{\text {mensal }}\right)^{n}$

(Equação 5.1)

Onde:

$P_{t}=$ perda de fluxo no tempo $t$ (meses)

$P_{\text {mensal }}=$ perda de fluxo mensal (relação entre as vazões de permeado em um período de 30 dias);

$\mathrm{n}=$ número de meses.

A perda de fluxo através da membrana é importante para a determinação da sua vida útil. Como exemplo, para membranas de nanofiltração e osmose reversa, onde se admite uma perda de fluxo de $10 \%$ ao ano (HYDRANAUTICS, 2006), a estimativa da vida útil da membrana é de cinco anos. Considerando-se estes dados, pode-se inferir que a máxima perda de fluxo no sistema, antes da substituição das membranas seja de $41 \%$, calculada a partir da equação 5.1. Admitindo-se que este seja o valor limite de perda de fluxo para a membrana de ultrafiltração, a vida útil, estimada para a membrana utiliżada é de 3 anos, que está dentro da faixa citada por Wagner (2001), que é de 2 a 4 anos.

Verifica-se que o valor de perda de fluxo resultante no sistema avaliado não é discrepante daqueles verificados na prática, enfatizando-se que ela pode ser menor se o sistema operar em condições mais adequadas.

Cabe observar que a perda de fluxo através da membrana $e$, conseqüentemente a sua vida útil, depende das condições de operação do sistema como, por exemplo, freqüencia das operações de limpeza química. Na Tabela 5.3 são apresentados os dados relativos às operações de limpeza química, realizadas ao longo da operação do sistema, assim como o tempo de operação entre limpezas.

Analisando-se os dados da Tabela 5.3, verifica-se que no início da operção da unidade piloto (até 17 de janeiro de 2006), as operações de limpeza química eram feitas, em média, a cada 211 horas. Com as alterações implantadas houve umú redução significativa da frequêencia de limpeza, que passou a ser realizada a cada 443,5 horas até 17/04/2006 e 847,2 horas, a partir desta data. 
Tabela 5.3 - Dados sobre as operações de limpeza química da unidade piloto PROSAB-04

\begin{tabular}{|c|c|c|c|}
\hline Período & $\begin{array}{l}\text { Tempo de } \\
\text { operação } \\
\text { (horas) }\end{array}$ & $\begin{array}{l}\text { Realização } \\
\text { da limpeza } \\
\text { química }\end{array}$ & Observações \\
\hline 01 a 25/ & 218,0 & $25 / 08 / 2005$ & \multirow{3}{*}{ Limpeza alcalina e ácida. } \\
\hline 06 a $29 /$ & 353,0 & $29 / 09 / 2005$ & \\
\hline $29 / 09$ a $07 / 10 / 2005$ & 189,5 & $07 / 10 / 2005$ & \\
\hline 07 a $21 / 10 / 2005$ & 331,0 & $21 / 10 / 2005$ & \multirow{3}{*}{$\begin{array}{l}\text { Início da descarga } \\
\text { intermitente de concentrado. } \\
\text { Substituição da válvula de } \\
\text { descarga de concentrado. }\end{array}$} \\
\hline $21 / 10$ a $01 / 11 / 2005$ & 258,2 & $01 / 11 / 2005$ & \\
\hline 01 a $07 / 11 / 2005$ & 142,5 & $07 / 11 / 2005$ & \\
\hline 07 a $16 / 11 / 2005$ & 213,0 & $16 / 11 / 2005$ & \multirow{2}{*}{$\begin{array}{l}\text { Utilização de Extran Alcalino } \\
\text { para limpeza. }\end{array}$} \\
\hline 16 a $25 / 11 / 2005$ & 210,0 & $25 / 11 / 2005$ & \\
\hline $25 / 11$ a $05 / 12 / 2005$ & 236,8 & $05 / 12 / 2008$ & \multirow{4}{*}{$\cdot$} \\
\hline 05 a $12 / 12 / 2005$ & 165,0 & $12 / 12 / 2005$ & \\
\hline 12 a $20 / 12 / 2005$ & 190,0 & 20/12/2005 & \\
\hline 20 a $27 / 12 / 2005$ & 163,5 & $27 / 12 / 2005$ & \\
\hline $\begin{array}{c}27 / 12 / 2005 a \\
03 / 01 / 2006\end{array}$ & 165,5 & $03 / 01 / 2005$ & \multirow{5}{*}{$\begin{array}{l}\text { Início da dosagem de } \\
\text { hipoclorito de sódio em } \\
27 / 12 / 2005,1,5 \mathrm{mg} \cdot \mathrm{L}^{-1} \text {. } \\
\text { Alteração no procedimento de } \\
\text { limpeza química, a membrana } \\
\text { passou a ser mantida na } \\
\text { solução de limpeza por uma } \\
\text { hora (molho). Aumento da } \\
\text { dosagem de hipoclorito de } \\
\text { sódio para } 2,0 \mathrm{mg} \cdot \mathrm{L}^{-1} \text {. }\end{array}$} \\
\hline 03 a 09/01/2006 & 141,0 & $09 / 01 / 2006$ & \\
\hline & & & \\
\hline 09 a 17/01/2006 & 188,0 & $17 / 01 / 2006$ & \\
\hline 17 a $31 / 01 / 2006$ & 306,0 & $31 / 01 / 2006$ & \\
\hline $31 / 01$ a $14 / 02 / 2006$ & 332,0 & $14 / 02 / 2006$ & \multirow{2}{*}{$\begin{array}{l}\text { Melhoria na produção de } \\
\text { permeado. }\end{array}$} \\
\hline $14 / 02$ a $03 / 03 / 2006$ & 505,0 & $17 / 03 / 2006$ & \\
\hline 03 a $28 / 03 / 2006$ & 596,5 & $28 / 03 / 2006$ & $\begin{array}{l}\text { Testes de parada e enxágüe } \\
\text { da membrana, para verificar a } \\
\text { melhoria no desempenho. } \\
\text { Início das operações }\end{array}$ \\
\hline $28 / 03$ a $17 / 04 / 2006$ & 478,0 & $17 / 04 / 2006$ & $\begin{array}{l}\text { automáticas de paradas } \\
\text { periócicas em 13/04/2006. }\end{array}$ \\
\hline $17 / 04$ a $26 / 05 / 2006$ & 932,0 & $26 / 06 / 2006$ & $\begin{array}{l}\text { peracético para sanitização } \\
\text { do sistema em 26/06/2006. }\end{array}$ \\
\hline $26 / 05$ a $30 / 06 / 2006$ & 794,0 & $30 / 06 / 2006$ & \\
\hline $30 / 06$ a $03 / 08 / 2006$ & 815,5 & $03 / 08 / 2006$ & $\begin{array}{l}\text { Dasativação da unidade } \\
\text { piloto. }\end{array}$ \\
\hline
\end{tabular}


Estes resultados mostram que os procedimentos operacionais $e$ modificações implantadas contribuiram de maneira significativa para a melhoria do desempenho do sistema de ultrafiltração.

Dentre os procedimentos adotados, a realização de paradas periódicas do sistema e a utilização do ácido peracético como agente de sanitização se mostraram bastante eficientes, pois possibilitaram reduzir a freqüência das operações de limpeza química em, praticamente, $50 \%$.

$O$ efeito das operações periódicas de parada sobre o desempenho do sistema está associado ao efeito de relaxamento e ação mecânica na remoção de materias acumulados e mantidos na superfície da membrana durante o processo de produção de água pelo efeito da pressão exercida pela água e pelo transporte convectivo. No instante em que a pressão do sistema é reduzida com o desligamento da bomba de alimentação, cessa o fluxo de permeado e, com isto, o transporte convectivo, cessando também a força atuante sobre os materiạis acumulados na superfície da membrana, decorrente da pressão. Quando é feito o enxágüe, isto é, com a válvula de descarte de concentrado completamente aberta, a ação hidrodinâmica resultante remove o material presente, o que permite um aumento na produção de água do sistema quando este volta a operar normalmente, o que também influencia na freqüência de limpeza química.

A influência dos procedimentos operacionais adotados pode ser constatada com base na comparação da variação da perda de carga na membrana antes e depois da adoção destes, Figuras 5.8 e 5.9 .

Comparando-se as expressões que relacionam a perda de carga na membrana com o tempo do operação nas Figuras 5.8 e 5.9, verifica-se que o coeficiente da expressão da perda de carga com o tempo de operação, na condição onde não era adotado o procedimento de paradas periódicas $(0,00099)$, é praticamente o dobro daquele onde são feitas as paradas periódicas $(0,00049)$. Outro aspecto a ser considerado é que, com este procedimento, a ação do hipoclorito de sódio favorece a melhoria do desempenho, pela menor concentração de matéria orgânica na superfície da membrana. 


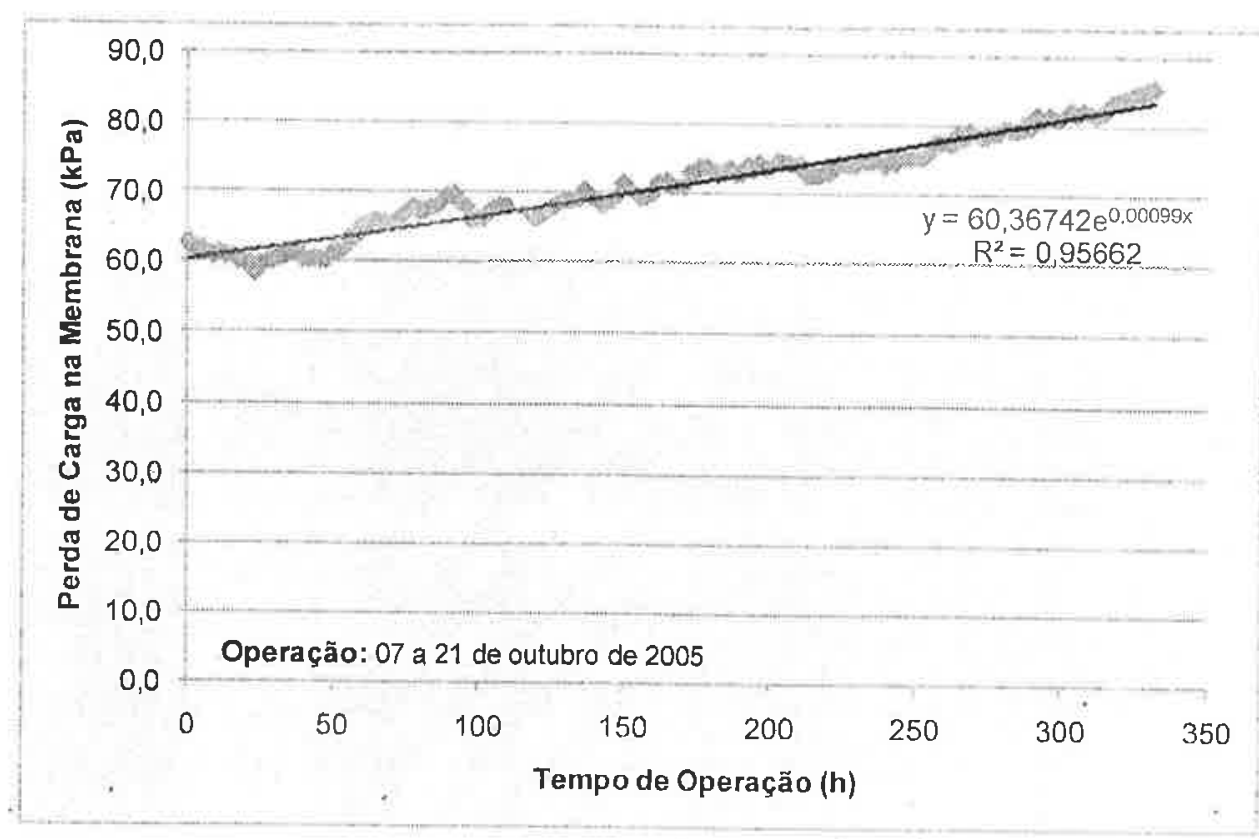

Figura 5.8 - Variação da perda de carga na membrana da unidade piloto antes da implantação dos procedimentos operacionais para melhoria de desempenho, no período de 07 a 21 de outubro de 2005

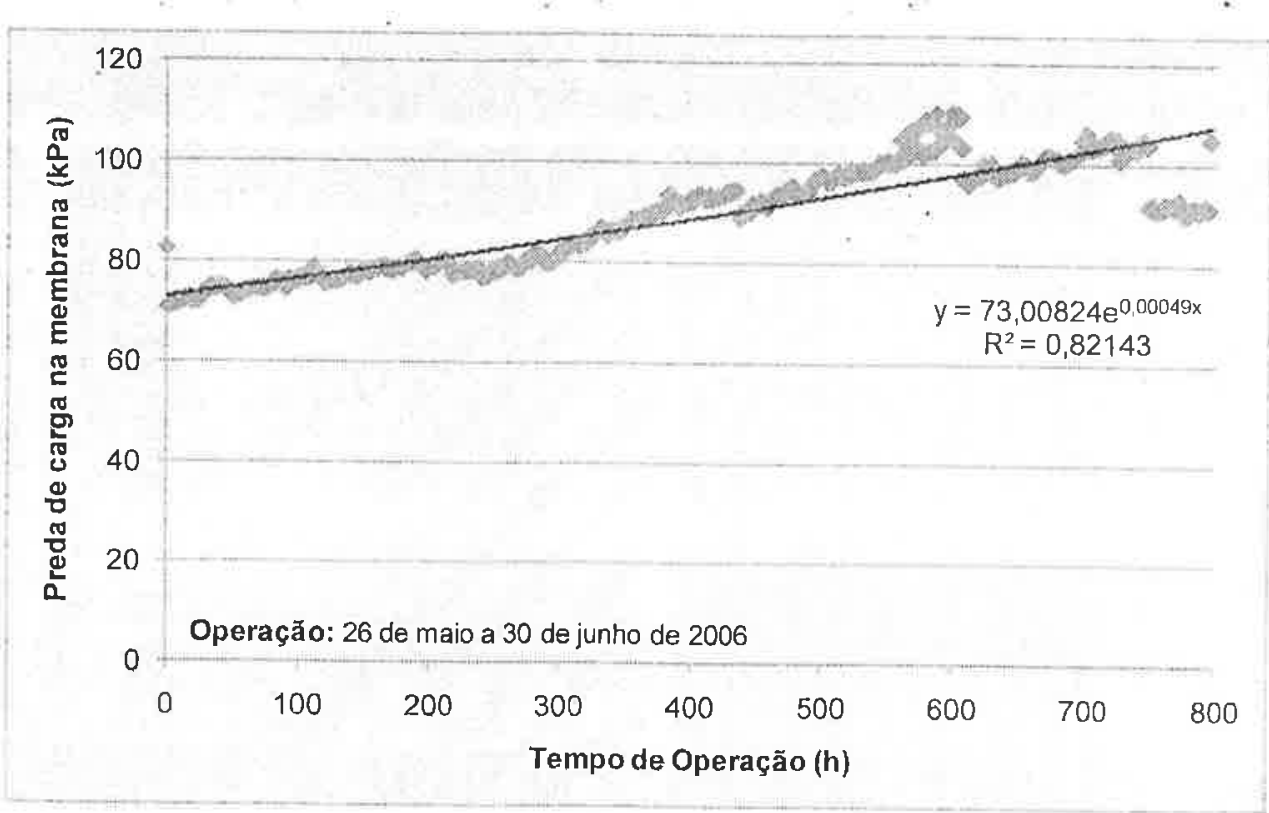

Figura 5.9 - Variação da perda de carga na membrana da unidade piloto após a implantaçäo dos procedimentos operacionais para a melhoria de desempenho, no periodo de 26 de maio a 30 de junho de 2006

O gráfico da Figura 5.10 apresenta os dados subre a produção de permeado e taxa de recuperação de água pela unidade piloto ao longo de todo o período de avaliação de desempenho. 
$\stackrel{0}{r}$

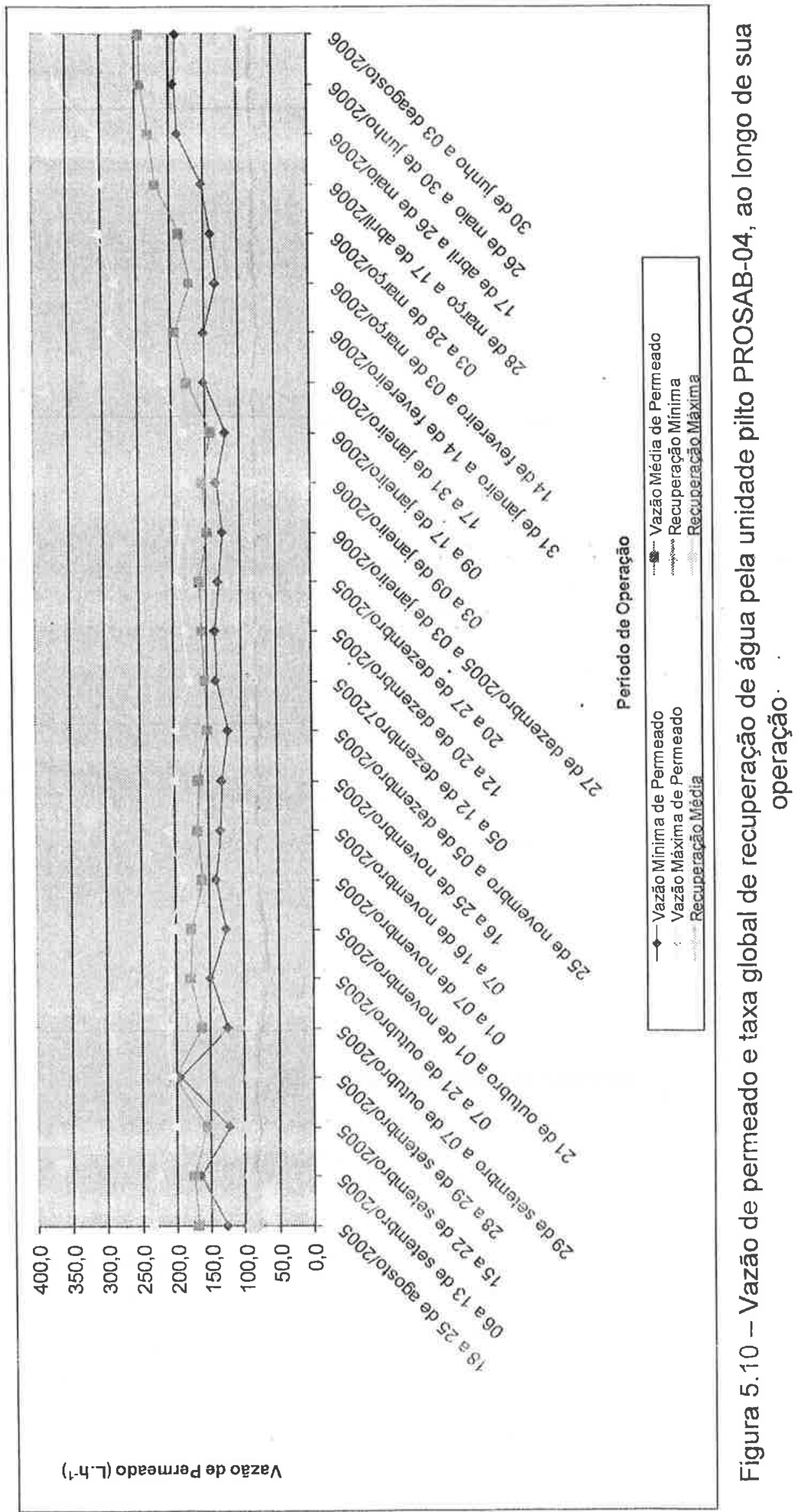


Pela análise da Figura 5.10, constata-se que a melhoria na produção de permeado, a partir de 17 de janeiro de 2006, ocorreu a partir da adoção dos procedimentos operacionais discutidos.

Tomando-se como base apenas os dados a partir de 17/01/2006, a vazão média de permeado é de 209,6 L.h $\mathrm{h}^{-1}$, com uma pressão de $384 \mathrm{kPa}$, que resulta em uma taxa de fluxo de $25,1 \mathrm{~L} \cdot \mathrm{h}^{-1} \cdot \mathrm{m}^{-2}\left(6,5 \times 10^{-02} \mathrm{~L} \cdot \mathrm{h}^{-1} \cdot \mathrm{m}^{-2} \cdot \mathrm{kPa} \mathrm{P}^{-1}\right)$, praticamente o mesmo valor obtido no primeiro ensaio com a água do Reservatório Guarapiranga. Estes resultados demonstram a necessidade de re-avaliar a perda de fluxo da membrana com o tempo e conseqüentemente a.estimativa de sua vida útil, mesmo porque o ensaio para a determinação das condiçōes de operação da unidade piloto teve curta duração e não foram utilizados os procedimentos operacionais otimizados.

5.2.2. Eficiência na remoção de contaminantes

Ao longo da operação, a unidade piloto de ultrafiltração se mostrou bastante eficiente na remoção dos contaminantes avaliados para o controle do seu desempenho. As Tabelas 5.4 a 5.7 mostram os resultados das análises realizadas.

Em nehuma das amostras analisadas pelo CIRRA foi detectada a presença de etinilestradiol e nonilfenol, em concentração superior aos limites de deteç̧ão dos métodos, enfatizando-se que não foi utilizado o procedimento de extração em fase sólida para concentração da amostra, o que melhoraria a sensibilidade do método.

Para obter dados sobre a capacidade de remoção de etinilestradiol, foi realizado em 12 de junho de 2006 um teste, com duração de uma hora, fazendo a dosagem de um anticoncepcional comercial no tanque de alimentação da unidade piloto. Foram utilizados dois comprimidos do anticoncepcional NEOVLAR da Shering, com uma massa de etinilestradiol 
de $50 \mu \mathrm{g}$ por comprimido, de forma a obter uma concentração final, na água de alimentação do sistema, de $0,2 \mu \mathrm{g} \cdot \mathrm{L}^{-1}$. Durante a realização do ensaio a válvula de alimentação do tanque de água bruta permaneceu fechada.

Tabela 5.4 - Resultados das análises de amostras da água bruta, realizadas pelo CIRRA (Agosto de 2005 a Abril de 2006)

\begin{tabular}{|c|c|c|c|c|c|}
\hline Variáveis & $\begin{array}{c}\mathrm{N}^{0} \text { de } \\
\text { Amostras }\end{array}$ & Média & $\begin{array}{l}\text { Valores } \\
\text { Minimo }\end{array}$ & Máximo & $\begin{array}{l}\text { Desvio } \\
\text { Padrão }\end{array}$ \\
\hline Absorção de Radiação UV $\left(\mathrm{cm}^{-1}\right)$ & 17 & 0,09 & 0,07 & 0,13 & 0.01 \\
\hline Alcalinidade $\left(\mathrm{mg} \mathrm{CaCO}_{3} \cdot \mathrm{L}^{-1}\right)$ & 20 & 40,98 & 37,62 & 61,66 & 5,09 \\
\hline Condutividade elétrica $\left(\mu \mathrm{S} . \mathrm{cm}^{-1}\right)$ & 25 & 141,86 & 109,00 & 170,90 & 16,63 \\
\hline Cor aparente (mg Pt-Co. $\mathrm{L}^{-1}$ ) & 22 & 29,1 . & 13,5 & 52,0 & 8,87 \\
\hline Dureza total $\left(\mathrm{mg} \mathrm{CaCO}{ }_{3} \cdot \mathrm{L}^{-1}\right)$ & 22 & 33,36 & 30,41 & 37,95 & 1,82 \\
\hline Fósforo Total (mg P. $\left.\mathrm{L}^{-1}\right)$ & 11 & $0,03^{\circ}$ & 0,02 & 0,06 & 0,01 \\
\hline Microcistinas $\left(\mu \mathrm{g} \cdot \mathrm{L}^{-1}\right)$ & 12 & $<0,1$ & $<0,1$ & 0,15 & ND \\
\hline Nitrogênio Amoniacal (mg N.L $\left.L^{-1}\right)$ & 10 & 0,17 & 0,04 & 0,33 & 0,1 \\
\hline Nitrogênio Kjeldahl (mg N. $\mathrm{L}^{-1}$ ) & 12 & 1,83 & 0,65 & 4,33 & 1,14 \\
\hline Nitrogênio orgânico (mg N.L $\left.{ }^{-1}\right)$ & 9 & 1,30 & 0,79 & 2,09 & 0,44 \\
\hline pH (unidades) & 23 & 7,52 & 6,71 & 8,78 & 0,37 \\
\hline Turbidez (UT) & 21 & 3,02 & 1,36 & 4,31 & 0,92 \\
\hline
\end{tabular}

ND - Não determinado

Tabela 5.5 - Resultados das análises de amostras do permeado, realizadas pelo CIRRA (Agosto de 2005 a Abril de 2006)

\begin{tabular}{|c|c|c|c|c|c|c|}
\hline Variáveis & $\begin{array}{c}\mathrm{N}^{0} \text { de } \\
\text { Amostras }\end{array}$ & Média & $\begin{array}{l}\text { Valores } \\
\text { Mínimo }\end{array}$ & Máximo & $\begin{array}{l}\text { Desvio } \\
\text { Padrăo }\end{array}$ & $\begin{array}{l}\text { Eficiência } \\
\text { média de }\end{array}$ \\
\hline Absorção de Radiação UV $\left(\mathrm{cm}^{-1}\right)$ & 17 & 0,03 & 0,02 & 0,08 & 0,01 & $66,7 \%$ \\
\hline Alcalinidade $\left(\mathrm{mg} \mathrm{CaCO}_{3} \cdot \mathrm{L}^{-1}\right)$ & 20 & 37,02 & 31,35 & 41,28 & 2,15 & $9,7 \%$ \\
\hline Condutividade elétrica $\left(\mu \mathrm{S} . \mathrm{cm}^{-1}\right)$ & 25 & 133,92 & 105,00 & 159,30 & 14,45 & $5,6 \%$ \\
\hline Cor aparente (mg Pt-Co. $\left.\mathrm{L}^{-1}\right)$ & 22 & 1,8 & $<1$ & 3,5 & 1,27 & $93,7 \%$ \\
\hline Dureza total ( $\left.\mathrm{mg} \mathrm{CaCO} \mathrm{CL}^{-1}\right)$ & 22 & 29,80 & $2.5,26$ & 35,90 & 2,27 & $10,7 \%$ \\
\hline Fósforo Total (mg P. $\left.\mathrm{L}^{-1}\right)$ & 11 & 0,02 & $<0,01$ & 0,04 & 0,01 & $33,3 \%$ \\
\hline Microcistinas $\left(\mu \mathrm{g} \cdot \mathrm{L}^{-1}\right)$ & 12 & $<0,1$ & $<0,1$ & $<0,1$ & $--x--$ & $--x--$ \\
\hline Nitrogênio Amoniacal (mg N. $L^{-1}$ ) & 10 & 0,19 & 0,09 & 0,63 & 0,16 & $--\mathrm{X}--$ \\
\hline Nitrogênio Kjeldahl (mg N. $\mathrm{L}^{-1}$ ) & 12 & 0,83 & 0,09 & 2,49 & 0,67 & $54,6 \%$ \\
\hline Nitrogênio orgânico (mg $\left.N L^{-1}\right)$ & 9 & 0,60 & 0,28 & 1,85 & 0,48 & $53,8 \%$ \\
\hline $\mathrm{pH}$ (unidades) & 23 & 7,36 & 6,84 & 7,86 & 0,22 & $-x-$ \\
\hline Turbidez (UT) & 21 & 0,20 & 0,05 & 0,47 & 0,12 & $93,4 \%$ \\
\hline
\end{tabular}


Tabela 5.6 - Resultados das análises de amostras da água bruta, realizadas pela SABESP (Setembro de 2005 a Março de 2006)

\begin{tabular}{|c|c|c|c|c|c|}
\hline Variável & $\begin{array}{c}\mathrm{N}^{0} \text { de } \\
\text { Amostras }\end{array}$ & Média & $\begin{array}{l}\text { Valores } \\
\text { Mínimo }\end{array}$ & Máximo & $\begin{array}{l}\text { Desvio } \\
\text { Padrão }\end{array}$ \\
\hline Alcalinidade (mg $\left.\mathrm{CaCO}_{3} \cdot \mathrm{L}^{-1}\right)$ & 79 & 33,20 & 28,00 & 36,00 & 1,8 \\
\hline Carbono Orgânico Total (mg C.L.' $)$ & 24 & 4,57 & 3,64 & 5,37 & 0,38 \\
\hline Coliformes Totais (NMP. $100 \mathrm{~mL}^{-1}$ ) & 18 & $1,47 E+04$ & $3,00 E+02$ & $1,60 \mathrm{E}+05$ & $3,70 E+04$ \\
\hline Contagems de Algas (UPA. $\mathrm{mL}^{-1}$ ) & 27 & $7,09 E+03$ & $1,68 \mathrm{E}+03$ & $5,00 E+04$ & $9,40 E+03$ \\
\hline Cor aparente (mg Pt-Co/L) & 80 & 32,6 & 30,0 & 80,0 & 17,8 \\
\hline Escherichia Coli (NMP.100 mL $\mathrm{mL}^{-1}$ ) & 18 & $2,42 . E+02$ & $0,00 \mathrm{E}+00$ & $1,70 E+03$ & $4,85 E+02$ \\
\hline Feriro (mg Fe. $\mathrm{L}^{-1}$ ) & 81 & 0,02 & 0,00 & 0,17 & 0,03 \\
\hline Manganês (mg Mn. $\mathrm{L}^{-1}$ ) & 81 & 0,03 & 0,00 & 0,27 & 0,05 \\
\hline $\mathrm{pH}$ (unidades) & 82 & 7,40 & 7,00 & 8,00 & 0,24 \\
\hline Turbidez (UT) & 82 & 2,89 & 1,66 & 8,84 & 0,87 \\
\hline
\end{tabular}

Tabela 5.7 - Resultacios das análises de amostras do permeado, realizadas pela SABESP (Setembro de 2005 a Março de 2006)

\begin{tabular}{|c|c|c|c|c|c|c|}
\hline Variável . & $\begin{array}{c}\mathrm{N}^{0} \mathrm{de} \\
\text { Amostr }\end{array}$ & Média & $\begin{array}{l}\text { Valores. } \\
\text { Mínimo }\end{array}$ & Máximo & $\begin{array}{l}\text { Desvio } \\
\text { Padrão }\end{array}$ & $\begin{array}{l}\text { Eficiência de } \\
\text { Remocăo (\%) }\end{array}$ \\
\hline Alcalinidade ( $\mathrm{mg} \mathrm{CaCO}_{3} \mathrm{~L}^{-1}$ ) & 79 & 31,46 & 26,00 & 36,00 & 2,07 & $5,24 \%$ \\
\hline Carbono Orgânico Total (mg C...-1 $)$ & 24 & 1,08 & 0,29 & 2,10 & 0,59 & $76,37 \%$ \\
\hline Coliformes Totais (NMP. $100 \mathrm{~mL}^{-1}$ ) & 18 & $0,00 E+00$ & $0,00 E+00$ & $0,00 E+00$ & $0,00 E+00$ & $100,00 \%$ \\
\hline Contagems de Algas (UPA. $\mathrm{mL}^{-1}$ ) & 27 & $7,60 \mathrm{E}-01$ & $0,00 E+00$ & $3,73 E+00$ & $9,40 E-01$ & $99,99 \%$ \\
\hline Cor aparente (mg Pt-Co/L) & 80 & 3,7 & 2,5 & 5,0 & 1,25 & $88,79 \%$ \\
\hline Escherichia Coli (NMP.100 $\mathrm{mL}^{-1}$ ) & 18 & $0,00 E+00$ & $0,00 \mathrm{E}+00$ & $0,00 E+00$ & $0,00 E+00$ & $100,00 \%$ \\
\hline Ferro (mg Fe. $L^{-1}$ ) & 81 & 0,01 & 0,00 & 0,11 & 0,02 & $50,00 \%$ \\
\hline Manganês (mg Mn. $\mathrm{L}^{-1}$ ) & 81 & 0,01 & 0,00 & 0,13 & 0,02 & $66,67 \%$ \\
\hline $\mathrm{pH}$ (unidades) & 82 & 7,24 & 6,80 & 7,60 & 0,17 & -. \\
\hline Turbidez (UT) & 82 & 0,13 & 0,07 & 0,55 & 0,07 & $95,50 \%$ \\
\hline
\end{tabular}

Após a dosagem e homogeneização do etinilestradiol no tanque de alimentação foram coletadas amostras da água bruta, do permeado e do concentrado. As amostras foram analisadas utilizando-se o kit da empresa Abraxis Kits. Os resultados obtidos são apresentados na Tabela 5.8 . 
Tabela 5.8 - Resultados do ensaio para remoção de etinilestradiol pelo sistema de ultrafiltração

\begin{tabular}{|c|c|c|c|c|}
\hline \multirow{2}{*}{$\begin{array}{l}\text { Tempo de Operação } \\
\text { (minutos) }\end{array}$} & \multicolumn{3}{|c|}{ Concentração ( $\left.\mu \mathrm{g} \cdot \mathrm{L}^{-1}\right)$} & \multirow{2}{*}{$\begin{array}{l}\text { Eficiência de } \\
\text { Remoção }(\%)\end{array}$} \\
\hline & Água Bruta & Permeado & Concentrado & \\
\hline 0 & 0,21 & & & \\
\hline 10 & $\ldots$ & $<0,05$ & 0,10 & $>76,7$ \\
\hline 20 & $\ldots$ & $<0,05$ & 0,15 & $>76,7$ \\
\hline 30 & $\ldots$ & $<0,05$ & 0,20 & $>76,7$ \\
\hline 40 & $\ldots$ & $<0,05$ & 0,19 & $>76,7$ \\
\hline 50 & $\ldots$ & $<0,05$ & 0,19 & $>76,7$ \\
\hline 60 & 0,22 & $<0,05$ & 0,26 & $>76,7$ \\
\hline
\end{tabular}

Pelos dados apresentados, verifica-se que o sistema de ultrafiltração permite a obtenção de água com elevado grau de qualidade, garantindo uma eficiência de 100\% na remoção de Escherichia coli e coliformes totais, mesmo sem a utilização do processo de desinfecção, pois, mesmo antes do início da dosagem de cloro, os valores de remoção eram elevados. Um aspecto que deve ser destacado é a capacidade de remoção de substâncias que absorvem radiação ultravioleta na faixa de $254 \mathrm{~nm}$, associadas à formação de $\mathrm{TMH}$, cuja eficiência foi superior a $66 \%$, e de COT, eficiência superior a $76 \%$, valores que, dificilmente, são obtidos com o uso de sistemas convencionais de tratamento.

Um estudo realizado por Chen (2007), sobre a eficiência de sete tipos de sistema de tratamento de água potável, mostrou que as eficiências de remoção de substâncias que absorvem radiação ultravioleta em $254 \mathrm{~nm}$ e COT variaram de $19 \%$ a $36 \%$ e de $2 \%$ a $30 \%$, respectivamente. Neste estudo foram avaliados sistemas combinando o processo convencional, carvão ativado, carvão biológicamente ativo, pré-oxidação com permanganato de potássio e ozônio e desinfecção com cloro livre e combinado.

Outra questão a ser destacada diz respeito ao potencial da unidade de ultrafiltração em remover perturbadores endórinos, no caso deste trabalho, o 17-a-etinilestradiol, obtendu-so una eficiência superior a $76 \%$ no ensaio realizado. É importante observar que o mecanismo de remoção, não está associado simplesmente à exclussão pela membrana, uma vez 
que a massa molecular desta substância é muito inferior ao PMC da membrana. Possivelmente, o processo de remoção envolva a adsorção do contaminante no material em suspensão e na matéria orgânica presentes na água bruta e na própria membrana. Tal hipótese está baseada no fato de que a concentração do etinilestradiol no concentrado ser, no início do ensaio, inferior à concentração na água bruta, ocorrendo uma elevação ao longo do tempo.

A hipótese formulada pode ser comprovada avaliando-se algumas propriedades físico-químicas do etinilestradiol, como o coeficiente de partição octanol e água ( $\mathrm{K}_{\mathrm{OW}}$ ) e carbono orgânico água (Koc). Dados disponíveis na literatura apresentam valores do log $K_{0 w}$ e log $K_{O C}$, próximos de 3,9 e 3,8 (Y.OUNG et al., 2004), indicando que tais substâncias são hidrofóbicas (CLEMENTS, 1996).

Os resultados obtidos com o projeto de pesquisa desenvolvido no âmbito do PROSAB-04 demontram o potencial do uso da tecnologia de ultrafiltração para tratamento de água, considerando-se os problemas de qualidade que os mananciais utilizados para abastecimento vêm apresentando, em especial nas grandes regiões metropolitanas.

\subsection{Resultados do desempenho da unidade piloto - PROSAB-05}

A partir dos resultados obtidos com a unidade piloto no edital $n^{\circ} 04$ do PROSAB procurou-se avaliar, com mais detalhes, a influência da dosagem de hipoclorito de sódio e paradas periódicas no desempenho de sistemas de ultrafiltração que utilizam membranas enroladas em espiral. Neste projeto não foram realizados ensaios para a determinação das condições operacionais do sistema, adotando-se aquelas em que a taxa de recuperação de água pela membrana ficasse abaixo de 10\%.

A operação da unidade piloto, após as devidas modificações e ajustes começou em 29 de agosto de 2007, ainda sem a dosagem de hipoclorito 
de sódio na alimentação. Assim, para efeito de comparação, serão utilizados os dados do período de 29/08 a 20/09/2007, como os valores de referência. Neste período, a vazão média de permeado foi de 208,3 L. $h^{-1}$, com uma pressão média de $133,3 \mathrm{kPa}$, recuperação na membranas de $7,3 \%$, resultando nas taxas de fluxo de $26,37 \mathrm{~L} \cdot \mathrm{h}^{-1} \cdot \mathrm{m}^{-2}$ e $1,98 \times 10^{-01}$ L. $\mathrm{h}^{-1} \cdot \mathrm{m}^{-2} \cdot \mathrm{kPa}{ }^{-1}$.

Em relação à vazão de permeado e taxa de fluxo, não normalizadas pela pressão, os resultados são próximos daqueles obtidos no PROSAB-04, quando do ensaio para determinação das condições de operação da membrana, porém cọm pressões diferentes.

A unidade piloto operou continuamente de 29/08/2007 a 22/12/2008, totalizando mais de 10.600 horas de operação, com produçãó média de 145,3 L.h. ${ }^{-1}$ de permeado, com uma pressão média de 160,9 kPa, resultando nas taxas de fluxo de $18,39 \quad \mathrm{~L}^{-1} \mathrm{~h}^{-1} \cdot \mathrm{m}^{-2}$ e $1,14 \times 10^{-01}$ $\mathrm{L} \cdot \mathrm{h}^{-1} \cdot \mathrm{m}^{-2} \cdot \mathrm{kPa} \mathrm{a}^{-1}$.

Comparando-se os resultados obtidos no início da operação do sistema com os valores acima, observa-se uma perda significativa do fluxo de água através da membrana. Contudo, a simples comparação dos valores obtidos pode conduzir a interpretações equivocadas por conta dos testes realizados para avaliação dos procedimentos operacionais no desempenho do sistema.

\subsubsection{Desempenho operacional}

Para demonstrar a influência das condições de operação estudadas, paradas periódicas e dosagem de hipoclorito de sódio, no desempenho do sistema e da variação da perda de carga com o tempo nas Figuras 5.11 a 5.13, são mostrados os gráficos de desempentio elaburados pelo programa do sistema de aquisição de dados da unidade piloto, para três condições operacionais avaliadas. 


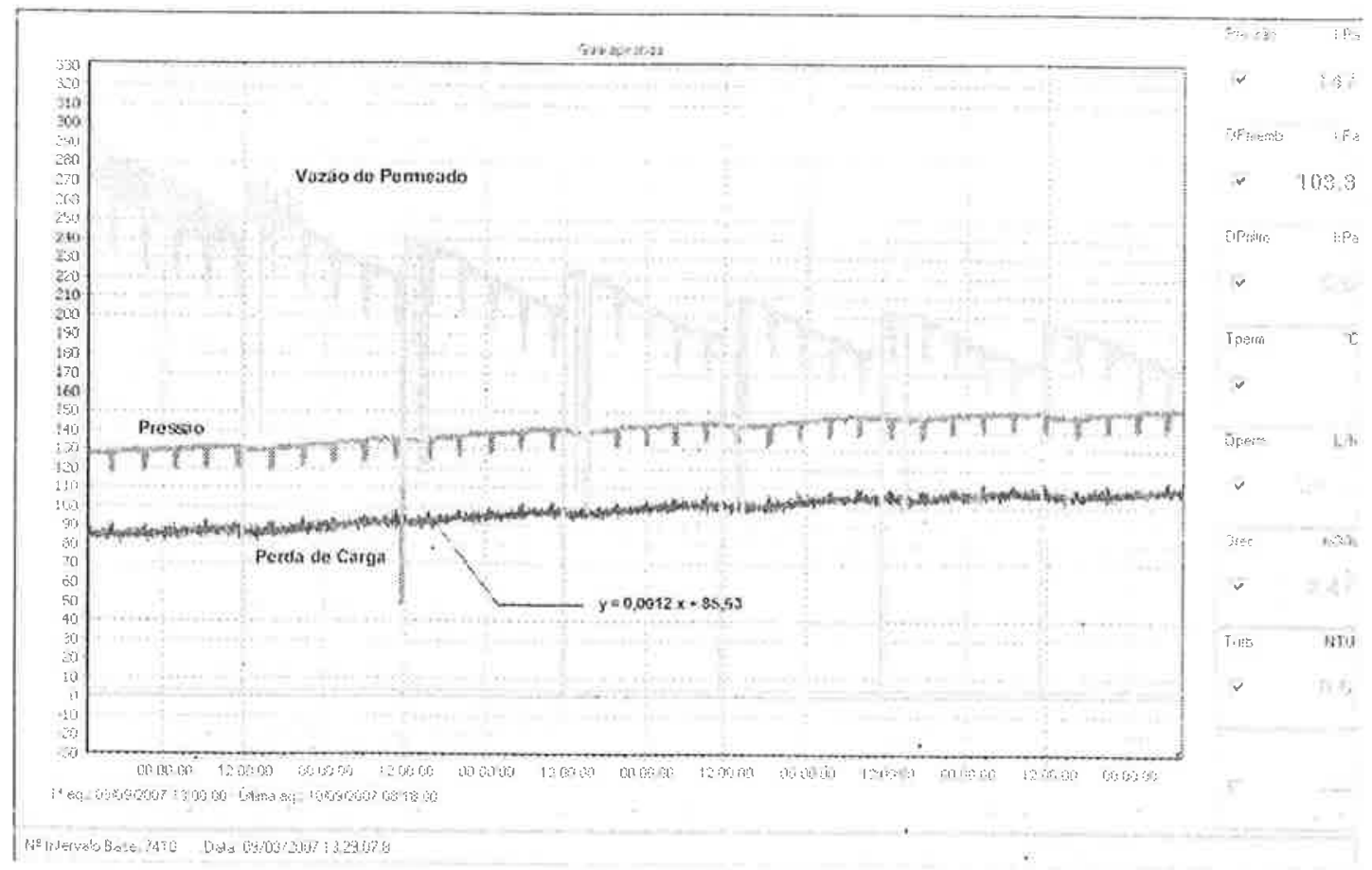

Figura 5.11 - Desempenho da unidade piloto no período de 03 a 10/09/2007, sem a dosagem de hipoclorito de sódio, mas com o procedimento de paradas periódicas

Pelo gráfico da Figura 5.11 é possível observar que em uma semana o fluxo de permeado, sem a dosagem de hipoclorito de sódio, foi reduzido a menos de $60 \%$ do inicial, mas que entre cada parada diária houve uma recuperação do fluxo. Também é possivel observar um aumento progressivo na perda de carga na membrana, assim como da pressão de alimentação.

Analisando-se a Figura 5.12 em com paração com a Figura 5.11, verificase que a dosagem de hipoclorito de sódio tem influência positiva sobre o fluxo de permeado, o qual sofre menor redução com o tempo de operação. No dia 02/10, ocorreu um problema elétrico que desativou o temporizador da válvula de descarte de concentrado e o sistema funcionou com recirculaçao total de concentrado, o que ocasionou a perda de vazão de permeado, aumento da pressão e da perda de carga rıo sistema. Após a normalização do descarte de concentrado a vazão de permeado foi recuperada e a perda de carga na membrana ficou establizada. As equações de ajuste linear da perda de carga com o tempo resultaram em coeficientes angulares negativos. 


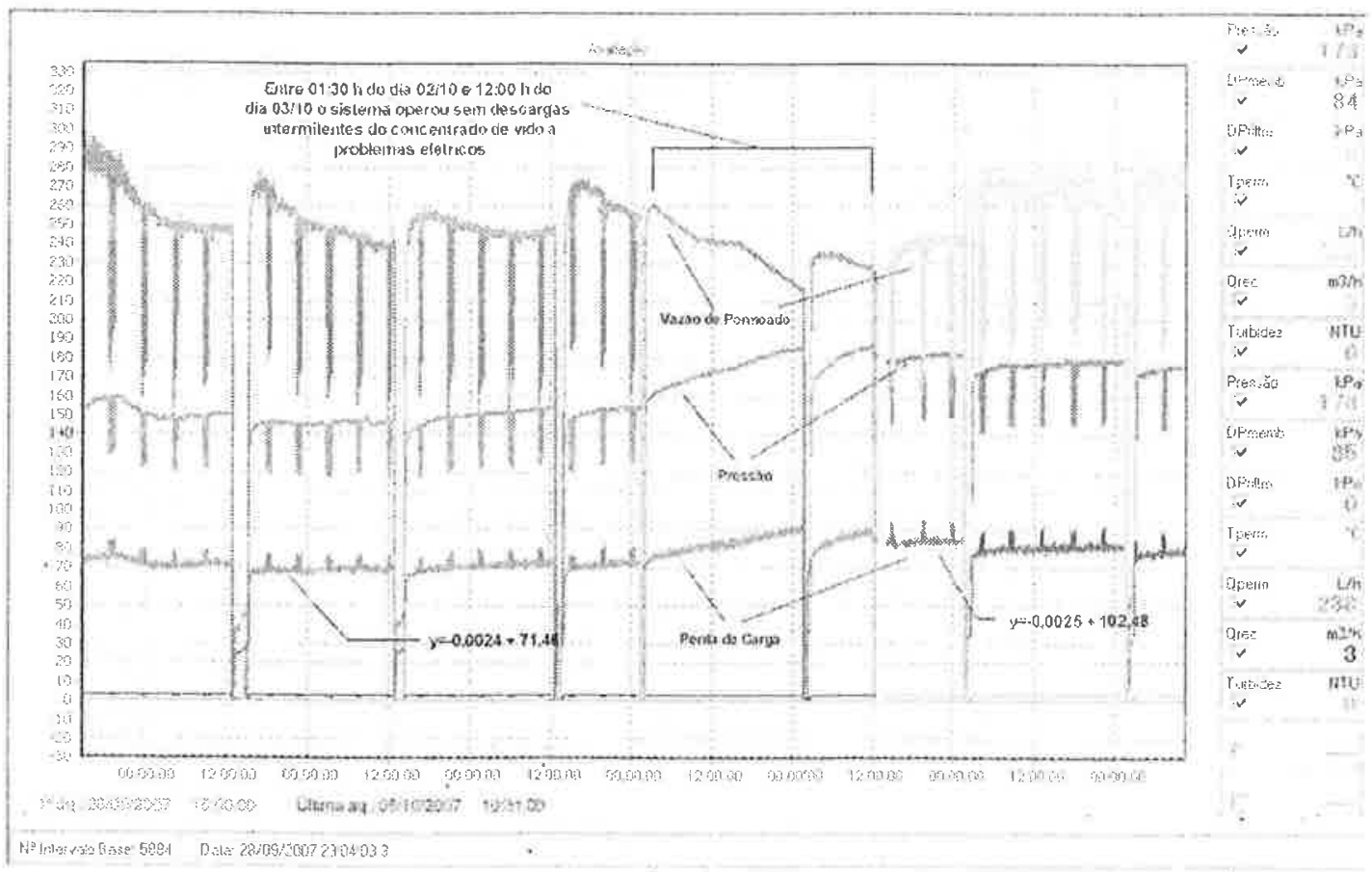

Figura 5:12 - Desempenho da unidade piloto no período de 28/09 a 05/10/2007, com o início da dosagem de hipoclorito de sódio e paradas periódicas

Na Figura 5.13, no início da operação do sistema, embora a vazão de permeado se mantivesse relativamente estável, claramente observa-se um aumento significativo da perda de carga na membrana e da pressão de alimentação do sistema e, mesmo assim, a vazão de permeado começou a cair. O ajuste linear da variação da perda de carga com o tempo resultou em um coeficiente angular superior ao obtido com o sistema operando sem dosagem de hipoclorito, porém com paradas periódicas. No dia $27 / 11 / 2007$ foi feito o ajuste da pressão do sistema para $150 \mathrm{kPa}$, diminuíndo, ainda mais, a vazão de permeado. Após o ajuste, a pressão de alimentação e a perda de carga voltaram a subir inuito rapidamente sem qualquer alieração significativa na vazäo de permeado, indicando problemas com a membrana. Em 30/11/2007 foi realizada uma operação de limpeza quimica emergencial para tentar recuperar a produço do sisterra, observando-se que hove recuperação da vazão de permeado, porém ela foi sendo reduzida rapidamente. 


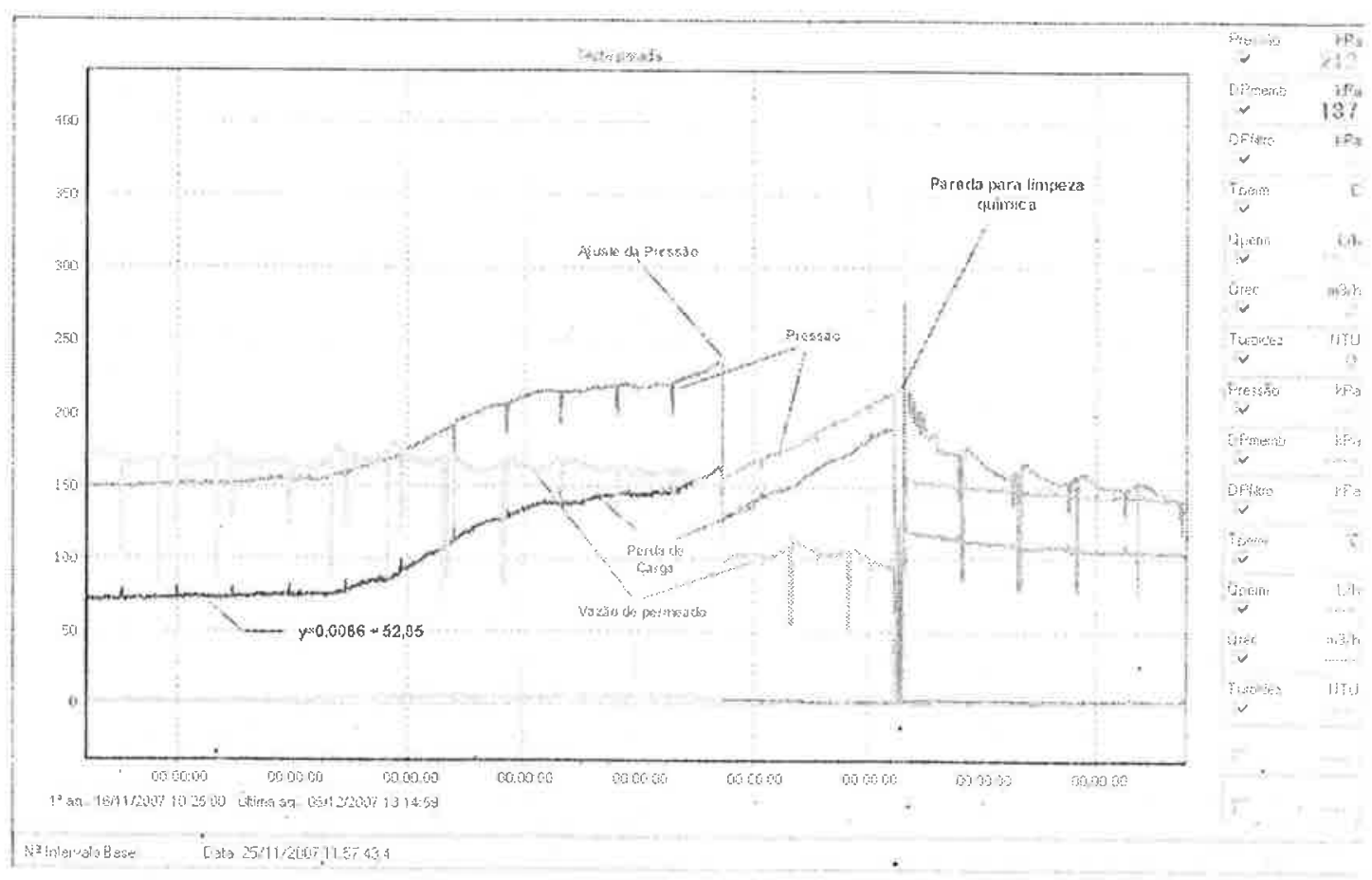

Figura 5.13 - Desempenho da unidade piloto no período de 16/11 a 05/12/2007, sem a realização das paradas periódicas, mas com dosagem de

hipoclorito de sódio

Analisando em conjunto os resultados dos testes realizados pode-se afirmar que as operações periódicas de parada e a utilização do hipoclorito de sódio são fundamentais para o desempenho do sistema de ultrafiltração. Com isto, a hipótese formulada na discussão, sobre a influência das operações periódicas no desempenho operacional da unidade piloto do projeto de pesquisa no âmbito do PROSAB-04, fica comprovada (item 5.2.1).

A partir de 18/12/2007 a unidade piloto voltou a operar com as paradas periódicas e dosagem de hipoclorito. Na Tabela 5.9 são apresentados os dados relativos às operaçōes de parada para limpeza química e outras informações sobre o modo de operação do sistema. Observa-se que, a partir de 28/03/2008, a unidade piloto passou a operar em condições mais estáveis, com un intervalo médio entre limpezas químicas de 894 horas, praticamente o mesmo obtido na unidade piloto PROSAB-04, após a adoção dos procedimentos operacionais discutidos. Contudo, em decorrência dos problemas ocorridos e da utilização de procedimentos 
não otimizados nos testes, a produção de permeado foi reduzida em relação ao início de operação da unidade. Contudo, observa-se que a capacidade da membrana estava sendo recuperada gradativamente. Apenas para comparação, a vazão média de permeado no período entre 28/03 a 22/12/2008 foi de 132,4 L.h ${ }^{-1}$ e a pressão de 161,7 kPa, resultando em taxas de fluxo de $16,76 \mathrm{~L} \cdot \mathrm{h}^{-1} \cdot \mathrm{m}^{-2}$ e $1,04 \times 10^{-01} \mathrm{~L} \cdot \mathrm{h}^{-1} \cdot \mathrm{m}^{-2} \cdot \mathrm{kPa}$, inferiores àquelas obtidas no início da operação da unidade.

Cabe observar que a pressão de operação utilizada, bem como a taxa de recuperaçăo de água pela membrana estiveram abaixo dos valores recomendados pelo fornecedor da membrana, de forma que o desempenho do sistema pode ser melhorado. É, portanto, indicada a realização de um ensaio específico para determinar a pressão ótima de trabalho.

Na Figura 5.14 são apresentados os resultados das vazões de permeado ao longo da operação da unidade pilto, onde pode ser constatada, com auxílio dos dados da Tabela 5.9, a influência dos procedimentos operacionais no seu desempenho. Os picos de vazão de permeado resultaram da alteração do modo de funcionamento da válvula solenóide instalada na linha de recirculação de concentrado para a bomba alimentação do sistema, que fecha por 10 segundos durante o descarte de concentrado, que ocorre a cada 10 minutos, elevando a pressão no sistema.

Durante a operação da unidade piloto a taxa global média de recuperação de água foi de $89,7 \%$. Na Figura 5.15 são apresentados os dados sobre a variação da taxa de recuperação de água durante a operação da unidade piloto. 


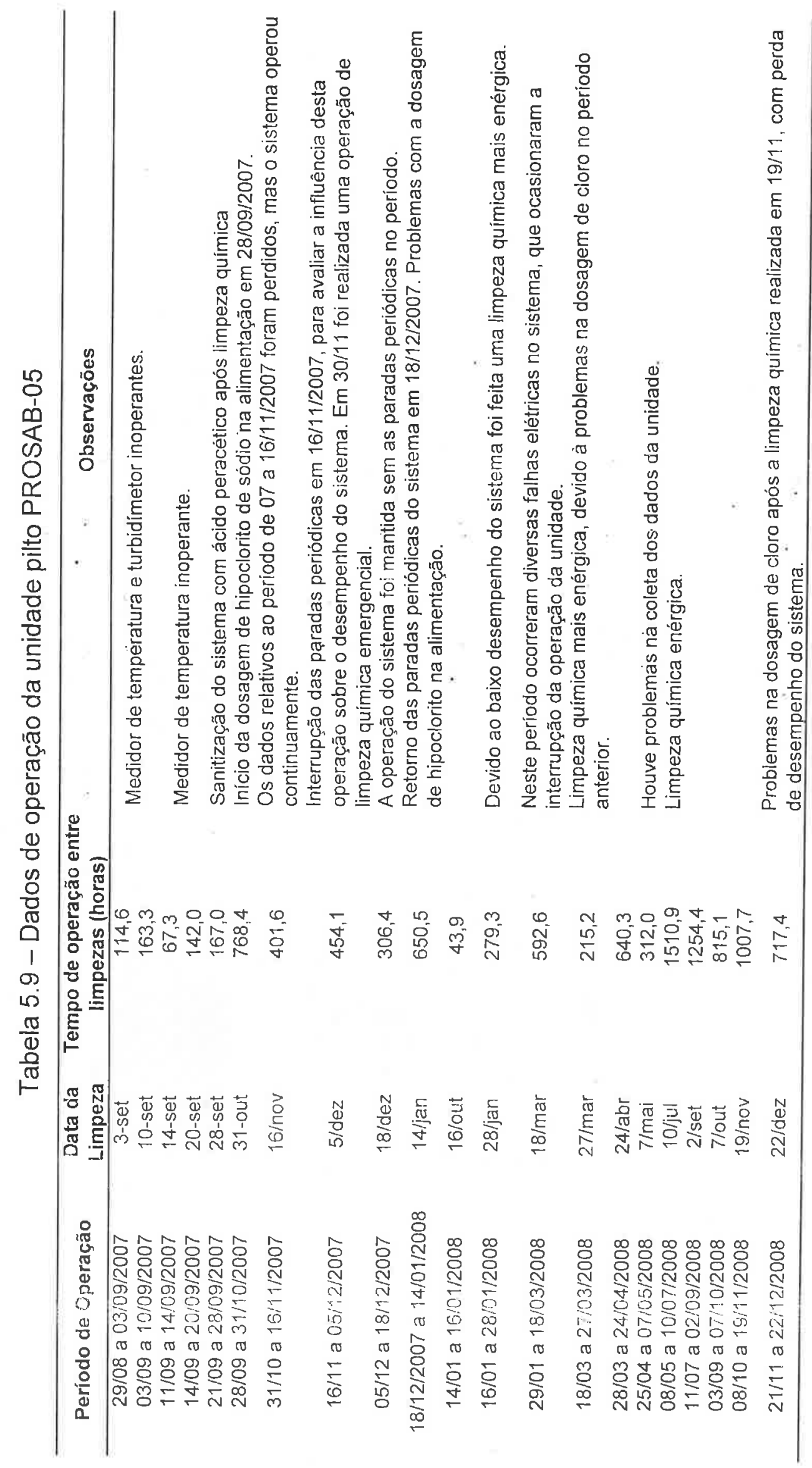


$\infty$

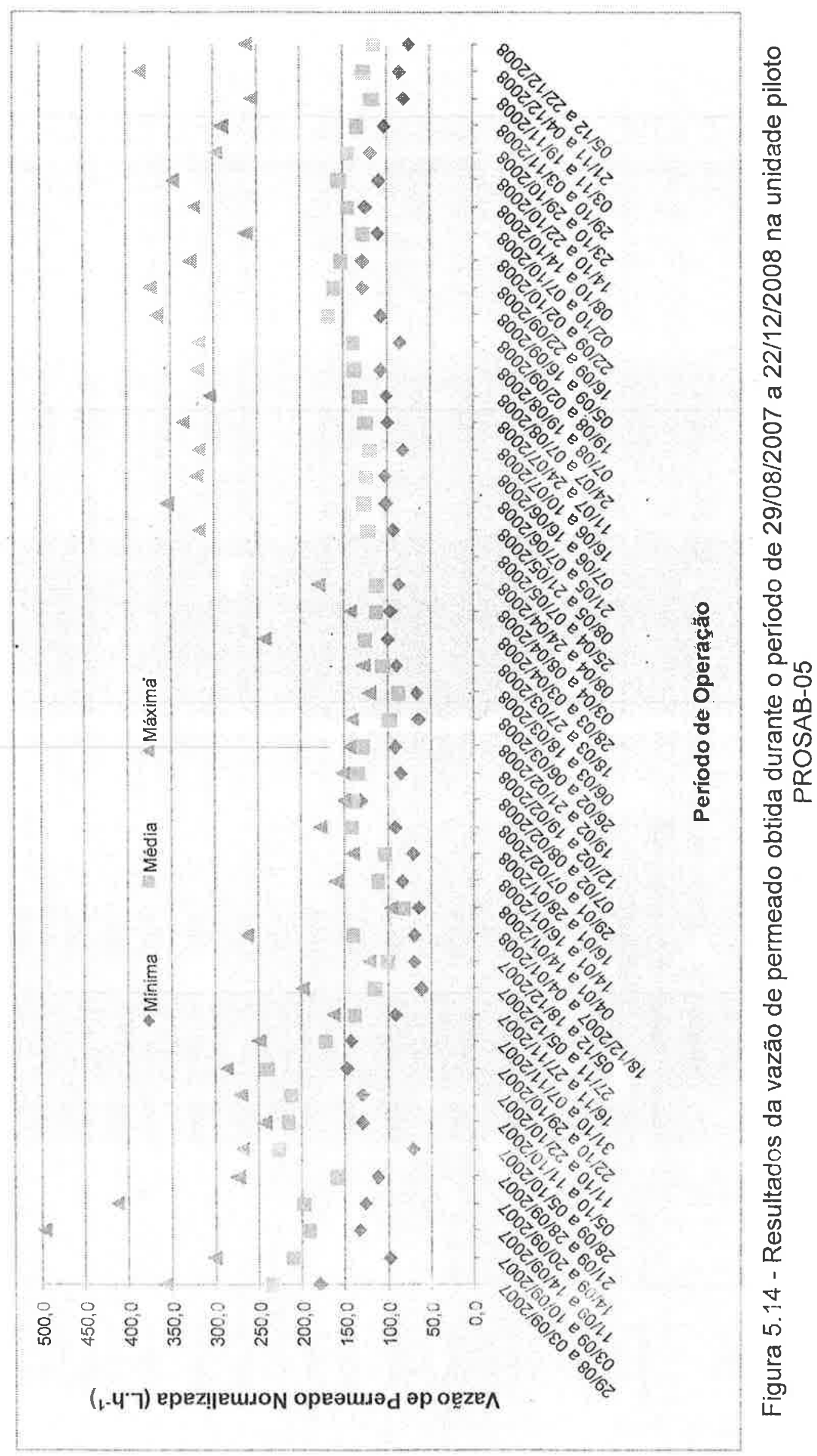




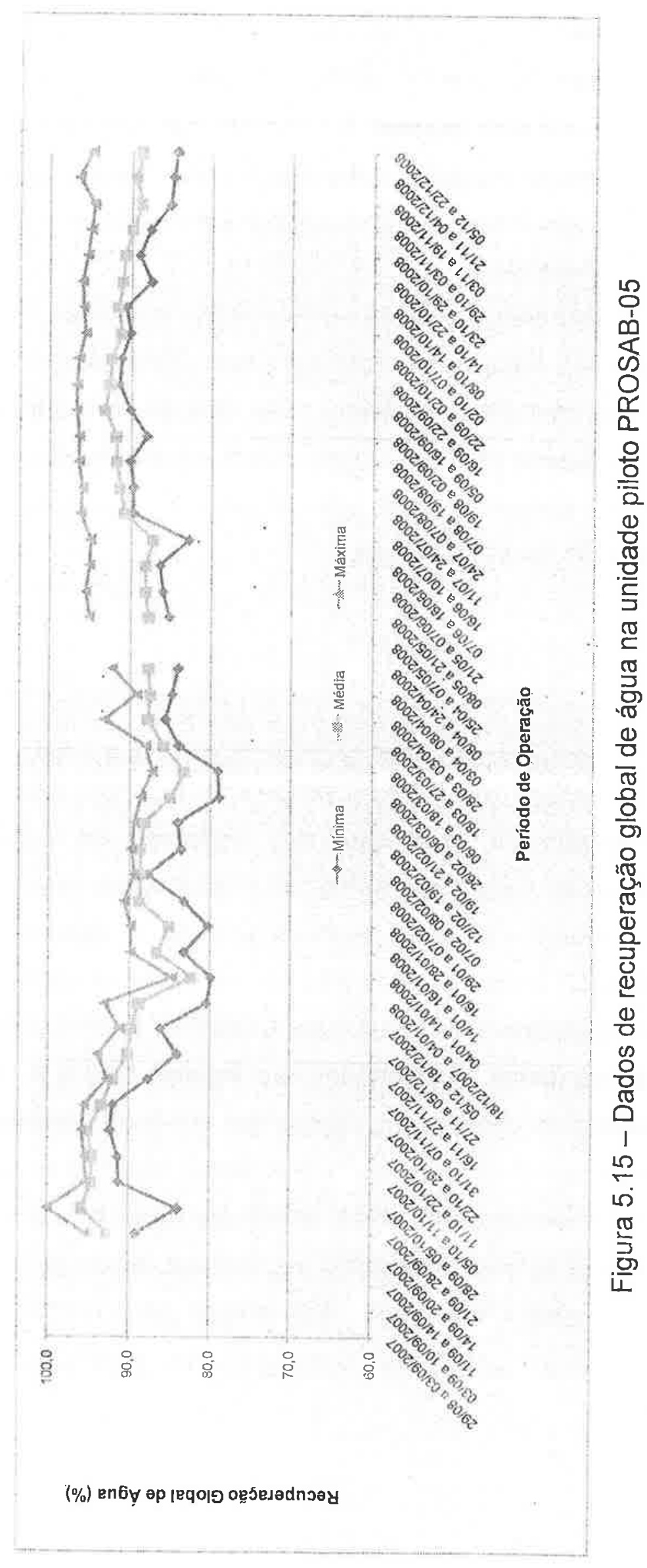


Um dado relevante sobre a operação de sistemas de separação por membranas, obtido durante o desenvolvimento do projeto, é que o procedimento de limpeza química tem efeito significativo sobre o seu desempenho, pois em algumas ocasiões foi necessária a utilização de condições de limpeza mais enérgicas para tentar recuperar a capacidade de produção da membrana.

Ressalta-se que durante o periodo de operação do sistema não foi feita uma avaliação mais detalhada do procedimento de limpeza química para a obtenção dos melhores resultados, em relação à recuperação da produção de permeado. Enfatiza-se que este é um item fundamental a ser considerado no desenvolvimento de projetos e na implantação de sistemas com base nesta tecnologia.

\subsubsection{Desempenho na remoção de contaminantes}

Como mencionado, a avaliação da eficiência de remoção de contaminantes pela unidade de ultrafiltração foi feita com base na coleta e análise de amostras de água bruta, permeado e concentrado. Nas Tabelas 5.10 e 5.11 são apresentados os resultados obtidos na análise das variáveis controladas, no período de 21/09/2007 a 16/10/2008.

Analisando-se os dados apresentados nas Tabelas 5.10 e 5.11, verificase que o sistema de ultrafiltração apresentou um bom desempenho com relaçăo à remoção das variáveis monitoradas, obtendo-se valores de $100 \%$ para Escherichia coli e coliformes totais e superiores a $90 \%$ para a remoção de cor e turbidez. Um ponto que merece destaque é a remoção de Carbono Orgânico Dissolvido, que atingiu valor médio de $60,7 \%$, indicando a capacidade para separação de moléculas orgânicas dissolvidas. 
Tabela 5.10 - Resultados das análises das amostras de água bruta para as variáveis utilizadas no controle da eficiência de remoção de contaminantes pela piloto PROSAB-05

\begin{tabular}{|c|c|c|c|c|c|c|}
\hline Variável & $\begin{array}{l}\text { Nümero de } \\
\text { amostras }^{a}\end{array}$ & Unidade & Minimo & Média & Máximo & $\begin{array}{l}\text { Desvio } \\
\text { Padrão }\end{array}$ \\
\hline Absorção de Radiação $U_{254}$ & 22 & $\mathrm{~cm}^{-1}$ & 0,030 & 0,103 & 0,307 & 0,063 \\
\hline Alcalinidade & 11 & $\mathrm{mg} \mathrm{CaCO} \mathrm{L}^{-1}$ & 37,74 & 40,89 & 48,96 & 3,46 \\
\hline Carbono Orgânico Dissolvido (COD) & 24 & $\mathrm{mg} C \cdot \mathrm{L}^{-1}$ & 3,12 & 5,47 & 14,63 & 3,18 \\
\hline Coliformes Totais & 14 & $\mathrm{NMP} / 100 \mathrm{~mL}$ & 63 & 824 & 2420 & 974 \\
\hline Condutividade Elétrica & 23 & $\mu S, \mathrm{~cm}^{-1}$ & 136,07 & 185,36 & 687,00 & 110,83 \\
\hline Cor Aparente & 20 & $\mathrm{uC}$ & 25,33 & 61,36 & 190,00 & 38,97 \\
\hline Dureza & 11 & $\mathrm{mg} \mathrm{CaCO}_{3}, \mathrm{~L}^{-1}$ & 39 & 47 & $5 \dot{2}$ & 3,7 \\
\hline Escherichia Coli & 16 & $\mathrm{NMP} / 100 \mathrm{~mL}$ & 0 & 49 & 306 & 81 \\
\hline $\mathrm{pH}$ & 24 & Unidade de $p H$ & 7,0 & 7,8 & 11,5 & 0,9 \\
\hline Turbidez & 23 & $\mathrm{uT}^{\prime}$ & 1,0 & 3,5 & 11,2 & 3,0 \\
\hline
\end{tabular}

Tabela 5.11 - Resultados das análises para amostras de permeado para as variáveis para controle da eficiência de remoção de contaminantes pela piloto PROSAB-05

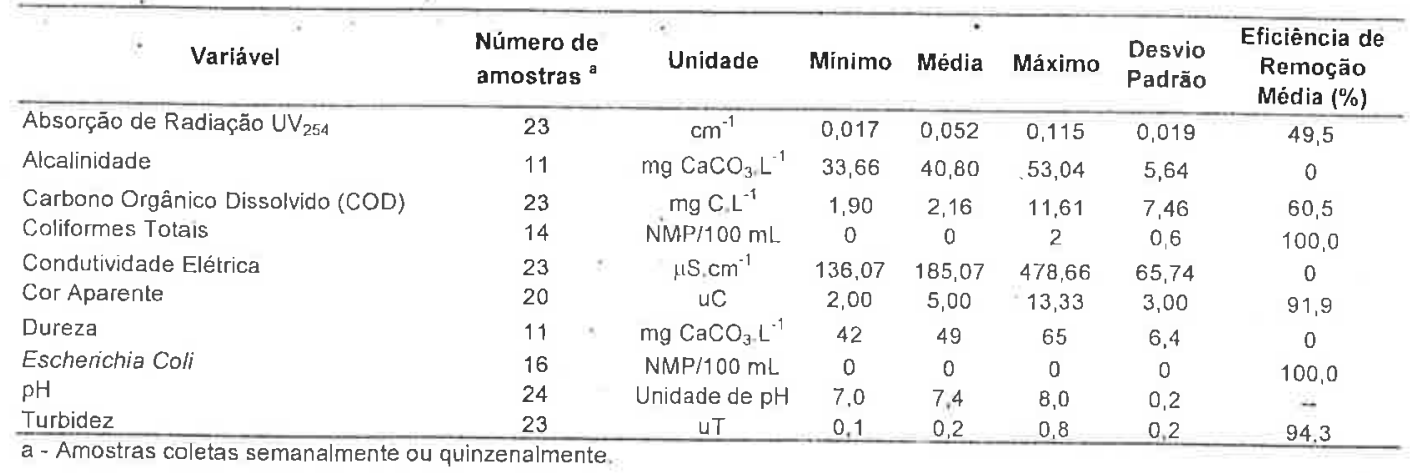

Em comparação aos resultados obtidos na unidade piloto PROSAB-04 verifica-se uma menor eficiência na remoção de substâncias que absorvem radiação ultravioleta no comprimento de onda de $254 \mathrm{~nm}$ e também de carbono orgânico, o que já era previsto em função do PMC da membrana utilizada. Contudo, os resultados são bastante satisfatórios, pois superam aqueles obtidos pelas tecnologias de tratamento de água estudadas por Chen (2007).

O monitoramento em linha da turbidez resultou em valores significativamente inferiores aos obtidos pela medida em laboratório, o que se justifica pela melhor precisão do equipamento e pelo fato da medida não depender do uso de vidrarias que podem causar 
interferência. O gráfico da Figura 5.16, mostra os valores médios de turbidez obtidos na operação da unidade piloto.



Figura 5.16 - Turbidez média obtida pelo analisador de processo na operação da unidade piloto PROSAB-05

Em relação aos desreguladores endócrinos avaliados, Estrogênios naturais, 17- $\alpha$-etinilestradiol e nonilfenol, não foram obtidas concentrações superiores ao limite de detecção do método na maioria das amostras analisadas, mesmo com a utilização do processo de extração em fase sólida. As Tabelas 5.12 a 5.14 mostram estes resultados.

Observa-se pelos resultados da Tabela 5.12, que mesmo não sendo detectada a presença de nonilfenol na água bruta, em algumas amostras do concentrado foram obtidos valores superiores ao limite de detecção, indicando a presença de norilfemol na água do Reservatório Guarapiranga, em concentrações muito baixas. Considerando-se a taxa média de recuperação de água no sistema e admitindo-se que a inembrana seja capaz de reter 100\% do norilfenol, à sua concentração na água bruta seria de $14 \mathrm{ng} / \mathrm{L}$, valor muito inferior ao reportado na literatura. 
Tabela 5.12 - Resultados do monitoramento de nonilfenol na unidade piloto PROSAB-05

\begin{tabular}{cccccc}
\hline \multicolumn{1}{c}{ Data } & \multirow{2}{*}{ Unidade } & \multicolumn{3}{c}{ Piloto Guarapiranga } & Observação \\
\hline $10 / 1 / 2008$ & $\mathrm{ng} / \mathrm{L}$ & $<50$ & $<50$ & $<50$ & Com extração \\
$15 / 1 / 2008$ & $\mathrm{ng} / \mathrm{L}$ & $<50$ & $<50$ & 136 & Com extração \\
$22 / 2 / 2008$ & $\mathrm{ng} / \mathrm{L}$ & $<50$ & $<50$ & 113 & Com extração \\
$29 / 2 / 2008$ & $\mathrm{ng} / \mathrm{L}$ & $<50$ & $<50$ & 175 & Com extração \\
$9 / 5 / 2008$ & $\mathrm{ng} / \mathrm{L}$ & $<50$ & $<50$ & $<50$ & Com extração \\
$26 / 5 / 2008$ & $\mathrm{ng} / \mathrm{L}$ & $<50$ & $<50$ & $<50$ & Com extração \\
$10 / 6 / 2008$ & $\mathrm{ng} / \mathrm{L}$ & $<50$ & $<50$ & $<50$ & Com extração \\
$1 / 7 / 2008$ & $\mathrm{ng} / \mathrm{L}$ & $<50$ & $<50$ & $<50$ & Com extração \\
\hline Mínimo & & $<50$ & $<50$ & $<50$ & \\
Média & $\mathrm{ng} / \mathrm{L}$ & $<50$ & $<50$ & 141 & \\
Máximo & & $<50$ & $<50$ & 175 & \\
Desvio Padrão & $\mathrm{ND}$ & $\mathrm{ND}$ & 31 & \\
\hline ND - Não determinado & & & & &
\end{tabular}

Limite de detecção do método com o processo de extração em fase sólida = $50 \mathrm{ng} / \mathrm{L}$

Tabela 5.13 - Resultados do monitoramento de estrogênios na unidade piloto PROSAB-05

\begin{tabular}{cccccc}
\hline \multicolumn{2}{c}{ Data } & Unidade & \multicolumn{4}{c}{ Piloto Guarapiranga } & Observação \\
\hline $12 / 11 / 2007$ & $\mathrm{ng} / \mathrm{L}$ & $<0.5$ & $<0.5$ & $<0.5$ & Com extração \\
$14 / 1 / 2008$ & $\mathrm{ng} / \mathrm{L}$ & $<0.5$ & $<0.5$ & $<0.5$ & Com extração \\
$22 / 1 / 2008$ & $\mathrm{ng} / \mathrm{L}$ & $<0.5$ & $<0.5$ & 0,72 & Com extração \\
$29 / 1 / 2008$ & $\mathrm{ng} / \mathrm{L}$ & $<0.5$ & $<0.5$ & $<0.5$ & Com extração \\
$9 / 5 / 2008$ & $\mathrm{ng} / \mathrm{L}$ & $<0.5$ & $<0.5$ & $<0.5$ & Com extração \\
$26 / 5 / 2008$ & $\mathrm{ng} / \mathrm{L}$ & $<0.5$ & $<0.5$ & $<0.5$ & Com extração \\
$10 / 6 / 2008$ & $\mathrm{ng} / \mathrm{L}$ & $<0.5$ & $<0.5$ & $<0.5$ & Com extração \\
$1 / 7 / 2008$ & $\mathrm{ng} / \mathrm{L}$ & 7,5 & 14,6 & 11,4 & Com extração \\
\hline Mínimo & & $<0.5$ & $<0.5$ & $<0.5$ & \\
Média & $\mathrm{ng} / \mathrm{L}$ & 7,5 & 14,6 & 6,06 & \\
Máximo & 7,5 & 14,6 & 11,4 & \\
Devio Padrão & $\mathrm{ND}$ & $\mathrm{ND}$ & 7,6 & \\
Limite de deteç̧ão do método com o processo de extraçăo em fase sólida $=0,5 \mathrm{ng} / \mathrm{L}$ &
\end{tabular}

Em relação aos estrogênios (Tabela 5.13), verifica-se que, em apenas uma das datas que foram feitas coletas a amostra de água bruta apresentou concentração significativamente superior ao limite de deteç̧ão do método e, consqüentemente, as amostras de permeado e concentrado, ainda são superiores aos da água bruta. Vale ressaltar que este é um ponto isolado, indicando a necessidade da contiruidade do monitoramento desta variável. De qualquer forma, o valor obtido encontrase dentro da faixa dos valores repostados na literatura (MOREIRA, 2008; USGS, 2002). 
Tabela 5.14- Resultados do monitoramento de etinilestradiol na unidade piloto PROSAB-05

\begin{tabular}{|c|c|c|c|c|c|}
\hline \multirow{2}{*}{ Data } & \multirow{2}{*}{ Unidade } & \multicolumn{3}{|c|}{ Piloto Guarapiranga } & \multirow{2}{*}{ Observação } \\
\hline & & Bruta & Permeado & Concentrado & \\
\hline $22 / 1 / 2008$ & $\mathrm{ng} / \mathrm{L}$ & $<0.5$ & $<0.5$ & $<0.5$ & Com extração \\
\hline $29 / 1 / 2008$ & $\mathrm{ng} / \mathrm{L}$ & $<0.5$ & $<0.5$ & $<0.5$ & Com extração \\
\hline $19 / 2 / 2008$ & $\mathrm{ng} / \mathrm{L}$ & $<0.5$ & $<0.5$ & $<0.5$ & Com extração \\
\hline $25 / 2 / 2008$ & $\mathrm{ng} / \mathrm{L}$ & $<0.5$ & $<0.5$ & $<0.5$ & Com extração \\
\hline $9 / 5 / 2008$ & $\mathrm{ng} / \mathrm{L}$ & $<0.5$ & $<0.5$ & $<0.5$ & Com Extração \\
\hline $26 / 5 / 2008$ & $\mathrm{ng} / \mathrm{L}$ & $<0.5$ & $<0.5$ & $<0.5$ & Com Extração \\
\hline $10 / 6 / 2008$ & $\mathrm{ng} / \mathrm{L}$ & $<0.5$ & $<0.5$ & $<0.5$ & Com Extração \\
\hline Minimo & & $<0.5$ & $<0.5$ & $<0.5$ & \\
\hline Média & $\mathrm{ng} / \mathrm{L}$ & $<0.5$ & $<0.5$ & $<0.5$ & \\
\hline Máximo & & $<0.5$ & $<0.5$ & $<0.5$ & \\
\hline
\end{tabular}

Limite de detecção do método com o processo de extraçăo em fase sólida $=0,5 \mathrm{ng} / \mathrm{L}$

Em relação ao etinilestradiol, Tabela 5.14, nem mesmo nas amostras de concentrado foi detectada a sua preșença.

Como conseqüência da baixa freqüência de detecção dos desreguladores endócrinos no Reservatório Guarapiranga, optou-se pela realização de três ensaios com a adição de concentrações conhecidas destas substâncias. Para isto foram utilizadas soluções preparadas com padrões de 4-Nonilfenol (Riedel-de Haën - 99,9\%) e 17-beta-Estradiol (SigmaAldrich - 97\%), cedidos pela Universidade Federal de Ouro Preto - UFOP, que integra a Rede 1 - Tema Água, do PROSAB-05, e com um anticoncepcional comercial, contendo 21 drágeas com $35 \mu \mathrm{gg}$ de etinilestradiol por drágea (Diane 35 - Schering), adquirido em farmácia.

Em todos os ensaios procurou-se produzir soluções que resultassem nas concentrações finais de $150 \mu \mathrm{g} \cdot \mathrm{L}^{-1}$ de 4-nonilfenol, e $1,5 \mu \mathrm{g} \cdot \mathrm{L}^{-1}$ de $17-$ beta-estradiol e de etinilestradiol. Após a preparação de uma solução concentrada, foi feita a adição no tanque de alimentação da unidade piloto, de 500 litros, previamente preenchido com a água bruta do Reservatório Guarapiranga. Cada teste teve a duração, aproximada, de duas horas, tendo sido coletadas uma amostra da água bruta e cinco amostras de permeado e de concentrado em cada teste. Algumas das amostras foram enviadas à UFOP para análise por cromatografia liquida. 
Os resultados obtidos nos ensaios de remoção de desreguladores endócrinos pelo processo de ultrafiltração, no Reservatório Guarapiranga, realizados nos dias 24, 28 e 30 de julho de 2008, estão apresentados nas Tabelas 5.15 a 5.17 . Analisando-se os dados apresentados, pode ser observada uma discrepância entre os resultados obtidos, tanto pelo método ELISA, como por cromatografia líquida/espectrometria de massas.

Tabela 5.15 - Resultados das análises de nonilfenol para os ensaios na unidade piloto PROSAB-05

\begin{tabular}{|c|c|c|c|c|c|c|c|}
\hline \multirow{3}{*}{ Data } & \multirow{3}{*}{$\begin{array}{c}\text { Tempo após o } \\
\text { início do } \\
\text { ensaio }\end{array}$} & \multicolumn{6}{|c|}{ Concentrações $\left(\mu \mathrm{g} \cdot \mathrm{L}^{-1}\right)$} \\
\hline & & \multicolumn{2}{|c|}{ Permeado } & \multicolumn{2}{|c|}{ Concentrado } & \multicolumn{2}{|c|}{ Bruta } \\
\hline & & EPUSP & UFOP & EPUSP & UFOP & EPUSP & UFOP \\
\hline \multirow{5}{*}{$24 / 7 / 2008$} & 20 & $<5$ & 63,7 & $<5$ & 64,5 & & \\
\hline & 40 & $<5$ & NA & $<5$ & NA & & \\
\hline & 60 & $<5$ & 56,2 & $<5$ & - 51,0 & $<5$ & 67 \\
\hline & 80 & $<5$ & NA & $<5$ & NA & & \\
\hline & 100 & $<5$ & 36,4 & $<5$ & 65,3 & & \\
\hline \multirow{5}{*}{$28 / 7 / 2008$} & 20 & $<5$ & 54,2 & $<5$ & 53,5 & & . \\
\hline & 40 & $<5$ & NA & $<5$ & NA & & \\
\hline & 60 & $<5$ & 48,3 & $<5$ & 51,5 & $<5$ & 0,38 \\
\hline & 80 & $<5$ & NA & $<5$ & NA & & \\
\hline & 100 & $<5$ & 44,8 & $<5$ & 41,4 & & \\
\hline \multirow{5}{*}{$30 / 7 / 2008$} & 20 & $<5$ & 43,1 & $<5$ & 43,2 & & \\
\hline & 40 & $<5$ & NA & $<5$ & NA & & \\
\hline & 60 & $<5$ & 25,2 & $<5$ & 44,7 & $<5$ & 31,4 \\
\hline & 80 & $<5$ & NA & $<5$ & NA & & \\
\hline & 100 & $<5$ & 59,7 & $<5$ & 44,7 & & \\
\hline
\end{tabular}

No caso especifico do nonilfenol, em função do padrão utilizado, os resultados pelo método ELISA já eram esperados, pois nas ocasiões em que se tentou uma intercalibração com o método de cromatografia, utilizando-se o mesmo padrão, foi verificado que o Kit utilizado não era sensivel a este composto, ao contrário do que ocorreu quando da análise de amostras naturais. Contudo, mesmo para os resultados por cromatografia líquida/espectrometria de massas, observa-se uma discrepância nos resultados, que pode estar associada ao fato de adicionar o contaminante cin água nalural não ter sido realizado o procedimento de limpeza da amostra e extração. O valor esperado para a concentração de nonilfenol na água bruta era de $150 \mu \mathrm{g} \cdot \mathrm{L}^{-1}$. 
Tabela 5.16 - Resultados das análises de 17-beta-estradiol para os ensaios na unidade piloto PROSAB-05

\begin{tabular}{|c|c|c|c|c|c|c|c|}
\hline \multirow{3}{*}{ Data } & \multirow{3}{*}{$\begin{array}{c}\text { Tempo após o } \\
\text { início do } \\
\text { ensaio }\end{array}$} & \multicolumn{6}{|c|}{ Concentrações $\left(\mu \mathrm{g} \cdot \mathrm{L}^{-1}\right)$} \\
\hline & & \multicolumn{2}{|c|}{ Permeado } & \multicolumn{2}{|c|}{ Concentrado } & \multicolumn{2}{|c|}{ Bruta } \\
\hline & & EPUSP & UFOP & EPUSP & UFOP & EPUSP & UFOP \\
\hline \multirow{5}{*}{$24 / 7 / 2008$} & 20 & $<0.05$ & $<L D$ & $<0.05$ & $<\mathrm{LD}$ & \multirow{5}{*}{$<0.05$} & \multirow{5}{*}{64,5} \\
\hline & 40 & $<0.05$ & NA & $<0.05$ & NA & & \\
\hline & 60 & $<0.05$ & 53,8 & $<0.05$ & 48,9 & & \\
\hline & 80 & $<0.05$ & NA & $<0.05$ & NA & & \\
\hline & 100 & $<0.05$ & $<L D$ & $<0.05$ & $<L D$ & & \\
\hline \multirow{5}{*}{$28 / 7 / 2008$} & 20 & $<0.05$ & $<\mathrm{LD}$ & 0,42 & $<L D$ & \multirow{5}{*}{1,14} & \multirow{5}{*}{$<\mathrm{LD}$} \\
\hline & 40 & $<0.05$ & NA & 0,27 & NA & & \\
\hline & 60 & $<0.05$ & 46,5 & 0,68 & 49,5 & & \\
\hline & 80 & $<0.05$ & NA & 0,27 & NA & & \\
\hline & 100 & $<0.05$ & 42,9 & 0,31 & $<\mathrm{LD}$ & & \\
\hline \multirow{5}{*}{$30 / 7 / 2008$} & 20 & $<0.05$ & 41,2 & $<0.05$ & 41,5 & \multirow{5}{*}{0,2} & \multirow{5}{*}{$<L D$} \\
\hline & 40 & $<0.05$ & NA & $<0.05$ & NA & & \\
\hline & 60 & $<0.05$ & 23,9 & $<0.05$ & 42,9 & & \\
\hline & 80 & $<0.05$ & NA & $<0.05$ & NA & & \\
\hline & 100 & $<0.05$ & 57,3 & $<0.05$ & 42,9 & & \\
\hline
\end{tabular}

$\mathrm{LD}=1,5 \mu \mathrm{g} \cdot \mathrm{L}^{-}$

$\mathrm{NA}=$ não analisada

Tabela 5.17 - Resultados das análises de etinilestradiol para os ensaios na unidade piloto PROSAB-05

\begin{tabular}{|c|c|c|c|c|c|c|c|}
\hline \multirow{3}{*}{ Data } & \multirow{3}{*}{$\begin{array}{c}\text { Tempo após } \\
\text { o início do } \\
\text { ensaio }\end{array}$} & \multicolumn{6}{|c|}{ Concentrações $\left(\mu \mathrm{g} \cdot \mathrm{L}^{-1}\right)$} \\
\hline & & \multicolumn{2}{|c|}{ Permeado } & \multicolumn{2}{|c|}{ Concentrado } & \multicolumn{2}{|c|}{ Bruta } \\
\hline & & EPUSP & UFOP & EPUSP & UFOP & EPUSP & UFOP \\
\hline \multirow{5}{*}{$24 / 7 / 2008$} & 20 & 0,11 & 0,77 & 0,07 & 1,38 & \multirow{5}{*}{$<0.05$} & \multirow{5}{*}{0,77} \\
\hline & 40 & 0,17 & NA & 0,14 & NA & & \\
\hline & 60 & $<0.05$ & 0,59 & 0,18 & 0,8 & & \\
\hline & 80 & $<0.05$ & NA & 0,15 & NA & & \\
\hline & 100 & $<0.05$ & 1,13 & 0,29 & 0,54 & & \\
\hline \multirow{5}{*}{$28 / 7 / 2008$} & 20 & 0,24 & 0,45 & 0,98 & 2,99 & \multirow{5}{*}{1,80} & \multirow{5}{*}{$<\mathrm{LQ}$} \\
\hline & 40 & $<0.05$ & NA & 1,76 & NA & & \\
\hline & 60 & 0,07 & $<\mathrm{LQ}$ & 2,82 & 0,93 & & \\
\hline & 80 & 0,11 & NA & 1,18 & NA & & \\
\hline & 100 & $<0.05$ & 0,41 & 1,36 & 0,49 & & \\
\hline \multirow{5}{*}{$30 / 7 / 2008$} & 20 & $<0.05$ & 0,82 & 0,24 & 0,89 & \multirow{5}{*}{0,31} & \multirow{5}{*}{0,69} \\
\hline & 40 & $<0.05$ & NA & 1,15 & NA & & \\
\hline & 60 & $<0.05$ & 1,15 & 0,18 & 0,37 & & \\
\hline & 80 & 0,32 & NA & $<0.05$ & NA & & \\
\hline & 100 & $<0.05$ & 3,67 & $<0.05$ & 1,19 & & \\
\hline
\end{tabular}

$\mathrm{L} \mathrm{Q}=5 \mu \mathrm{g} \mathrm{L}^{-1}$ (houve problemas para concentraçăo da amostra).

NA = nâa analisada

Em relação aos resultados para estrogênios, neste caso 17-beta-estradiol, observa-se que a discrepância entre os resultados da EPUSP e UFOP foi 
muito maior. A concentração esperada deste contaminante na água bruta era de $1,5 \mu \mathrm{g} \cdot \mathrm{L}^{-1}$. Por fim, verifica-se que os resultados das análises de etiniestradiol foram as que apresentaram menor divergência, porém ela ainda foi significativa. Da mesma forma que para o 17-beta-estradiol, a concentração esperada de etinilestradiol na água bruta era de $1,5 \mu \mathrm{g} \cdot \mathrm{L}^{-1}$. Apenas para efeito de uma avaliação preliminar, tomando-se como base os resultados da EPUSP, para as análises de 17-beta-estradiol e etinilestradiol, do dia 28/07/2008, uma vez que os valores de concentração na água bruta estiveram próximos ao valor esperado. Estes resultados mostram que a unidade de ultrafiltração foi capaz de remover tais desreguladores endócrinos, mesmo com o concentrado apresentando valores de concentração, na maioria das amostras, inferiores à alimentação. Tomando-se como base os valores encontrados no permeado e a concentração na água bruta, obtem-se eficiências médias de remoção de $95,6 \%$ e $94,2 \%$ para o 17-beta-estradiol e para o etinilestradiol, respectivamente. Um aspecto a ser observado é que os valores utilizados nos ensaios são significativamente superiores aos encontrados naturalmente nos mananciais, exigindo cautela na sua interpretação.

Em relação ao etinilestradiol, verifica-se uma concordância com os resultados obtidos no ensaio realizado durante a operação da unidade piloto $P R O S A B-04$, quando a eficiência de remoção foi superior a $76,7 \%$. Como no PROSAB-05 o PMC da membrana utilizada foi superior ao da membrana utilizada no PROSAB-04, a hipótese de remoção indireta do etinilestradiol torna-se mais consistente. $O$ mesmo pode ser inferido para o 17-beta-estradiol.

Um estudo desenvolvido por Jermann e colaboradores (2008), sobre a influência da matéria orgânica natural na remoção de lbuprofen e estradiol por ultrafiltração, uilizando membranas de polietersulfona (PES), com PMC de $100.000 \mathrm{~g} \cdot \mathrm{mol}^{-1}$, mostrou que a retenção de estradiol pode ter um acréscimo de até $40 \%$, na presença de MON. Membranas com carácter 
hidrofóbico, como o caso da membrana de PES, podem adsorver centenas de miligramas de estradiol por metro quadrado.

Assim, para uma avaliação mais precisa da eficiência de remoção dos perturbadores endócrinos pelo processo de ultrafiltração é necessário realizar um ensaio de maior duração, com dosagem contínua dessas substâncias.

Os resultados obtidos com o desenvolvimento do projeto PROSAB-05 permitem concluir que o processo de ultrafiltração apresenta grande potencial para utilização em sistemas de tratamento de água para abastecimento, complementando e ratificando os dados obtidos no projeto PROSAB-04

5.3.3. Avaliação da presença de perturbadores endócrinos em mananciais da RMSP e impactos sobre a saúde pública

Além do monitoramento de desreguladores endócrinos no Reservatório Guarapiranga também foi feita a avaliação no Rio Cotia, em um ponto a montante da Estação de Tratamento Baixo Cotia e no Reservatório Billings, junto à estação elevatória de Pedreira.

Foi detectada a presença de estrogênios naturais e do nonilfenol, com maior freqüência no Rio Cotia e Reservatório Billings, enquanto que no Reservatório Guarapiranga, em apenas uma das amostras foi possível detectar a presença de estrogênios. A concentração de nonilfenol variou de 51 a $2.185 \mathrm{ng} \cdot \mathrm{L}^{-1}$, enquanto a concentraçäo de estrogênios variou de 0,72 a $17,1 \mathrm{ng} \cdot \mathrm{L}^{-1}$. A concentração de etinilestradiol, nos três mananciais, sempre esteve abaixo do limite de detecção do método, que com o processo de exiração em fase sólida chaga a $0,5 \mathrm{ng} \cdot \mathrm{L}^{-1}$. Os resultacios obtidos nas análises estão apresentados nas Tabelas 5.18 e 5.19. 
Tabela 5.18 - Resultado do monitoramento de nonilfenol

\begin{tabular}{|c|c|c|c|c|}
\hline \multirow{2}{*}{ Data } & \multicolumn{3}{|c|}{ Concnetração (ng. $\left.\mathrm{L}^{-1}\right)$} & \multirow{2}{*}{ Observação } \\
\hline & Guarapiranga & Billings & Baixo Cotia & \\
\hline $10 / 1 / 2008$ & $<50$ & $<50$ & $<50$ & Com extração \\
\hline $15 / 1 / 2008$ & $<50$ & 115 & 51 & Com extração \\
\hline $22 / 2 / 2008$ & $<50$ & 96 & $<50$ & Com extração \\
\hline $29 / 2 / 2008$ & $<50$ & 114 & 841 & Com extração \\
\hline $9 / 5 / 2008$ & $<50$ & 1057 & NA & Com extração \\
\hline $26 / 5 / 2008$ & $<50$ & 295 & 982 & Com extração \\
\hline $10 / 6 / 2008$ & $<50$ & 1168 & 1719 & Com extração \\
\hline $1 / 7 / 2008$ & $<50$ & 1767 & 2185 & Com extração \\
\hline Minimo & $<50$ & $<50$ & $<50$ & \\
\hline Média & $<50$ & 659 & 1156 & \\
\hline Máximo & $<50$ & 1767 & 2185 & \\
\hline Desvio Padrão & ND & 669 & 826 & \\
\hline
\end{tabular}

Tabela 5.19 - Resultados do monitoramento de estrogênios

\begin{tabular}{|c|c|c|c|c|}
\hline \multirow{2}{*}{ Data } & \multicolumn{3}{|c|}{ Concnetração (ng. $\left.\mathrm{L}^{-1}\right)$} & \multirow{2}{*}{ - Observação } \\
\hline & Guarapiranga & Billings & Baixo Cotia & \\
\hline $12 / 11 / 2007$ & $<0.5$ & 0,83 & 2,28 & Com extração \\
\hline $14 / 1 / 2008$ &.$<0.5$ & $<0.5$ & $<<0.5$ & Com extração \\
\hline $22 / 1 / 2008$ & $<0.5$ & 1,47 & 1,71 & Com extração \\
\hline $29 / 1 / 2008$ & $<0.5$ & 1,11 & 1,17 & Com extração \\
\hline $9 / 5 / 2008$ & $<0.5$ & $<0.5$ & $<0.5$ & Com extração \\
\hline $26 / 5 / 2008$ & $<0.5$ & 0,80 & $<0,5$ & Com extração \\
\hline $10 / 6 / 2008$ & $<0.5$ & $<0.5$ & $<0,6$ & Com extraçāo \\
\hline $1 / 7 / 2008$ & 7,5 & 17,1 & 6,6 & Com extração \\
\hline Mínimo & $<0.5$ & $<0.5$ & $<0.5$ & \\
\hline Média & 7,5 & 6,56 & 3,16 & \\
\hline Máximo & 7,5 & 17,1 & 6,6 & \\
\hline Desvio Padrão & ND & 9,1 & 3,0 & \\
\hline
\end{tabular}

A faixa de concentração de nonilfenol obtida neste estudo é similar aos valores reportados por Moreira (2008), Raimundo (2007), Mibu et al. (2004) e Solé et al. (2000), mas é menor que a faixa de concentração reportada por Ghiselli (2006), Yang, Luan e Lan (2006) e Lagana et al. (2004).

Os valores de concentração obtidos para o estradiol e estrogênios estão de acordo com os valores relatados na maioria dos trabalhos relacionados ao monitoramento destas substâncias, conforme levantamento elaborado por Moreira (2008). A mesma consideração pode ser feita para o etinilestradiol que é, normalmente, de difícil detecção e está presente 
sempre em menor concentração quando comparado com o estradiol e estrogênios.

Pelos resultados obtidos, verifica-se que ocorre a presença de perturbadores endócrinos nos mananciais da RMSP, assim como em outros manancias utilizados para abastecimento, em diversas regiões do país. Contudo, a simples presença de perturbadores endórcinos nos mananciais não implica em um dano à saúde dos consumidores, sendo necessário realizar uma avaliação de risco para uma avaliação mais precisa.

$\mathrm{Na}$ Figura 5.17 é apresentado um diagrama esquemático de um procedimento para a avaliação e caracterização de riscos, associados aos desreguladores endócrinos, proposto por Knacker et al. (2006).

Para se adotar este procedimento é necessário ter disponível as concentrações dos pertubadores endócrinos na água e as concentrações de efeito não observado, que são obtidas por estudos epidemiológicos.

O documento preparado pelo IPCS (WHO, 2002 - Chapter 5, p. 63), apresenta as faixas de dose de desregulador endócrino que resultaram em efeitos adversos nas cobaias utilizadas nos testes, pela exposição intraperitoneal para o noniffenol e oral para o estradiol e etinilestradiol. Os valores para efeitos observados são apresentados abaixo:

- Nonilfenol

- Estradiol

- Etinilestradiol $\rightarrow 0,8$ a $8 \mathrm{mg} \cdot \mathrm{kg}^{-1} \cdot \mathrm{d}^{-1}$

$\rightarrow 0,82$ a $4,12 \mathrm{mg} \cdot \mathrm{kg}^{-1} \cdot \mathrm{d}^{-1}$;

$\rightarrow 0,02$ a $2 \mu \mathrm{g} \cdot \mathrm{kg}^{-1} \cdot \mathrm{d}^{-1}$.

Os menores valores apresentados podem ser admitidos como sendo as menores doses para efeito observado, portanto, de acordo com 0 procedimento da Organização Mundial da Saúde - OMS (WHO, 2006), é possivel estimar concentração de efeito não observado (CENO) para os desreguladores endócrinos em questão, em função do consumo de água. 
Б

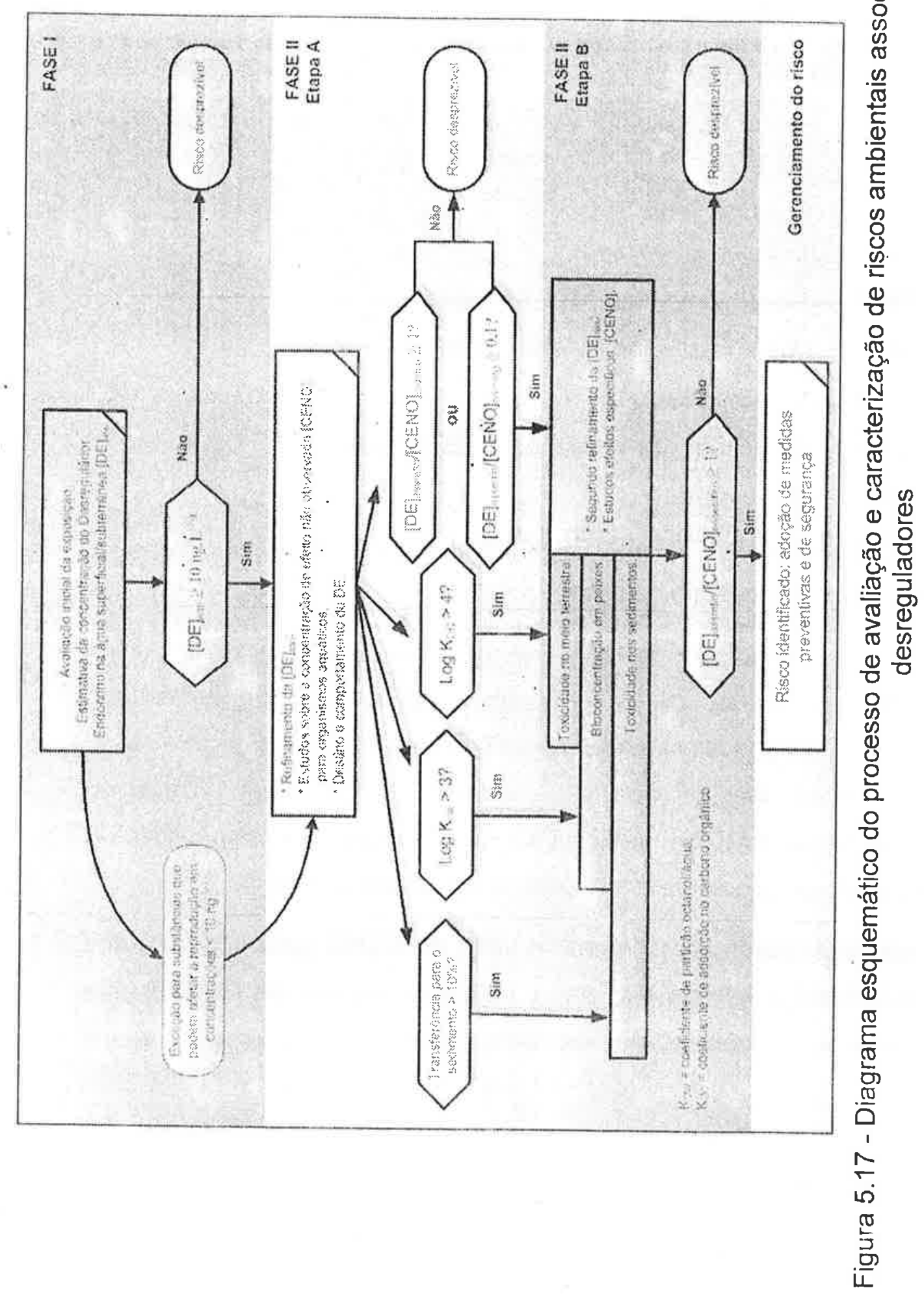


Adaptando-se o procedimento da OMS, os valores de CENO para substâncias químicas são obtidos pelas relações apresentadas a seguir:
DDA $=($ DENO ou MDEO $) / F I$
equação 5.2
$\mathrm{CENO}=\left(\mathrm{DDA}^{*} \mathrm{MC} \mathrm{C}^{*} \mathrm{FA}\right) / \mathrm{C}$
equação 5.3

Onde:

- DDA - Dose diária aceitável;

- DENO - Dose para efeito não observado;

- MDEO - Menor dose para efeito observado;

- Fl-Fator de incerteza;

- CENO - Concentração para efeito não observado

- MC - Peso corpóreo;

- FA - Fração da IDT atribuída à água;

- C - Consumo diário de água.

Como para os mananciais monitorados na RMSP não foram obtidos resultados, para o etinilestradiol, acima do limite de detecção do metódo utilizado, serão considerados na avaliação os resultados obtidos no estudo de Moreira (2008), relativos ao monitoramento de mananciais da RMBH, uma vez que estes foram obtidos no âmbito do PROSAB-05.

Para que seja possivel determinar o valor do CENO para cada um dos desreguladores é necessário, ainda, definir os valores de FI e FA que serão utilizados, bem como estabeler qual o grupo crítico para a exposição. Apenas para efeito de avaliação, em função das muitas incertezas associadas à obtenção, principalmente, de FA, uma vez que este pode variar de 0 (zero) a 1 (um), a Tabela 5.20 apresenta os possiveis valores da CENO para os desremuladores endócrinos considerados no estudo desenvolvido, adotando-se um valor de $\mathrm{Fl}$ igual a 100, conforme recomendado pelo OMS (WHO, 2006). 
Tabela 5.20 - Valores de CENO para Nonilfenol, 17-beta-Estradiol e Etinilestradiol

\begin{tabular}{|c|c|c|c|c|c|c|c|c|c|}
\hline \multirow{3}{*}{ FA } & \multicolumn{9}{|c|}{ CENO } \\
\hline & \multicolumn{3}{|c|}{ Nonilfenol $\left(\mu \mathrm{g} \cdot \mathrm{L}^{-1}\right)$} & \multicolumn{3}{|c|}{ 17-beta-Estradiol ( $\mu \mathrm{g} \cdot \mathrm{L}^{-1}$ ) } & \multicolumn{3}{|c|}{ Etinilestradiol (ng. $\mathrm{L}^{-1}$ ) } \\
\hline & Bebês & Crianças & Adultos & Bebês & Crianças & Adultos & Bebês & Crianças & Adultos \\
\hline 0,1 & 5,33 & 8,00 & 24,00 & 5,47 & 8,20 & 24,60 & 0,13 & 0,20 & 0,60 \\
\hline 0,2 & 10,67 & 16,00 & 48,00 & 10,93 & 16,40 & 49,20 & 0,27 & 0,40 & 1,20 \\
\hline 0,3 & 16,00 & 24,00 & 72,00 & 16,40 & 24,60 & 73,80 & 0,40 & 0,60 & 1,80 \\
\hline 0,4 & 21,33 & 32,00 & 96,00 & 21,87 & 32,80 & 98,40 & 0,53 & 0,80 & 2,40 \\
\hline 0,5 & 26,67 & 40,00 & 120,00 & 27,33 & 41,00 & 123,00 & 0,67 & 1,00 & 3,00 \\
\hline 0,6 & 32,00 & 48,00 & 144,00 & 32,80 & 49,20 & 147,60 & 0,80 & 1,20 & 3,60 \\
\hline 0.7 & 37,33 & 56,00 & 168,00 & 38,27 & 57,40 & 172,20 & 0,93 & 1,40 & 4,20 \\
\hline 0,8 & 42,67 & 64,00 & 192,00 & 43,73 & 65,60 & 196,80 & 1,07 & 1,60 & 4,80 \\
\hline 0,9 & 48,00 & 72,00 & 216,00 & 49,20 & 73,80 & 221,40 & 1,20 & 1,80 & 5,40 \\
\hline 1,0 & 53,33 & 80,00 & 240,00 & 54,67 & 82,00 & 246,00 & 1,33 & 2,00 & 6.00 \\
\hline Massa Corpórea (kg) & 5,00 & 10,00 & 60,00 & & & & & & \\
\hline Consumo de água (L) & 0,75 & 1.00 & 2,00 & & & & & & \\
\hline
\end{tabular}

Com base nos valores de concentração para o efeito não observado apresentados na Tabela 5.20 e valores de concentração de desreguladores endócrinos encontrados nos mananciais estudados nas Regiões Metropolitanas de Belo Horizonte e de São Paulo, é possivel fazer a caracterização dos riscos destes poluentes. Utilizando-se os maiores resultados obtidos no monitoramento dos mananciais da RMBH e da RMSP, ou seja, pior cenário em termos da análise de risco, obtém-se a Tabela 5.21.

Tabela 5.21 - Relação entre as concentrações máximas dos desreguladores endócrinos identificados nos mananciais da RMBH e RMSP e valores da CENO

\begin{tabular}{|c|c|c|c|c|c|c|c|c|c|}
\hline \multirow{3}{*}{ FA } & \multicolumn{9}{|c|}{ Relaçāo [DE] $]_{\mathrm{AS}} / \mathrm{CENO}$} \\
\hline & \multicolumn{3}{|c|}{ Nonilfenol } & \multicolumn{3}{|c|}{ 17-beta-Estradiol } & \multicolumn{3}{|c|}{ Etinilestradiol } \\
\hline & Bebês & Criancas & Adultos & Bebês & Crianças & Adultos & Bebês & Crianças & Adultos \\
\hline 0,1 & 0.41 & 0,27 & 0,09 & 0,01 & 0,00 & 0,00 & 405,00 & 270,00 & 90,00 \\
\hline 0,2 & 0,20 & 0,14 & 0,05 & 0,00 & 0,00 & 0,00 & 202,50 & 135,00 & 45,00 \\
\hline 0,3 & 0,14 & 0,09 & 0,03 & 0,00 & 0,00 & 0,00 & 135,00 & 90,00 & 30,00 \\
\hline 0,4 & 0,10 & 0,07 & 0,02 & 0,00 & 0,00 & 0,00 & 101,25 & 67,50 & 22,50 \\
\hline 0,5 & 0,08 & 0,05 & 0,02 & 0,00 & 0,00 & 0,00 & 81,00 & 54,00 & 18,00 \\
\hline 0,6 & 0,07 & 0,05 & 0,02 & 0,00 & 0,00 & 0,00 & 67,50 & 15,00 & 15,00 \\
\hline 0,7 & 0,06 & 0,04 & 0,01 & 0,00 & 0.00 & 0,00 & 57,86 & 38,57 & 12,86 \\
\hline 0,8 & 0,05 & 0,03 & 0,01 & 0,00 & 0,00 & 0,00 & 50,63 & 33,75 & 11,25 \\
\hline 0,9 & 0,05 & 0,03 & 0,01 & 0,00 & 0.00 & 0,00 & 45,00 & 30,00 & 10,00 \\
\hline 1,0 & 0,04 & 0,03 & 0,01 & 0,00 & 0,00 & 0,00 & 40,50 & 27,00 & 9,00 \\
\hline $\begin{array}{l}\text { Concentração } \\
\text { considerada para } \\
\text { avaliaçäo (ng. } \mathrm{L}^{-1} \text { ) }\end{array}$ & \multicolumn{3}{|c|}{2.185} & \multicolumn{3}{|c|}{36,8} & \multicolumn{3}{|c|}{54} \\
\hline
\end{tabular}

Considerando-se os fatores de inceiteza utilizados para a determinação dos valores da CENO, propõem-se os valores apresentados na Tabela 5.22 para caracterização de riscos associados aos desreguladores endócrinos, contemplados neste estudo. 
Tabela 5.22 - Proposta para caracterização de riscos associados à presença de desreguladores endócrinos em mananciais de abastecimento

\begin{tabular}{cc}
\hline Relação [DE] $]_{\text {AS }} /$ CENO & Risco \\
\hline$<0,01$ & Inexistente \\
0,01 a 0,1 & Desprezível \\
0,1 a 1,0 & Baixo \\
1 a 10 & Moderado \\
10 a 100 & Médio \\
$>100$ & Alto \\
\hline
\end{tabular}

Embora não seja comum a utilização do termo inexistente para riscos, neste trabalho esta indicação foi utilizada para que fosse possivel contemplar o maior fator de incerteza que pode ser considerado pelo método proposto pela OMS, que é 10.000 .

Comparando-se os valores ápresentados nas Tabelas 5.21 e 5..22, verifica-se que a relevância dos desreguladores para a água de abastecimento público é, em ordem decrescente, etinilestradiol, nonilfenol e 17-beta-estradiol. Para estes desreguladores, o grupo mais crítico é o dos bebês, em primeiro lugar por ser o grupo sujeito à maior exposição $e$ em segundo, pelo fato dos efeitos dos desreguladores endócrinos ser mais relevante para os organismos em que o sistema endócrino ainda esteja em desenvolvimento.

Uma vez feita a caracterização do risco associado aos desreguladores endócrinos, torna-se necessário desenvolver estratégias para gerenciar este risco. No caso especifico da água para abastecimento público, esta estratégia passa, necessariamente, pela adoção de tecnologias de tratamento que sejam capazes de remover estes contarninantes.

No estudo em questăo, para que sejá posível atingir um nível de risco aceitável, [DE] as/CENO, considerando-se o grupo crítico, a tecnologia de tratamento a ser adotada deve ter uma eficiência para a remoção de etiniestradiol superior a $97,5 \%$ para a condiçấo mais favoravel e $99,8 \%$ para a mais crítica, ou seja, o log de remoção deve estar compreendido entre 1,61 e 2,6 . 
Embora os resultados obtidos com o desenvolvimento dos ensaios na unidade pilto de ultrafiltração, tanto no PROSAB-04, como no PROSAB-05, tenham indicado valores de remoção para o etinilestradiol superiores a $76 \%$ e 94\%, o que é um indicativo do potencial de aplicação desta tecnologia, são necessários estudos mais aprofundados. De qualquer forma, o sistema convencional de tratamento de água, segundo Moreira (2008), não é suficiente, pois no monitoramento da água tratada de três mananciais avaliados foi detectada a presença de etinilestradiol e nonilfenol, antes da etapa de desinfecção.

\subsection{Avaliação preliminar de custos do processo de ultrafiltração para tratamento de água de abastecimento}

Como um dos produtos obtidos no desenvolvimento do projeto de pesquisa no âmbito do PROSAB-04, foi feita uma avaliação preliminar de custos da utilização do sistema de ultrafilração, para uma estação de tratamento com capacidade de $100 \mathrm{~L} . \mathrm{s}^{-1}$, suficente para abastecer 43.200 pessoas, comparando o custo de instalação e operação com os sistemas convencional e convencional com carvão ativado (MIERZWA et al., 2008). Com o resultado deste estudo, foi obtida a curva do custo do metro cúbico da água tratada em função do tempo de amortização do investimento, Figura 5.18, sendo os valores referentes a março de 2006.

Pela análise da Figura 5.18 verifica-se que o custo de tratamento pelo sistema de ultrafiltração é superior ao convencional, porém fica próximo do custo do sistema convencional, complementado com carvão ativado. A inclusão do sistema de carvão ativado ao sistema convencional na comparação se justifica pelo fato deste arranjo possibilitar a obtenção de uma água com qualidade mais próxima àquela obtida pelo processo de ultrafiltração. 
É importante destacar, também, que no custo do sistema de ultrafiltração, o item mais oneroso são as membranas, conforme pode ser verificado na Figura 5.19, uma vez que estas devem ser importadas.

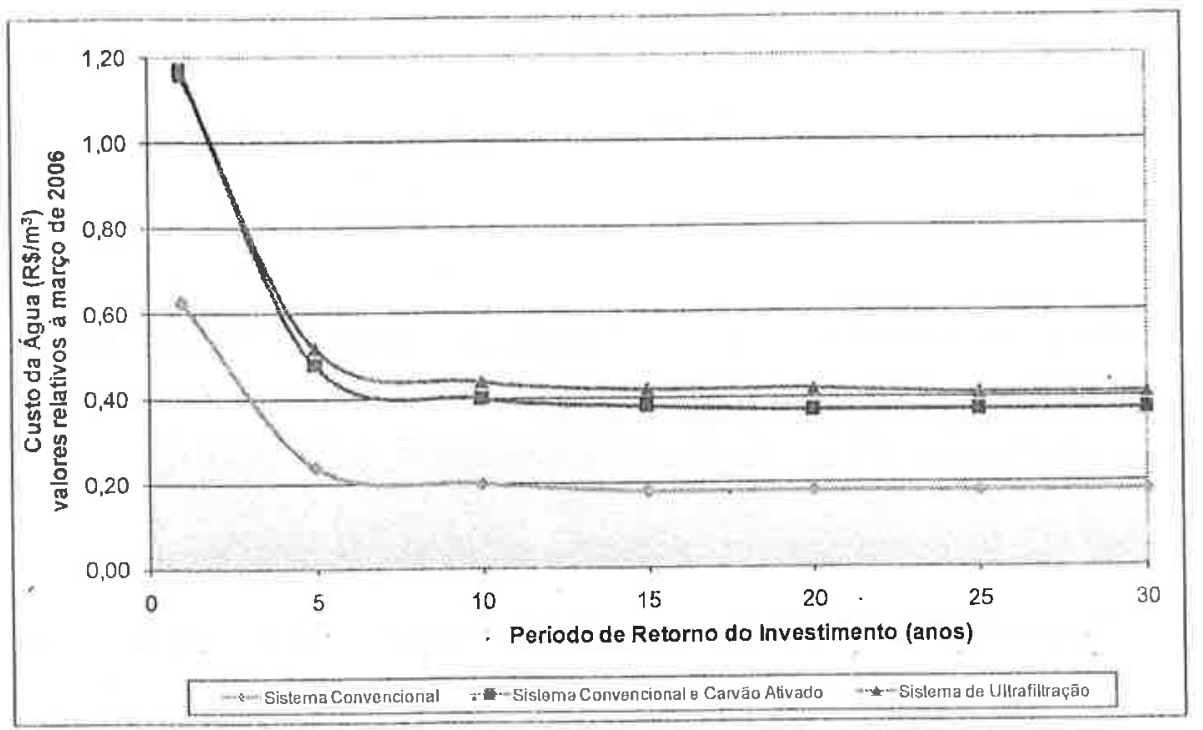

Figura 5.18 - Comparação do custo de tratamento de água pelos processos de ultrafiltração, convencional e convencional com carvão ativado

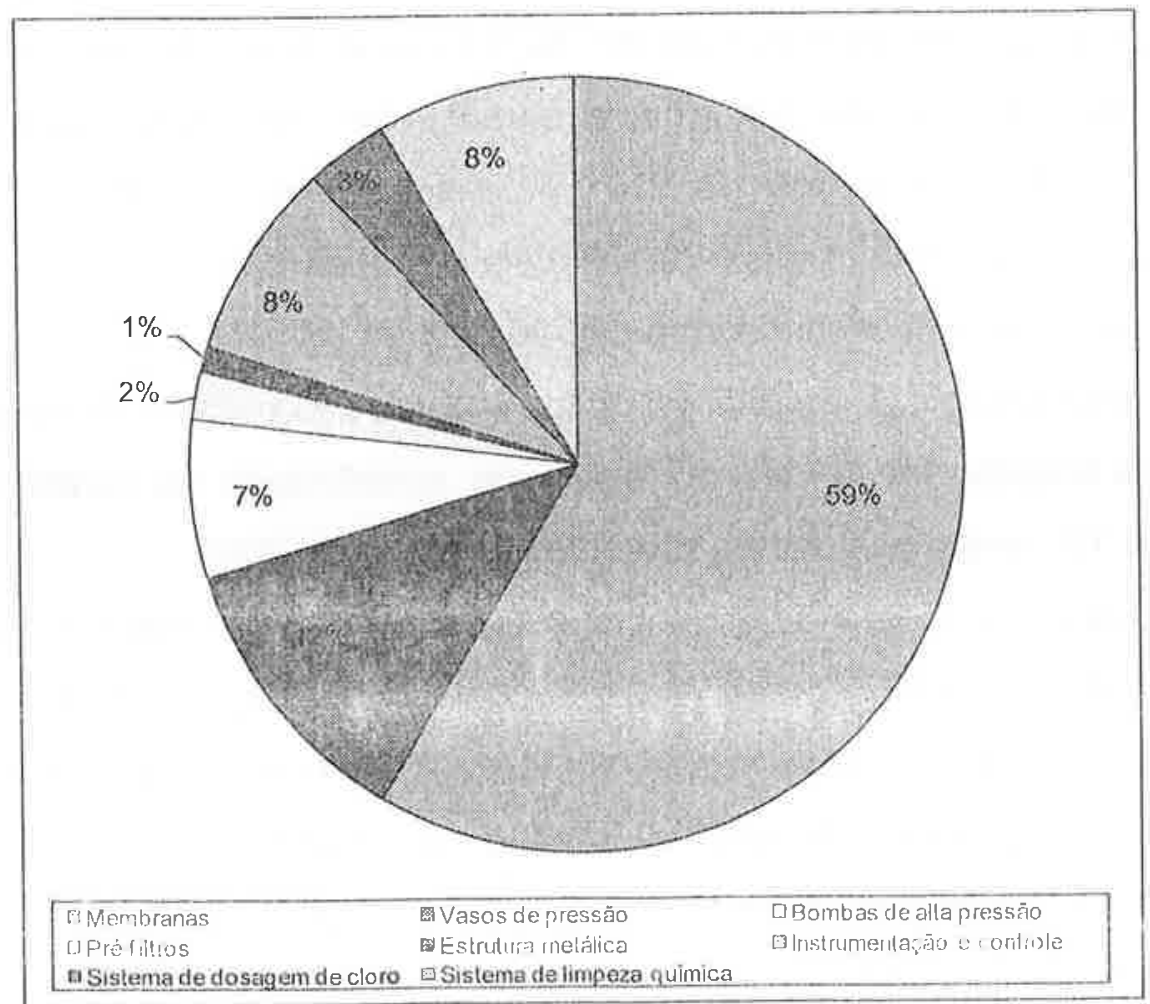

Figura 5.19 - Composição dos custos do sistema de ultrafiltração PROSAB-04 
Com base nos resultados obtidos no desenvolvimento do projeto no âmbito do PROSAB-05, da composição de custos da Figura 5.19 e consulta a um fornecedor de membranas, foi desenvolvida uma planilha para dimensionamento e cálculo do custo de sistemas de ultrafiltração. Os resultados estão apresentados nas Figuras 5.20 a 5.25, considerando-se os valores em dólares. Os custos de produtos químicos, energia, insumos, montagem e mão de obra foram obtidos através de consulta a fornecedores e à SABESP.

Dados de Entrada:

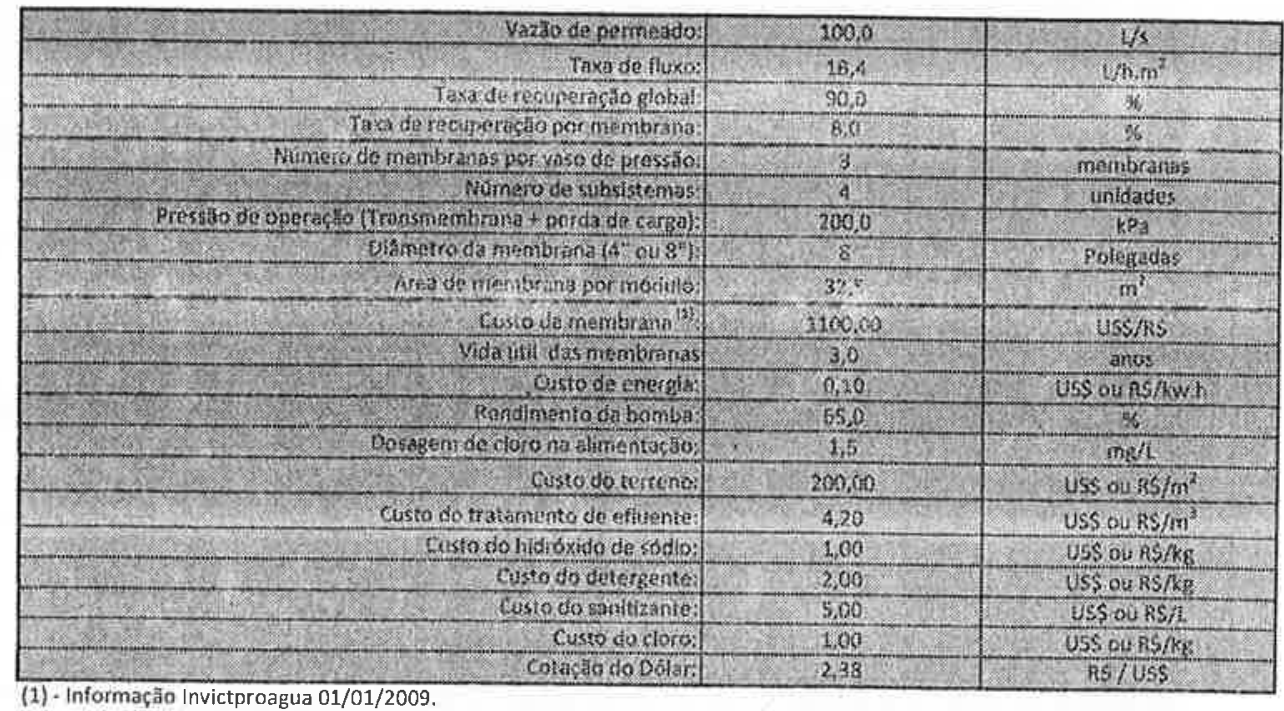

Figura 5.20 - Planilha de entrada de dados para cálculo do sistema de ultrafiltração

Resultados por Subsistema:

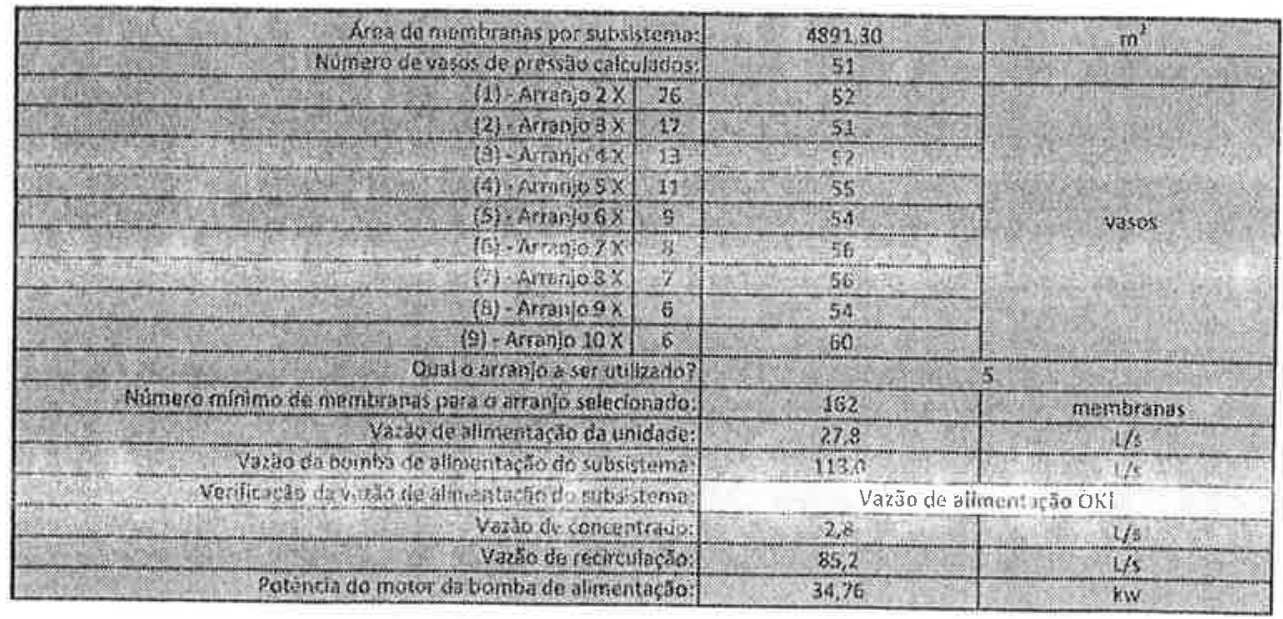

Figura 5.21 - Planilha com os resultados do dimensionamento do sistema de ultrafiltração 


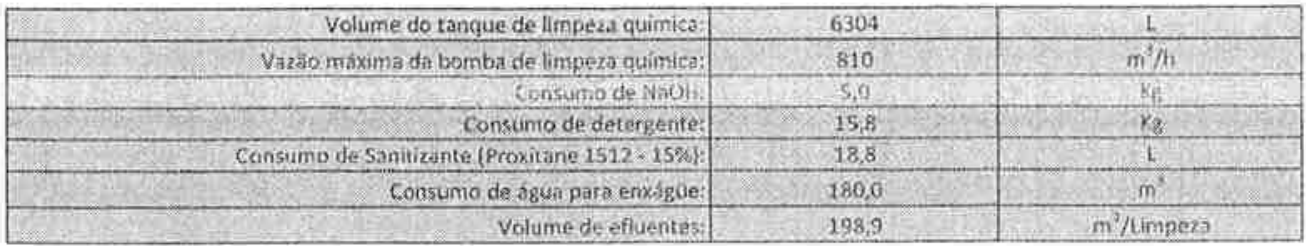

Figura 5.22 - Planilha do dimensionamento do sistema de limpeza química e cálculo do consumo de reagentes

Eustos:

\begin{tabular}{|c|c|c|c|}
\hline D. & Membranas: & $178.200,00$ & USS/RS \\
\hline & Custo de enerigas: & 0,04 & USS Su RS/m \\
\hline & Custo do cleno: & $1,314,00$ & USS OU RS ano \\
\hline & 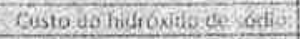 & (fo) 52 & 155 uufotane \\
\hline 3 & Gusto do detervents: & 378,80 & USs ou RStone \\
\hline & Custo do Santizante & 1.125 .76 & USS outps/ano \\
\hline
\end{tabular}

Figura 5.23 - Planilha dos custos associados ao sistema de ultrafiltração

Custa do Sistema:

\begin{tabular}{|c|c|c|c|}
\hline Componento & 8 & Custo (USS / RS) & Custo Total RSS / RS) \\
\hline Membrallas & 58,3 & $178,200,00$ & 712300,00 \\
\hline Vasos de pressio & 11.7 & 35762,26 & 143049,06 \\
\hline  & 5,6 & 2017358 & 80594.34 \\
\hline Fre-illeros & 2,0 & $6,117,21$ & $2 ; 45 \% 8 \%$ \\
\hline Estrutula svetálicics & 1,5 & 458291 & $13,359,52$ \\
\hline instrungentaça e controlez & \&,2 & $25,064,15$ & $100,256,30$ \\
\hline Sistenia da dosagen de rloro & 3,4 & 10,39265 & 41,50958 \\
\hline Sistema de limpeź quimaca & 8,2 & & 10: 258,60 \\
\hline Subtotal & 80 & $305,650,36$ & $1.222 .841,51$ \\
\hline Conslícuca a montajgen & 20,0 & $81.1320 \mathrm{~s}$ & $24452 a .30$ \\
\hline Custo flo terreno(250 n!? & & 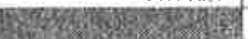 & 50,00000 \\
\hline Custo Total do Sistenaa & & $369.792,45$ & $9.5 \% 7.159,5 \%$ \\
\hline
\end{tabular}

Figura 5.24 - Planitha com o custo de investimento da unidade de ultrafiltração

Custo de Operação

\begin{tabular}{|l|r|}
\hline \multicolumn{1}{|c|}{$\quad$ Item } & Custo anual (US\$ / RS) \\
\hline Mão de obra & $40.956,84$ \\
\hline Produtos químicos & $11.514,16$ \\
\hline Reposiçũo de membranas & $237.600,00$ \\
\hline Custo com energia $^{\text {Custo de disposição de efluentes }}{ }^{\text {a }}$ & $116.054,80$ \\
\hline Custo total de operaçáo & $10.025,21$ \\
\hline
\end{tabular}

a - Disposição do efluente da limpeza química no sistema de esgotos.

Figura 5.25 - Planilha com os custos de operação 
Com base nos valores apresentados é possivel obter o custo do tratamento da água por ultrafiltração, relativo ao PROSAB-05, que é próximo de US $\$ 0,20$ (vinte centavos de dólares), a partir de um periodo de retorno de 15 anos, conforme mostrado na Figura 5.26. Foi considerado no cálculo que a substituição das membranas seria efetuada a cada três anos.

É importante mencionar que a estimativa do custo de tratamento do sistema de ultrafiltração para o PROSAB-05, está muito próxima daquela obtida para o sistema do PROSAB-04, ressaltando-se que as membranas, por serem importadas, são as que resultam em maior impacto no custo do sistema.

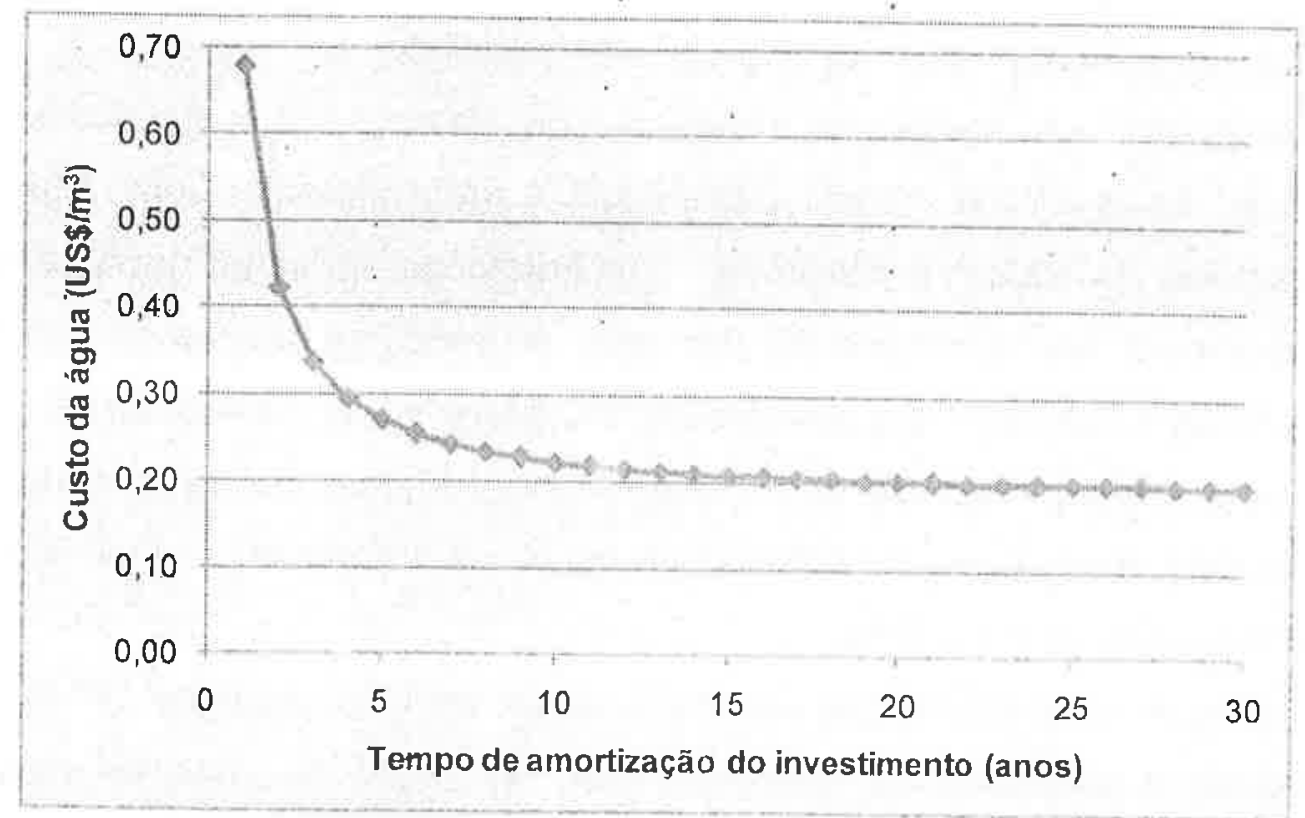

Figura 5.26 - Custo do tratamento de água por ultrafiltração PROSAB-05 


\section{CONCLUSÕES}

Devido aos atuais problemas de poluição dos mananciais utilizados para abastecimento público, o que é confirmado pelos dados sobre a quantidade de substâncias e compostos químicos disponiveis no mercado e baixos índices de coleta e tratamento de esgotos, foi constatado que o tratamento de água para abastecimento é um grande desafio na atualidade.

O monitoramento do nonilfenol, de estrogênios naturais e de etinilestradiol, no âmbito do Programa de Pesquisa em Saneamento Básico, revelou que estas substâncias estão presentes em alguns manancias da RMSP e RMBH em concentrações variadas, na faixa de nanogramas até microgramas por litro. A presença destas, e outras substâncias químicas nos mananciais, caracterizam um perigo para o ser humano, considerando-se que a maioria das estações de tratamento de água para abastecimento utiliza o processo convencional, o qual não é eficiente para sua remoção.

A avaliação e caracterização dos riscos associados ao nonilfenol, 17-betaestradiol e etinilestradiol revelaram que, do ponto de vista de saúde pública, o etinilestradiol e o nonilfenol, respectivamente, são os que despertam maior preocupação, principalmente para o grupo de bebês, que foi caracterizado como o mais critico. Para o etinilestradiol, considerando-se a faika de concentração encontrada nos mananciais da $\mathrm{RMBH}$, verificou-se que a eficiência de remoção a ser atingida pelos sistemas de tratamento de água deve ser superior a $97,5 \%$ para a condição mais favorável e $99,8 \%$ para a mais crítica.

Como resultado do desenvolvimento de dois projetos de pesquisa no âmbito do Programa de Pesquisa em Saneamento Básico, editais $n^{\circ} 04$ e 
$n^{\circ}$ 05, através da instalação e operação de uma unidade piloto no Reservatório Guarapiranga foi possivel concluir que:

O processo de ultrafiltração, utilizando membranas enroladas em espiral, é uma tecnologia com grande potencial para aplicação no tratamento de água para abastecimento.

A operação contínua da unidade piloto, totalizando 7.866 horas no PROSAB-04 e 10.600 horas no PROSAB-05, utilizando membranas com PMC de corte de 3.500 e $10.000 \mathrm{~g} \cdot \mathrm{mol}^{-1}$, respectivamente, resultou em taxas médias de fluxo de $21,47 \mathrm{~L} \cdot \mathrm{h}^{-1} \cdot \mathrm{m}^{-2}$, com pressão de $418,3 \mathrm{kPa}$, e $18,39 \mathrm{~L} \cdot \mathrm{h}^{-1} \cdot \mathrm{m}^{-2}$, com pressão de $160,9 \mathrm{kPa}$. Os valores da taxa de fluxo encontram-se dentro das faixas especificadas pelos fornecedores das membranas.

Foi verificado que a utilização de procedimentos operacionais adequados, como dosagem de hipoclorito de sódio e paradas periódicas para enxágue, possibilitam reduzir a freqüência das operações de limpeza química e aumentam a produção de permeado, resultando na melhoria do desempenho global do sistema. Com estes procedimentos operacionais o tempo médio entre as operações de limpeza química chegou a 871 horas. Embora as taxas de fluxo de água, através das membranas, tenham ficado dentro da faixa especificada, em uma instalação para tratamento de água elas poderão ser superiores, uma vez que, nos ensaios realizados, as mesmas foram submetidas a condiçôes operacionais severas.

A operação de sistemas de ultrafiltração pode ser otimizada por meio do estudo da produção de permeado em função da pressão de operação.

Em relação à eficiência de remoção de contaminantes, as membranas avaliadas apresentaram desempenho bastante satisfatório, obtendo-se remoções de $100 \%$ para Escherichia coli, coliformes totais e fitoplâncton, $76,4 \%$ e $60,5 \%$ para Carbono Orgânico Total e 66,7\% e 49,8\% para substâncias que absorvem radiação ultravioleta em $254 \mathrm{~nm}$. Estes valores são, significativamente, superiores aos que podem ser obtidos pelo uso de sistemas convencionais de tratamento. 
A remoção de turbidez e cor, através das medidas em laboratório, foi superior a $90 \%$, obtendo-se, no permeado, valores médios inferiores a 2 uT e 3 uC, respectivamente $O$ valor médio da turbidez medida pelo equipamento de processo instalado na unidade piloto PROSAB-05 foi de 0,03 uT.

Testes realizados para a remoção de etinilestradiol indicaram o potencial da tecnologia de ultrafiltração, com as membranas utilizadas, obtendo-se eficiências de remoção superior a $76 \%$ no PROSAB-04 e superior a $94 \%$ no PROSAB-05. As remoções obtidas podem estar associadas ao fenômeno de adsorção do etinilestradiol nos sólidos e matéria orgânica presentes na água bruta e também na membrana, caracterizando um processo indireto de remoção.

Finalmente; a partir de uma avaliação preliminar de custos, obteve-se que - custo de tratamento de água por ultrafiltração, considerando-se o investimento e a operação do sistema, é de US $\$ 0,20$ por metro cúbico de água produzida. Este resultado demonstra a viabilidade econômica do processo de ultrafiltração em relação aos sistemas tradicionalmente utilizados no tratamento de água para abastecimento público, principalmente quando se considera os problemas atuais de qualidade encontrados em muitos mananciais.

Com base na avaliação de custos realizada, verificou-se que o item mais relevante para o sistema de ultrafiltração são as membranas, as quais não são fabricadas no país. Esta condição se traduz em uma oportunidade para o desenvolvimento de novos estudos e pesquisas, tanto para a aplicação da tecnologia de separação por membranas, como também para a fabricação de membranas e equipamentos. 


\section{LISTA DE REFERÊNCIAS}

AMARAL MENDES, J.J. The endocrine disrupters: a major medical challenge. Food and Chemical Toxicology, v. 40, n. 6, p. 781-788, June, 2002.

ARNAL, J.M. et al. Design and construction of water potabilization membrane facility and its application to the third world countries. Preliminary tests. Desalination, v. 145, n. 1-3, p. 305-308, September, 2002.

ARNAL, J.M. et al. Selection of the most suitable ultrafiltration membrane for water disinfection in developing countries. Desalination, v. 168, n. 15 . p. 265-270, august, 2004.

ARNAL, J.M. et al. Aquapot: UF real application for water potabilization in developing countries. Problems location and solutions adopted. Desalination, v. 204, n. 1-3, p. 316-321, February, 2007.

BARBOT, E.; MOULIN, P. Swimming pool water treatment by ultrafiltration-adsorption process. Journal of Membrane Science, v. 314, n. 1-2, p. 50-57, April, 2008.

BARTRAM, J. et al. Introduction. In: CHRORUS, I.; BARTRAM, J. (Editors). Toxic cyanobacteria in water: $\mathbf{A}$ guide to their public health consequences, monitoring and management. Edited by. World Health Organization. 1999. 400p.

BENTAMA, J. et al. Technological innovation for the production of drinking water by membrane processes. Desalination, v. 168 , n. 1-4, p. 283-286, August, 2004.

BOYD, G.R. et al. Pharmaceuticals and personal care product; (PPCPs) in surface and treated waters of Louisiana, USA and Ontario, Canada. The Science of Total Environment, v. 311, p. 135-149, 2003. 
BRASIL. Instituto Brasileiro de Geografia e Estatística (IBGE). Pesquisa Industrial - Produto. Volume 25, número 2. Rio de janeiro: 188 p., 2006. Contagem da população 2007 - Agregado por setores censitários. Tabela (em formato zip). Disponivel em: http://www.ibge.gov.br/home/estatistica/populacao/contagen2007/default.shtm. Acesso em: 22 de janeiro de 2009.

BRASIL. Programa de Modernização do Setor de Saneamento (PMSS). Diagnóstico dos serviços de água e esgotos - 2006. Parte 1 - Texto: Visão geral da prestação de serviços. Ministério das Cidades, Secretaria Nacional de Saneamento Ambiental. Brasília, DF. 2007.

CARABIAS-MARTINEZ, R. et al Evolution over time of the agricultural pollution of waters in an area of Salamanca and Zamora (Spain). Water Research, v. 37, p. 928-938, 2003.

CARSON, R. Silent Spring - With an introduction by Vice President Al Gore. Houghton Mifflin Company. New York. 1962/2004: 368 p.

CEREJEIRA, M. J. ET al. Pesticides in Portuguese surface and ground waters. Water Research, v.37, p.1055-1063, 2003.

CHEN, C. ET al. Comparison of seven kinds of drinking water processes to enhance organic material removal: A pilot test. Science of the Total Environment, v. 382, n. 1, p. 93-102, August, 2007.

CHEN, J.J.; YEH, H.H. The mechanims of potassium permanganate on algae removal. Water Research, v. 39, p. 4420-4428, 2005.

CHEN, J.J.; YEH, H.H.; TSENG, I.C. Effect of ozone and permanganate on algae coagulation removal - Pilot and bench scale tests. Chemosphere, v. 74, n. 6, p. 840-846, February, 2009.

CHENG, W.P.; CHI, F.H. Influence of eutrophycation on the coagulation efficiency in reservoir water. Chemosphere, v. 53, n. 7, p. 773-778, 2003. CLEMENTS, R.D. (Editor). Estimating toxicity of industrial chemicals to aquatic organisms using Structure-activity Relationships. U.S. Environmental Protection Agency. Washingion, 1996. 
CLEVER, $M$. et al. Process water production from river water by ultrafiltration and reverse osmosis. Desalination, v.131, n. 1-3, p. 325336, December, 2000.

COMUNIDADE EUROPÉIA. Commission of the European Communities (CEC). COMMISSION STAFF WORKING DOCUMENT on implementation of the Community Strategy for Endocrine Disrupters - a range of substances suspected of interfering with the hormone systems of humans and wildlife (COM (1999) 706). SEC (2004) 1372 , Brussels, 28/10/2004.

COMUNIDADE EUROPÉIA. Commission of the European Communities (CEC). COMMISSION STAFF WORKING DOCUMENT on the implementation of the "Community Strategy. for Endocrine Disrupters" - a range of substances suspected of interfering with the hormone systems of humans and wildife (COM (1999) 706), (COM (2001) 262) and (SEC (2004) 1372). SEC (2007) 1635. Brussels, $30 / 11 / 2007$.

DESAL Membrane Products. Element specifications - PW4040F ultrafiltration, post-treatment of RO and NF. GE-Osmonics, 2006. Disponivel em: htpp//Wwwdesalwater.con/Literature.15p? Model=PW4040F, Acesso em: 31 de março de 2006.

DOMANY, Z. et al. Humic substances removal from drinking water by membrane filtration. Desalination, v.145, n. 1-3, p. 333-337, September, 2002.

DOYEN, $W$. Latest development in ultrafiltration for large scale drinking water applications. Desalination, v. 113, n.2-3, p. 165-177, Novernber, 1997.

ESTADOS UNIDOS. American Water Works Association (AWWA). Water treatment - Membrane processes. American Water Works Association Foundation, Lyonnaise des Faux, South Africa Water Research Commission. McGraw-Hill. 1996. 
- Environmental Protection Agency (EPA) - a. Alternative disinfectants and oxidants guide manual. United States Environmental Protection Agency. Office of Water: April, 1999. (EPA 815-R-99-014).

b. Enhanced coagulation and enhanced precipitative softening guidance manual. United States Environmental Protection Agency. Office of Water: May, 1999. (EPA 815-R-99-012).

The history of drinking water treatment. United States Environmental Protection Agency. Office of Water: February, 2000. (EPA 816-F-00-006).

Removal of endocrine disruptor chemicals using drinking water treatment processes. United States Environmental Protection Agency. Office of Research and Development: March, 2001. (EPA 625-R-00-015).

Membrane filtration. guidance manual. United States Environmental Protection Agency. Office of Water: November, 2005. (EPA 815-R-06-009).

American Public Health Aassociation (APHA), American Water Works Association (AWWA), Water Environmental Federation (WEF). Standard methods for the examination of water and wastewater. 21 ed. Washington: APHA-WEF, 2000.

National Sanitation Foundation (NSF) a. Physical removal of Cryptosporidium oocysts and Giardia cysts in drinking water. Acquasource North America. Ultrafiltration system model A35. Environmental Technology Verification Report. NSF 00/07/EPADW395. May 2000.

b. Physical removal of microbiological and parículate contaminants in drinking water. Ionics UF-1-7T Ultrafiltration Membrane System. Environmental Technology Verification Report. NSF 00/13/EPADW395. September 2000.

c. Physical removal of inicrobiological and particulate contaminants in drinking water. Hydranautics, HYDRACap Ultrafiliration Membrane System. Environmental Technology Verification Report. NSF 00/04/EPADW395. September 2000. 
Physical removal of criptoptosporidium oocysts; E colli, and Bacillus spores in drinking water. Pall Corporation. Microza microfiltration 3-inch unit, Model 4 UFD40004-45. System. Environmental Technology Verification Report. NSF 02/18/EPADW395. March, 2002.

Physical removal of microbiological and particulate contaminants in drinking water. US Filter DM10C. Mcrofiltration Membrane System. Environmental Technology Verification Report. NSF 03/07/EPADWCRT. June, 2003.

. United States Geological Survey (USGS). Pharmaceuticals, hormones, and other organic wastewater contaminants in U.S. streams. June 2002, (USGS Fact Sheet FS-027-02).

Chemical Abstract Service (CAS). The latest CAS Registry Number and.Substance Count. Disponivel em: http:/www.cas.org/cgibin/cas/regreport.pl. Acesso em: 05 de Fevereiro de 2009.

GE-OSMONICS. Ultrafiltration membranes elements - G-20. Manufacturer's Data sheet. 2006.

GHISELLI G., Avaliação da qualidade das águas destinadas ao abastecimento público na região de Campinas: ocorrência da determinação dos interferentes endócrinos (IE) e produtos farmacêuticos e de higiene pessoal (PFHP). 2006. 190 p. Tese (Doutorado). Instituto de Química, Universidade Estadual de Campinas, Campinas, SP, 2006.

HARRISON, P.T.C.; HOLMES, P.; HUMFREY, C.D.N. Reproductive health in human and wildlife: are adverse trends associated with environmental chemical exposure? The Science of the Total Environment, v. 205, n. 2-3, p 97-106, October, 1997.

HOFMAN, J.A.M.H. et al. Enhanced surface water treatment by ultrafiltration. Desalination, v. 119, n. 1-3, p. 113-125, September, 1998.

HRUDEY. S. et al. Remedial measures. In: CHRORUS, I.; BARTRAM, J. (Editors). Toxic cyanobacteria in water: $A$ guide to their public health consequences, monitoring and management. Edited by. World Health Organization. 1999. 400p. 
HYDRANAUTICS. IMSDesign Integrated Membrane Solutions. Software Hydranautics - Sistema de membranas v.2006 - Menu Ajuda Design Limits. 2006.

JACANGELO, J.G; TRUSSELL, R.R; WATSON, M. Role of membrane technology in drinking water treatment in the United States. Desalination, v. 113, n. 2-3, p. 119-127, November, 1997.

JERMANN, D. et al. The role of NOM fouling for the retention of estradiol and ibuprofen during ultrafiltration. Journal of Membrane Science, In press. doi:10.1016/j.memsci.2008.12.016. Disponivel em: http://www.sciencedirect.com. Acesso em: 27 de janeiro de 2009.

JONES, O.A.; LESTER, J.N.; VOULVOULIS, N. Pharmaceuticals: a threat to drinking water? Trends in Biotechnology, v. 23, n. 4, p. 163-167, 2005.

KNACKER, T.; LIEBIG, M.; MOLTMANN, J.F. Environmental risk assessment. - In: TERNES, T.A.; JOSS, A. (Editors): Hưman pharmaceuticals, hormones and fragrances. The challenge of micropollutants in urban water management. IWA Publishing. Cornwall, UK. 2006. 453p.

LAGANA A. et al. A. Analytical methodologies for determining the occurrence of endocrine disrupting chemicals in sewage treatment plants and natural waters. Analytica Chimica Acta, v. 501, p. 79-88, 2004.

$\mathrm{LI}, \mathrm{T}$. et al. Impact of preozonization on the performance of coagulated flocs. Chemosphere, in press. Disponivel em: http://www. sciencedirect com. Acesso em: 28 de janeiro de 2009.

LIDE, D.R. (Editor-in-Chief). CRC Handbook on chemistry and physics. 89 $9^{\text {th }}$ edition. 2008-2009. Taylor and Francis Group LLC. 2009.

LIPP, P. et al. Treatment of reservoir water with a backwashable MF/UF spiral wound membrane. Desalination, v. 179, n. 1-3, p. 83-94, July, 2005.

MA, W.; et.al. Application of membrane technology for cirinking water. Desalination, v. 119, n. 1-3, p. 127-131, September, 1998. 
MALLEVIALLE, J.; ODENDAAL, P.E.; WISNER, M.R. The emergence of membranes in water and watewater treatment. In: AWWA Research Foundation, Lyonnaise des Eaux, South Africa Water Research Commission. Water Treatment Membrane Processes. McGraw-Hill. 1996.

MEMBRANE TECHNOLOGY. Research trends: Application of UF membrane filtration for removing humic acid from drinking water. Membrane Technology, v. 2008, n. 10, p. 11-13, October, 2008.

MIBU, $K$. et al. Distribution of estrogen, nonylphenol and its derivatives in the sediments of a shallow lake. Water Science and Technology, v. 50, n. 5, p.173-179, 2004.

MICKLEY, M.C. Membrane concentrate disposal: Practices and regulation . (Second edition). Desalination and water purification research and development program report $n^{\circ} 123$. U.S. Department of Interior - Bureau of Reclamation. April 2006.

MIERZWA, J.C.; HESPANHOL, I: - a. Procedimentos e técnicas de tratamento de efluentes para eliminar o potencial de riscos - Parte 2. Gerenciamento Ambiental. Ano 3, $n^{\circ}$ 13. Jan./Fev. 2001. p. 43-47.

MIERZWA, J.C.; HESPANHOL, I. - b. Procedimentos e técnicas de tratamento de efluentes para eliminar o potencial de riscos - Parte 4. Gerenciamento Ambiental. Ano 3, $n^{\circ}$ 15. Jul./Ago. 2001. p. 33-397. MIERZWA, J.C.; HESPANHOL, I. Técnicas para o tratamento de água na indústria. In: MIERZWA, J.C; HESPANHOL, I. Água na indústria - Uso racional e reúso. Oficina de Textos, São Paulo, 2005. $144 \mathrm{p}$.

MIERZWA, J.C. ET al. Tratamento de água para abastecimento por ultrafiltração: Avaliação comparativa através dos custos diretos de implantação e operação com os sistemas convencional e convencional com carvão ativado. Engenharia Sanitária e Ambiental, v. 13, n. 1, p. 78-87, jan/mar, 2008.

MOREIRA, D. S.; Desenvolvimento de métodos cromatográficos para monitoramento dos perturbadores endócrinos nonilfenol e $\alpha$ estradiol em mananciais de abastecimento de água. 2008. 108 p. 
Dissertação (Mestrado), Programa de Pós-Graduação em Engenharia Ambiental, Universidade Federal de Ouro Preto, Minas Gerais, 2008.

NAKATSUKA, S.; NAKATE, I.; MIYANO, T. Drinking water treatment by using ultrafiltration hollow fiber membranes. Desalination, v. 106, n. 1-3, p. 55-61, August, 1996.

NICOLAISEN, B. Developments in membrane technology for water treatment. Desalination, v. 153, n. 1-3, p. 355-360, February, 2003.

OKUN, D.A. Drinking water and public health protection. In: PONTIUS, F.W. (Editor) Drinking water regulation and health. John Wiley and Sons, Inc. 2003. 1029 p.

PARANÁ ONLINE. Estudo revela falta de utilização da pilula anticoncepcional. Vida e Saúde - Notícias. Março de 2008. Disponível em: hitp://www.parana-online.com.br/canal/vida-e-saude/news/287108/. Acesso em 19/01/2009.

PETER-VARBANETS, M. et al. Decentralized systems for potable water and the potential of membrane technology. Water Research, v. 43, n. 2, p. 245-265, Februay, 2009.

PIANTA, R. et al. Micro and ultrafiltration of karstic spring water. Desalination, v. 117, n. 1-3, p. 61-71, September, 1998.

RAIMUNDO, C. C. M. Ocorrência de interferentes endócrinos e produtos farmacêuticos nas águas superficiais da bacia do rio Atibaia. 2007. Dissertação (Mestrado), Instituto de Química, Universidade Estadual de Campinas. Campinas - SP, 2007.

ROJAS, J.C. et al. Potabilization of low MON reservoir water by ultrafiltration spiral wound membranes. Journal of Hazardous Materials, v. 158, n. 2-3, p. 593-598, October, 2008.

SÃO PAULO. Companhia de Tecnologia de Saneamento Ambiental do Estado de São Paulo (CETESB). Relatório de qualidade das águas interiores do estado de São Paulo 2001 / CETESB. São Paulo: CETESB, 2002.

Relatório de qualidade das águas interiores do estado de São Paulo 2002 / CETESB. São Paulo: CETESB, 2003. 
Relatório de qualidade das águas interiores do estado de São Paulo 2003 / CETESB. São Paulo: CETESB, 2004.

Relatório de qualidade das águas interiores do estado de São Paulo 2004 / CETESB. São Paulo, CETESB, 2005.

Relatório de qualidade das águas interiores do estado de São Paulo 2005 / CETESB. São Paulo, CETESB, 2006.

Relatório de qualidade das águas interiores do estado de São Paulo 2006 / CETESB. São Paulo, CETESB, 2007.

Relatório de qualidade das águas interiores do estado de São Paulo 2007 / CETESB. São Paulo, CETESB, 2008.

SOARES, A. et al. Nonylphenol in the environment: A critical review on occurrence, fate, toxicity and treatment in wastewaters. Environment International, v. 34, n. 7 . p. 1033-1049, October, 2008.

SCHNEIDER, R. P, TSUTIYA, M. T. Membranas Filtrantes para o tratamento de água, esgoto e água de reúso. $A B E S$ - Associação Brasileira de Engenharia Sanitária e Ambiental. São Paulo, 2001. 234 p. SOLÉ, M. et al. Long-term exposure effects in vitellogenin, sex hormones, and biotransformation enzymes in female carp in relation to a sewage treatment works. Ecotoxicology and Environmental Safety, v. 56, p.373-380, 2003.

SONNENSCHEIN, C.; SOTO, A. M. An updated review of environmental estrogen and androgen mimics and antagonists. The Journal of Steroid Biochemistry and Molecular Biology. v. 65, n. 1-6, p. 143-150, AprilJune, 1998.

STACKELBERG, P.E. et al. Persistence of pharmaceutical compounds and other organic wastewater contaminants in a conventional drinking water treatment plant. Science of the Total Environment, v. 329, n. 1-3, p. 99-113, August, 2004.

TERNES, T. A.; STUMPF, M.; MUELLER, J., HABERER, K., WILKEN, R. - L., SERVOS, M. Behavior and occurrence of estrogens in municipal sewage treatment plants- I. Investigations in Germany, Canada and Brazil. 
The Science of the Total Environment, v. 225, n. 1-2, p. 81-90, January, 1999.

TERNES, T.A. Assessment of technologies for the removal of pharmaceuticals and personal care products in sewage and drinking water facilities to improve indirect potable water reuse. POSEIDON Project. Report related to the overall project duration: January $1^{\text {st }}, 2001-$ June $30^{\text {th }}, 2004$. August, 2004. Disponivel em: hup://www.cu-poseidon.com, Acesso em: 11 de junho de 2006.

TERNES, T. A.; GIGER, W.; JOSS, A. Introduction. In: TERNES, T.A.; JOSS, A. (Editors) Human pharmaceuticals, hormones and fragrances. The challenge of micropollutants in urban water management. IWA Publishing. Cornwall, UK. 2006. 453p.

VON GUNTEN, $U$. et al. Removal of PPCP during drinking water treatment. In: TERNES, T.A.; JOSS, A. (Editors) Human pharmaceuticals, hormones and fragrances. The challenge of micropollutants in urban water manágement. IWA Publishing. Cornwall, UK. 2006. 453p.

WAGNER, J. Membrane filtration handbook - Practical tips and hints. Second Edition, Revision 2. Osmonics Filtration and Separation Group. Minnetonka, 2001. $128 \mathrm{p}$.

WILBERT, M.C. et al. The desalting and water treatment manual: A guide to membranes for municipal water treatment. R-98-05. $2^{\text {nd }}$ edition. U.S. Department of the Interior. Bureau of Reclamation. July 1998. WORLD HEALTH ORGANIZATION (WHO), Global assessment of the state-of-the-science of Endocrine Disruptors. Edited by Terri Damstra; Sue Barlow; Aake Bergman; Robert Kavlock; Glen Van Der Kraak. International Programme on Chemical Safety. 2002.

WORLD HEALTH ORGANIZATION (WHO). Guidelines for drinkingwater quality - First Addendum to Third Edition Volume 1 Recommendations. WHO Library Cataloguing-in-Publication Data. 2006. YANG, L.; LUAN, T.; LAN, C. Solid-phase microextraction with on-fiber silylation for simultaneous determinations of endocrine disrupting 
chemicals and steroid hormones by gas chromatography-mass spectrometry. Journal of Chromatography A, v.1104, n. 1-2, p.23-32, February, 2006.

YING, G.G.; KOOKANA, R.; RU, Y. Occurrence and fate of hormone steroids in the environment. Environment International, v. 28, n. 6, p. 545-551, December, 2002.

YOON, Y. et al. Nanofiltration and uyltrafiltration of endocrine disrupting compounds, pharmaceuticals and personal care products. Journal of Membrane Science, v. 270, n. 1-2, p. 88-100, February, 2006.

YOUNG, W.F. et al. Proposed Predicted-No-Effect-Concentrations (PNECs) for Natural and Synthetic Steroid Oestrogens in Surface Waters. Environment Agency, Bristol, 2004. (R\&D Technical Report P2T04/1).

ZACERKOWNY, O. Membrane technology's 25 years evolution. Filtration+Separation, v. November, p. 32-34, November, 2007. 
